University of Louisville

ThinkIR: The University of Louisville's Institutional Repository

Electronic Theses and Dissertations

$12-2016$

\title{
Assessing moral injury and existential well-being in returning servicemembers using the spiritual attitudes inventory - revised (2010).
}

\author{
LeAnn E. Armes-Bruce \\ University of Louisville
}

Follow this and additional works at: https://ir.library.louisville.edu/etd

Part of the Social Work Commons

\section{Recommended Citation}

Armes-Bruce, LeAnn E., "Assessing moral injury and existential well-being in returning servicemembers using the spiritual attitudes inventory - revised (2010)." (2016). Electronic Theses and Dissertations. Paper 2595.

https://doi.org/10.18297/etd/2595

This Doctoral Dissertation is brought to you for free and open access by ThinkIR: The University of Louisville's Institutional Repository. It has been accepted for inclusion in Electronic Theses and Dissertations by an authorized administrator of ThinkIR: The University of Louisville's Institutional Repository. This title appears here courtesy of the author, who has retained all other copyrights. For more information, please contact thinkir@louisville.edu. 


\title{
ASSESSING MORAL INJURY AND EXISTENTIAL WELL-BEING \\ IN RETURNING SERVICEMEMBERS USING THE \\ SPIRITUAL ATTITUDES INVENTORY - REVISED (2010)
}

\author{
By \\ LeAnn E. Bruce \\ B.A., Western Kentucky University, 1996 \\ MSSW, University of Louisville, 1999

\begin{abstract}
A Dissertation
Submitted to the Faculty of the

Raymond A. Kent School of Social Work of the University of Louisville

In Partial Fulfillment of the Requirements

For the Degree of
\end{abstract}

Doctor of Philosophy in Social Work

Kent School of Social Work

University of Louisville

Louisville, Ky.

December 2016 
Copyright 2016 by LeAnn E. Bruce

All rights reserved 



\title{
ASSESSING MORAL INJURY AND EXISTENTIAL WELL-BEING IN RETURNING SERVICEMEMBERS USING THE \\ SPIRITUAL ATTITUDES INVENTORY - REVISED (2010)
}

\author{
By \\ LeAnn E. Bruce \\ B.A., Western Kentucky University, 1996 \\ MSSW, University of Louisville, 1999
}

A Dissertation Approved on

November 30, 2016

By the following Dissertation Committee:

Michiel Van Zyl, Ph.D.

Adrian Archuleta, Ph.D.

\begin{tabular}{c}
\hline Chris Flaherty, Ph.D. \\
\hline
\end{tabular}

Thomas Lawson, Ph.D.

Sunshine Rote, Ph.D. 


\section{DEDICATION}

This dissertation is a testament of honor, respect and gratitude to the brave men and women who have shouldered the burden of serving our country. It has been my privilege to work with them, to hear their stories, and to help them weave the threads of their lives into new tapestries. They are my inspiration. I hope this study serves to cast light on the complexity of their struggle, share their stories of reintegration, restoration and recovery, and inspires others to look deeper. This dissertation belongs to them.

This is also a labor of love in honor of my dear granddaughters. They are my heart and soul. The completion of this goal raises the bar for them to aim high, set their own goals, and to know they can achieve them through hard work and dedication. This achievement is theirs.

This is also a labor of gratitude to my mother and grandmothers. Because it is through their lessons, love and lives that I have come to be. They are with me in spirit, in all that I do, and all that I am. I remain grateful for the compassion and tenacity they instilled within me. This is their accomplishment too.

This dissertation represents a decade of work woven into a life lived. It has been written in eight states, two countries, on planes, cars, and even boats. It has seen me through job changes, sickness and health, and has accompanied me to family functions, while sitting vigil in hospital rooms, and in waiting rooms. My life has woven itself around this work and this work is woven in me. 


\section{ABSTRACT \\ ASSESSING MORAL INJURY AND EXISTENTIAL WELL-BEING \\ IN RETURNING SERVICEMEMBERS USING THE \\ SPIRITUAL ATTITUDES INVENTORY - REVISED (2010)}

\section{LeAnn E. Bruce}

November 30, 2016

Military personnel returning from deployment often report a variety of distressing symptoms stemming from exposure to prolonged, extreme deployment stress, and traumatic experiences. In addition to reporting symptoms consistent with the diagnosis of Post-Traumatic Stress Disorder, they are also known to report struggling with existential angst often leading to great despair and a sense of profound changes in the core of their being. While this phenomenon, referred to herein as Moral Injury, has traditionally received little attention, it is beginning to emerge as a potentially viable construct in practice and research and may assist in explaining the effects of war on the whole person than Post-Traumatic Stress Disorder (PTSD) alone. However, this concept has yet to be empirically defined, and its relationship to other known constructs such as PTSD, Disorders of Extreme Stress - Not Otherwise Specified (DESNOS), and Existential WellBeing (EWB), appears to be conceptually related but has not well established.

Using data gathered from the administration of the Spiritual Attitudes Inventory Revised (2010) to OEF/OIF Servicemembers upon return from deployment, this study explored the relationships between the constructs in question to identify the differences, similarities, and relationships to obtain a clearer picture of the complexity of post- 
deployment distress. This instrument assessed respondents on each of the constructs including Post-Traumatic Stress Disorder (PCL-M), Disorders of Extreme Stress - Not Otherwise Specified, Existential Well-Being. The theoretical model for the concept of Moral Injury was extrapolated from the DESNOS sub-domains.

The results indicated that the parent constructs PTSD, Moral Injury and Existential Well-Being were highly correlated with and between one another. However, when the analysis delved into exploring the relationships at the sub-domain level, differences could be identified which provided a more detailed model of the thematic intersections between these constructs. By doing so, this study fills a gap in the current body of research by offering a preliminary conceptual model of Moral Injury from a symptomological perspective while also illustrating the relationship between this emerging construct, PTSD and Existential Well-Being. 


\section{TABLE OF CONTENTS}

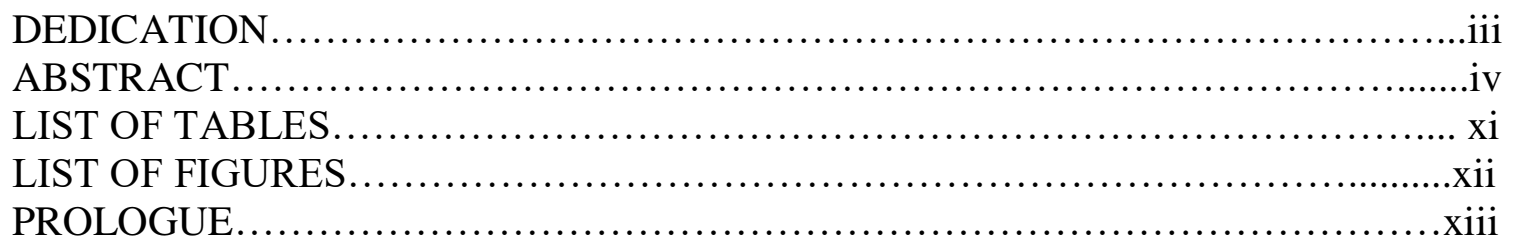

CHAPTER I - PROBLEM STATEMENT ................................................

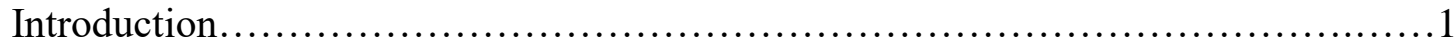

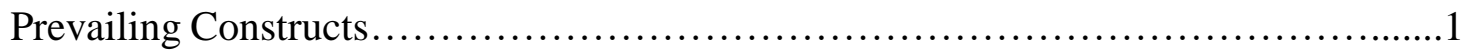

Post-Traumatic Stress Disorder................................................ 3

Existential Well-Being................................................. 4

Disorders of Extreme Stress Not Otherwise Specified...........................5

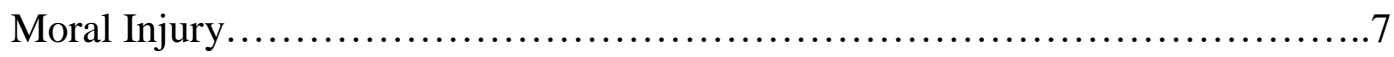

Indicators of Reintegration Problem................................................. 8

Psychosocial and Societal Indicators...........................................

Clinical Indicators...........................................................

Problem Statement Summary.................................................... 10

Purpose of this Study ........................................................

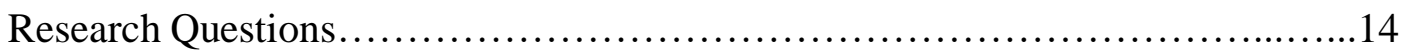

CHAPTER II - LITERATURE REVIEW ........................................16

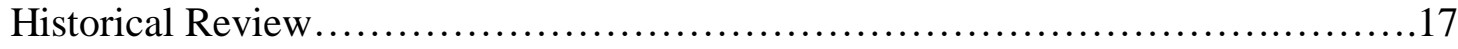

Ancient Warriors.............................................................. 18

U.S. Civil War Era (1861-1865) .........................................19

World War I Era (1914-1919) ...........................................20

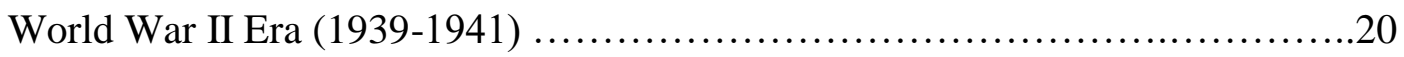

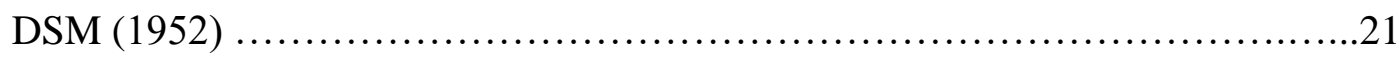

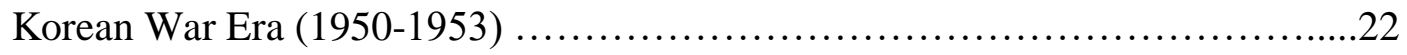

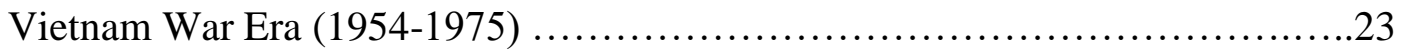




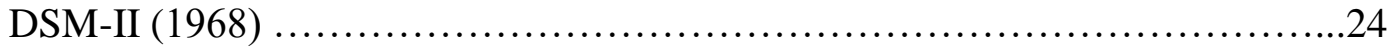

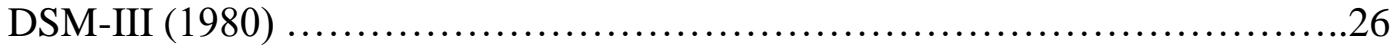

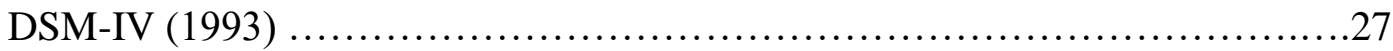

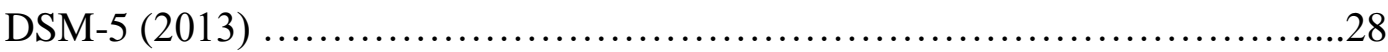

Historical Review Summary......................................................

Same story - Different War........................................... 31

Clinical Reaction....................................................... 32

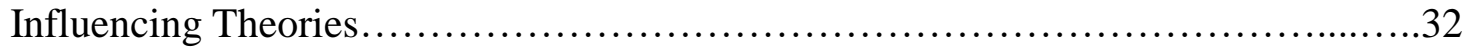

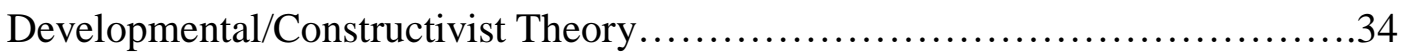

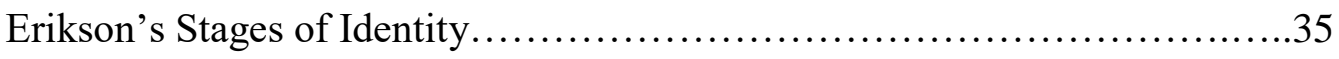

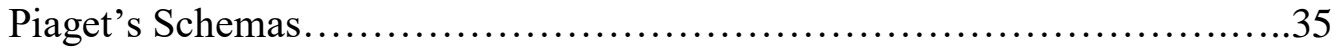

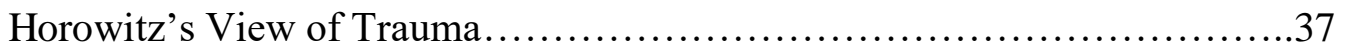

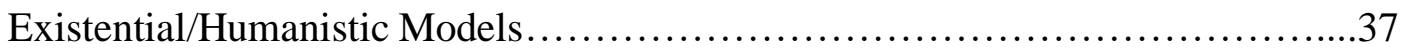

Tick's Soul Wound..................................................... 38

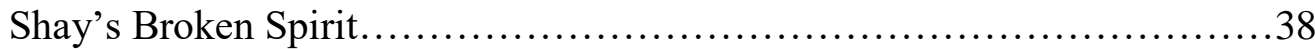

Heimler's Social Functioning...........................................39

Frankl's Existential Vacuum...........................................40

Quantifying the Moral Domain ........................................... 43

Existential Anxiety Questionnaire .....................................43

Qualitative Existential Social Work Model................................44

Existential Well-Being Scale ...........................................45

Influencing Theories Summary.......................................... 46

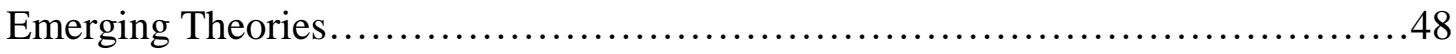

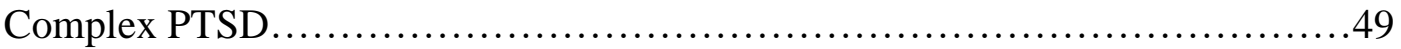

Disorders of Extreme Stress Not Otherwise Specified.........................50

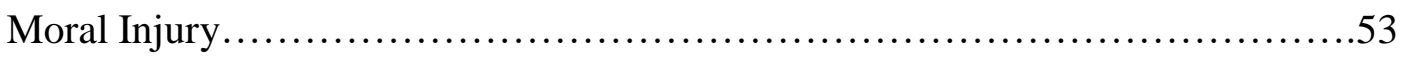

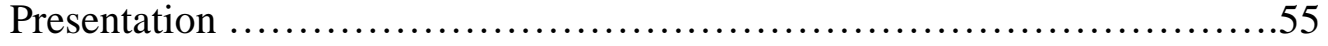

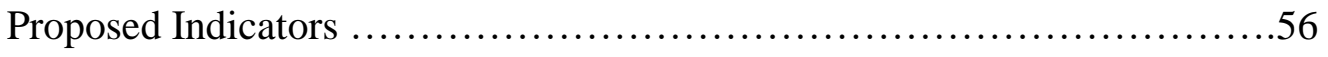

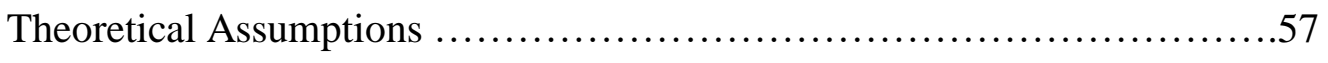

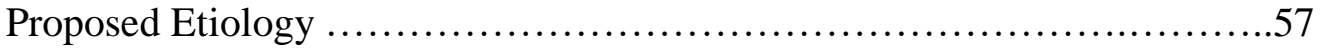

Assessing Moral Injury............................................. 59 
Literature Review Summary ................................................. 61

Discussion of Similarities/Difference between Constructs......................65

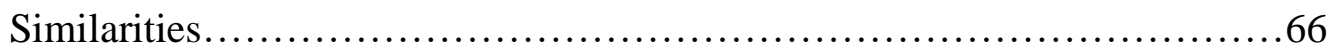

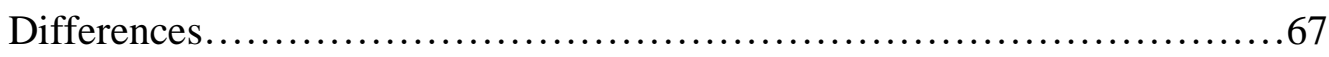

Discussion of Content Analysis with Refined Research Questions................70

CHAPTER III - METHODOLOGY .............................................. 71

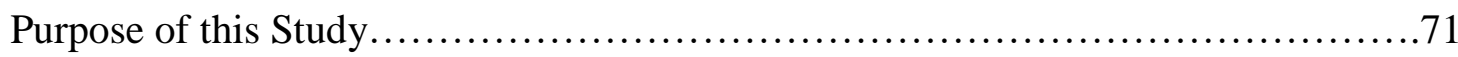

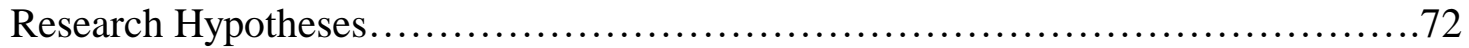

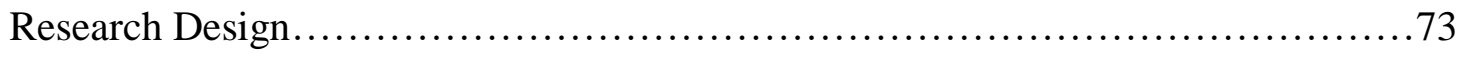

Population and Sampling Methods........................................74

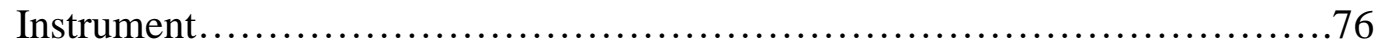

Original Spiritual Attitudes Inventory (2009) …........................76

Revised Spiritual Attitudes Inventory (2010) ..........................76

Conceptual and Operational Definitions of Independent Variables...............77

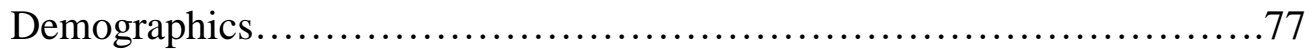

Conceptual and Operational Definitions of Dependent Variables................78

Existential Well-Being Scale ........................................78

Military Stress Indicator Checklist (MSI) ............................78

Post-Traumatic Stress Checklist-Military Version (PCL-M) .............79

Disorders of Extreme Stress Not Otherwise Specified (DESNOS)........80

Moral Injury Sub-Scale ........................................ 81

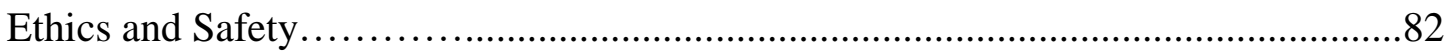

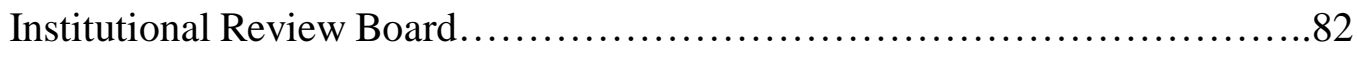

Walter Reed Army Medical Center IRB ................................ 82

University of Louisville IRB ...................................... 82

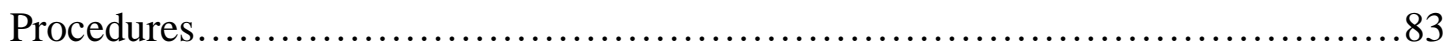

Data Entry, Evaluation, Cleaning and Recording...........................83

Data Entry and Evaluation........................................... 83

Data Cleaning and Re-coding...................................... 83

Re-coding Independent Variables.................................... 83

Re-coding Dependent Variables..................................... 85 


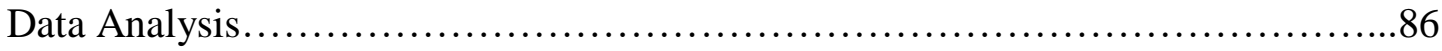

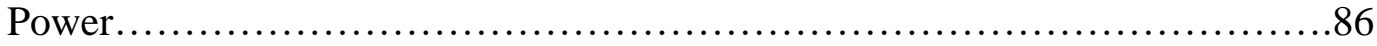

Frequencies and Descriptive Analyses................................... 86

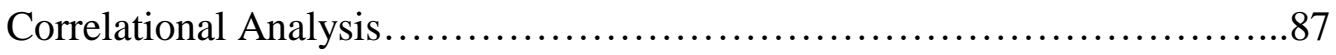

Summary of Methodology ..................................................... 90

CHAPTER IV - RESULTS................................................. 91

Demographics and Descriptive Data Findings.....................................91

Dependent Variable Data Findings .............................................94

How are the constructs, PTSD \& MI, and their sub-domains related within and across the domains? .............................................94

How well do the existing constructs, PTSD and Moral Injury,

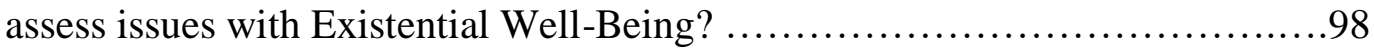

To which Moral Injury sub-domain is low to moderate Existential Well-Being more strongly related?

To which PTSD sub-domain is low to moderate Existential Well-Being more closely related?

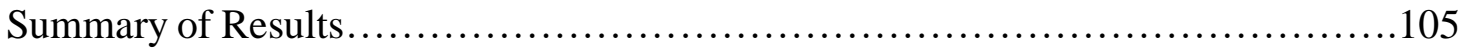

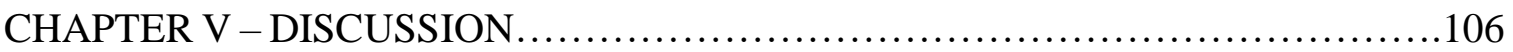

Discussion of Population \& Descriptive Analysis.................................. 108

Discussion of Results of Analysis related to each Research Question................109

How are the constructs, PTSD \& MI, and their sub-domains related

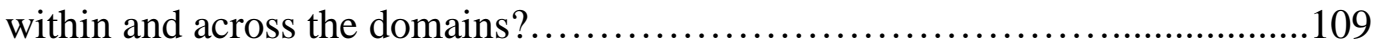

How well....do the existing constructs, PTSD and Moral Injury, assess issues with Existential Well-Being?.

To which Moral Injury sub-domain is low to moderate Existential Well-Being more strongly related?.

To which PTSD sub-domain is low to moderate Existential Well-Being more closely related?.

Limitations. 116

Implications 
Research....................................................... 172

Practice.............................................................. 118

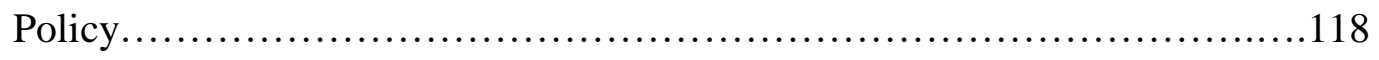

Conclusion............................................................119

REFERENCES ........................................................ 121

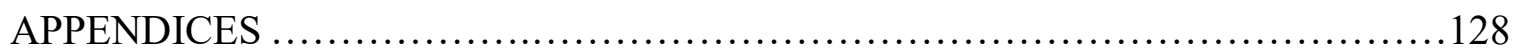

A. PTSD/DESNOS/MORAL INJURY item comparison for content analysis.......129

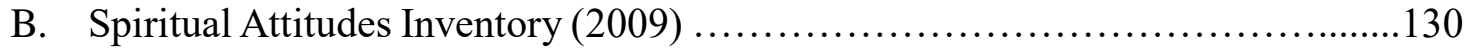

C. Spiritual Attitudes Inventory - Revised (2010) .......................... 133

CURRICULUM VITAE.................................................... 136 


\section{LIST OF TABLES}

Table 1 Summary of Theoretical Models, Terms and Descriptions................40

Table 2 Overview of Relevant Assessment Instruments.......................44

Table $3 \quad$ Classification of DESNOS .......................................49

Table 4 Comparison of DESNOS and Moral Injury Proposed Indicators..........55

Table 5 Recoded Independent Variables................................80

Table $6 \quad$ Recoded Dependent Variables...................................81

Table 7 Comparison of Demographic Variables to Army at Large................87

Table 8 Summary of Descriptive Findings for Independent Variables.............88

Table 9 PCL-M and Moral Injury Sub-Domains Correlation..................92

Table 10 EWB, PCL-M and Moral Injury Total Scores Correlation................94

Table $11 \quad$ EWB and Moral Injury Sub-Domains Correlations...................95

Table 12 EWB and MI Self-Perception (Identity) \& Non-Self-Perception (Identity) Sub-Domains Correlation....................................95

Table 13 EWB and MI Meaning \& Non-Meaning Sub-Domains Correlation......96

Table $14 \quad$ EWB and PCL-M Sub-Domains Correlations.........................97

Table 15 EWB and PCM-M's Numbing and Non-Numbing Correlation...........98

Table 16 EWB and PCL-M's Hyper-Arousal/Non-Hyper-Arousal Correlation......99 


\section{LIST OF FIGURES}

Figure $1 \quad$ Working model of Moral Injury..................................56

Figure 2 Example of Moral Injury Scale................................59

Figure 3 Comparison of PTSD, DESNOS \& Moral Injury Sub-Domains..........62

Figure 4 Comparison of Sub-Domains of PTSD \& Moral Injury.................66

Figure 5 Illustration of the relationship between PTSD and Moral Injury sub-domains.................................... 108 


\section{PROLOGUE}

"I'm not the person I used to be."

Mark $^{1}$ enters the therapist's office with his military bearing intact. Standing tall and confident, he makes eye contact and is polite, in keeping with his presentation as a proud professional soldier. He chats amicably while providing the requested intake information. However, when asked how things have changed since returning from deployment, his demeanor and facial expression visibly shift to a distant gaze. Momentarily taken aback, he becomes quiet and withdrawn as his eyes fix on the beret folded neatly in his lap. Slowly, with halting fragments of words and thoughts, he describes the changes that have occurred since his second deployment in Iraq. The intensity of his inner struggle is briefly exposed as he states, "I'm not the person I used to be. I'm different-I can't describe it. You wouldn't understand, no one can understand." Clearly struggling to find the words to effectively convey his thoughts, he tries to describe how unprepared he feels to cope with this pervasive feeling that something deep within him was radically and permanently changed. (M.J., personal communication, 2012).

$J_{o s e}{ }^{1}$, a highly decorated and dedicated Master Sergeant with a long and proud military career returns from his fourth deployment, during which time he reports feeling betrayed by his upper command who made decisions that he believes put his men in jeopardy and led to unnecessary civilian casualties. "The other times weren't like this,"

\footnotetext{
${ }^{1}$ Names have been changed to protect privacy and confidentiality.
} 
he explains. "I don't know what is wrong with me this time - I can't shake it!" He admits that he has begun to isolate himself, severing ties with his friends and family members. Struggling with many significant physical injuries, along with his intense emotional pain, Jose takes so many medications as prescribed by his various physicians that he must be monitored closely for accidental overdose-yet, he reports there is still no relief from his symptoms. With his heart visibly pounding through his uniform, he states, "There is no relief-there never will be. Meds can't take away this kind of pain...You don't understand... it is like a part of me has died. I don't know who I am anymore. In Iraq, I was part of a mission, I had a purpose. Now, who am I? Why am I here?" He considers not returning to his family because he feels that he has changed so much that they wouldn't know him anymore. He states, "Hell, I don't even know myself!” (J.Q., personal communication, 2008).

Lisa $^{1}$, a combat medic, returns from a recent assignment at a hospital command center located at Abu Ghraib. This site had previously been used as a prison where Saddam Hussein had created a complex of torture chambers, and where American Soldiers had been accused of torturing detainees (2004). As a medic, her mission was to care for the wounded (allies and enemy soldiers, alike). However, each day, she faced the complex moral and emotional conflict of having to treat the wounded Iraqi detainees who, just hours before, were killing her fellow soldiers. They would frequently threaten to kill her, even as she attended to their medical needs. As a female thrust into a culture that oppresses and disrespects women, she was forced to fulfill her mission to care for the detainees who would spit on her and demoralize her for being a female and an American. 
Throughout her 15-month deployment, she wrestled with intense inner conflict as she has struggled to gain some validation for her suffering and anger. Since returning from deployment, she describes feeling an overwhelming presence of evil that she just cannot shake. She states that she fears the evil of that place has become a part of her and changed her at the core of her soul. She reports feeling that no one understands her trauma and suffering. Since she did not experience battle first hand, many of her doctors, friends and even commanders do not acknowledge that she has been injured too (D.F., personal communication, 2010).

The stories presented above are a mere glimpse into the deeply personal experiences of brave individuals who have answered the call to serve, borne the battle, and returned with a feeling of being deeply and profoundly changed. While many Servicemembers and Veterans report being fully aware of the risks to their physical and emotional well-being prior to deployment, they often remark that they were unprepared for the profound self-transformation they would face. In these, and the narratives of countless others, are heard the echoes of generations of Veterans who have come before as reports of deep personal change following war has been documented for centuries. While it has long been acknowledged that war has the capacity to injure the physical, mental, and emotional facets of an individual, the stories offered above suggest that there is much more to be understood about the complexity of the reintegration process and the effects on the individual's sense of self or existential well-being. It is this existential phenomenon that may hold the key to fully understanding the impact of the experience of war and is the topic of exploration for this study. 


\section{CHAPTER I}

\section{PROBLEM STATEMENT}

The United States military has been engaged in combat in Afghanistan (Operation Enduring Freedom - OEF and Operation New Dawn (OND) and Iraq (Operation Iraqi Freedom - OIF) campaigns as well as other military operations worldwide. According to the RAND report, Measuring Army Deployments to Iraq and Afghanistan (2013), over two million U.S. Troops have returned to our communities since 2002. As the stories above illustrate, and history supports, the reintegration process is complex and multifaceted. Upon return from deployment, military personnel face a myriad of distressing bio-psycho-social stressors resulting from exposure to general deployment stress, combat stress, and both physical and emotional trauma. Some returning Servicemembers also report experiencing what might be regarded as an existential, or personal identity, crisis (Tick, 2009) following prolonged deployment. Clinicians who serve this population report hearing the same haunting refrain voiced by previous generations of warriors. The comment, I am not the person I used to be, has become the battle cry of Veterans who report a pervasive and profound change has occurred to the core of their being (Bruce, Moral Injury Presentation, 2014).

\section{Prevailing Constructs}

Previous research related to war and post-deployment reintegration focused extensively on the identification and treatment of the cognitive-emotional response to experiencing traumatic events. However, the accounts of returning Servicemembers, such 
as those offered in the prologue, illustrate that the struggle to heal and reintegrate following deployment reaches beyond physical wounds and emotional reactions to traumatic events. Some individuals struggle, not only to heal the physical and emotional wounds, but also to cope with deeply intense and debilitating psychic wounds and the sense that these experiences have changed the very fabric of their identity, moral foundation, and personal worldview (Levinson, 2012). Despite several decades of research on post-deployment stress, the narratives of returning warriors exemplify the concern that "research about the link between combat and changes in morality and spirituality is lacking" (Drescher, Foy, Kelly, Schultz, Kerri, and Litz, 2013). This deficit in the body of current research may partially be due to the lack of a comprehensive theoretical or conceptual paradigm to fully explain, understand, and treat the far-reaching scope of both the experiences of war trauma, as well as the effects of the prolonged extreme stress of deployment on the moral core. This growing acknowledgement that the experiences of war have the capacity to injure the moral or spiritual core, posits that this may lead to a disintegration of a sense of moral identity (Levinson, 2012).

Many theories have been proposed to address this elusive phenomenon, yet the terminology offered is often vague, inconsistent, and difficult to operationalize. It has been referred to as a soul wound (Tick, 2009), existential vacuum (Frankl, 1969), or Moral Injury (Litz, Stein, Delaney, Lebowitz, Nash, et. al, 2009). While the terms and implications differ, the common thread that runs through them all recognizes this condition as a deeply disturbing experience of personal transformation and existential crisis - distinguishable from physical or emotional injuries. Theorists studying this phenomenon suggest that this conceptual domain represents the seat of personal identity 
where core values, beliefs, sense of morality and purpose, and the perception of the self in relation to society. It is postulated that this domain may also be injured by extreme stress or trauma or through experiences that transgress or shatter one's deeply held beliefs or views. Contemporary researchers have begun to develop, or build upon existing, conceptual models to describe and explain the changes associated with injury to this domain. Of these, four predominant models have emerged in the discussion and are consistent with therapeutic observation. These will be briefly discussed here and more fully explored in the literature review in Chapter II.

\section{Post-Traumatic Stress Disorder.}

The diagnosis of Post-Traumatic Stress Disorder (PTSD) entered the professional vernacular in 1980 with the publication of the Diagnostic and Statistical Manual of Mental Health Disorders (third ed.). Much like the current DSM-5 diagnostic criteria, the DSM-III diagnosis was aligned under the anxiety disorders section and was predicated by the presence of a traumatic event, accompanied by significant impairment including intrusive memories, avoidance, and hyper-arousal related to the traumatic event. At that time, it was assumed the symptoms were transient and would resolve once the stressor was removed. Three years later, in response to concerns voiced by multiple Vietnam Veterans groups and the Department of Veterans Affairs, Congress initiated the National Vietnam Veterans Readjustment study (1983) to investigate the prevalence of post-war psychological problems. This massive study utilized a multi-method approach assessing both the Veteran and civilian population across 100 life-adjustment indices and assessment of PTSD with both a self-report and clinical interview. The findings revealed a prevalence of PTSD in this population of $30.9 \%$ for male Veterans (Price and Stevens, 
2007). However, a follow-up student was conducted nearly 14 years later by Koenen, et. al. of 4490 respondents found that approximately $10 \%$ of the Veterans continued to meet the diagnostic criteria for PTSD at a severe level indicating that, for a segment of the population, PTSD was a chronic rather than transient condition.

The respondents in the Veteran's Readjustment Study also reported continued interpersonal relationship stressors, less life satisfaction, increased mental health complaints and an array of non-specific health issues (2008). Test-retest reliability was .88 between the first survey and the second 14 years later. From early in the history of the adoption of the PTSD diagnostic criteria, its ability to encompass the depth, complexity and chronicity was questioned. One such inquirer was Judith Herman, whose work with victims of domestic violence was leading to a theory that the nature, frequency and duration of the traumatic experience could influence how the symptoms manifested. She coined the term Complex PTSD (C-PTSD) to refer to the qualitative differences in presentation for individuals who have endured prolonged or repeated episodes of trauma. This progression of theories will be explored more fully in the literature review.

\section{Existential Well-Being.}

The concept of existential well-being, or conversely existential angst or distress, has recently re-entered the discussion pertaining to returning military personnel to address the commonly heard report of a feeling of significant loss of sense of identity, meaning, or purpose in one's life. The study of existentialism from a philosophical standpoint is concerned with the question about the meaning of life in the abstract. However, as it has been adopted into the psychological realm, it become more individualistic and speaks to the quest for each person to seek and define their own 
perceived sense of meaning and purpose to define their existence. Many $20^{\text {th }}$ century theorists embraced some aspects of existentialism in their conceptual theories or models such as Paul Tillich and Viktor Frankl (Stanford dictionary of philosophy, 2015).

A small number of instruments have been developed to assess this construct but had not been specifically designed to assess the military or Veteran population. The most recent to be developed, and used to assess the military population is the Existential WellBeing Scale (EWBS), developed by Raymond Paloutzian (1982). This 10-question subscale of the Spiritual Well-Being Scale (SWB) is a straight-forward self-report assessment designed to assess the individual's sense of life purpose and overall life satisfaction. The respondent chooses an answer that most closely matches his or her agreement with a series of statements such as: I don't know who I am, where I came from, or where I am going; Life doesn't have much meaning; or I feel very fulfilled and satisfied with life. The negative statements are reverse scored to produce the overall score of existential well-being. Higher scores indicate a greater sense of existential wellbeing. Given the preponderance of reports from servicemembers during reintegration that they are struggling with questions related to existential transformation or crisis, the ability to assess this construct in conjunction with the others mentioned could provide valuable insights into the relationship between the concepts.

\section{Disorders of Extreme Stress Not Otherwise Specified.}

Expanding on the theoretical model of Complex-PTSD proposed by his colleague Judith Herman, Bessel van der Kolk constructed the classification system known as Disorders of Extreme Stress Not Otherwise Specified (DESNOS). This framework included an array of confounding symptoms often seen in individuals who have endured 
prolonged extreme stress and/or trauma. Van der Kolk sought to include an assessment of changes to the individual's self-perception and sense of personal meaning and purpose tapping into the changes in the existential realm. He observed that individuals who endure extreme prolonged stress (as opposed to a single identifiable traumatic event) frequently display a common set of atypical symptoms that do not fit neatly in the prevailing PTSD diagnostic criteria of that era (DSM III). He postulated the following broad classification structure as a comprehensive assessment model.

The DESNOS classification structure included:

1. Alteration in regulation of affect and impulses

2. Alteration in attention or concentration

3. Alterations in self-perception

4. Alterations in relations with others

5. Somatization

6. Alterations in systems of meaning

The inclusion of the categories related to Alteration in Self-Perception, Alterations in Systems of Meaning, as well as Alterations in Relations with Others, represented a departure from the previously accepted diagnostic criteria for PTSD which was firmly rooted in the trauma-anxiety etiology and classification structure. These aspects of the individual in relation to others, his or her place in the world, along with significant distress related to a sense of personal meaning, are consistent with the clinical observation of returning Servicemembers as well. Van der Kolk recognized that the core qualities of an individual could be significantly changed by prolonged, extreme stressful life experiences. The DESNOS model represents the first comprehensive attempt to provide an inclusive, comprehensive classification structure for the reported symptoms that were not previously adequately acknowledged in the PTSD criteria. 


\section{Moral Injury.}

The term, Moral Injury, was said to have been first coined in the war time correspondence of Vietnam Veteran, Camillo "Mac” Bica (Brock \& Lettini, 20136, pg. xiv) and has been cited in numerous publications (Shay, 2014). But, it wasn't until recent studies began to revisit this term that it entered contemporary literature sources. In recent years, both the medical and mental health fields have turned to this construct to gain a more complete understanding of the injuries suffered across all facets of the individual including the physical, emotional, cognitive, social, and spiritual or existential. According to Shay, Moral Injury has the capacity to "deteriorates character, impairs trust, and elevates despair, suicidality and interpersonal violence (2014, p.182) The recognition that the experience of war is capable of injuring not only the body and mind, but also has the capacity to cause a profound change to the core self or identity is not new (Nash and Litz, et. al., 2013). In fact, this concept has its roots in many ancient civilizations and cultures. Yet, empirical exploration of this concept appears to be in its infancy.

In his extensive research investigating the complexity of reintegration challenges of returning Servicemembers, Dr. Brent Litz has adopted the term, Moral Injury (MI), to describe the phenomenon of deep personal change following deployment (2009). While not fully embraced by the professional field at this time, this term represents a beginning of formal inquiry into this gap in understanding. The emergence of this term in literature, interviews, and presentations on the topic of reintegration suggests that many of today's subject matter experts in the field of post-deployment psychology appear to be accepting the concept of Moral Injury as a working conceptual framework for further study and believe it to be necessary to address this obscure domain (Drescher, et. al., 2011). 
While Moral Injury is not currently recognized as a medical or psychological condition, the factors associated with it appear to be prevalent in self-reports and do not appear to be adequately covered by the existing diagnostic criteria. Unanimously, a group of panel members interviewed in the research conducted by Drescher (2011) agreed that PTSD and Moral Injury are separate but frequently co-occurring problems (Copland, 2013). This assumption is supported in the findings of Ford (2010) which found that the construct Disorders of Extreme Stress Not Otherwise Specified (DESNOS) was separate from, yet highly co-morbid with, PTSD. Examining the two constructs of Moral Injury and DESNOS reveal a great deal of conceptual similarities in presentation, yet postulate different etiological theories, which will be discussed in greater detail in Chapter 2. The call to delve deeper into these concepts has been heard across many settings. In a 2010 address to military and civilian clinicians and leaders, LT General Zilmer asserted, "The concept of Moral Injury is one factor that can lead to these illnesses and is the least acknowledged form of combat stress which needs further study." (Walker, 2010, p.1).

\section{Indicators of the Reintegration Problem}

In spite of innumerable policies, directives, and programs implemented across all branches of the Armed Forces and Veterans Administration to address the needs of this population, the prevalence of psychosocial, societal and clinical signs of this struggle continue. These indicators suggest that we still have much to understand about the mental health and reintegration needs of our Veterans. As the numbers of Servicemembers who are leaving the military and returning to their homes, families and communities increases, the concerns about their successful reintegration also increases. The following sections provide a snapshot of the scope of the current problems that are arising from unsuccessful 
reintegration and illustrate how it affects the individual, the family and the community at large.

\section{Psychosocial and Societal Indicators.}

Psychosocial and societal indicators illustrating the struggle of returning Servicemembers to successfully reintegrate following deployment has been extensively documented and reported. Despite the rise of countless programs, research and policies, the rate of suicide, substance abuse, domestic violence, joblessness, homelessness, and serious mental illness continue to rise to unprecedented proportions within this target population. With over two million Servicemembers having deployed to theaters of combat — some numerous times - the concern for providing effective reintegration support continues to rise (National Research Council, 2013). These societal indicators (discussed in greater detail in Chapter 2) emphasize the critical need for social work research and practice to strive to better understand and treat the full extent of reintegration needs of our returning Veterans.

\section{Clinical Indicators.}

The indicators presented above provide a wide-lens view of the societal and psychosocial implications of Veterans' failure to successfully reintegrate back into civilian life. By examining this problem from a clinical perspective, the lack of thorough understanding of the complexity of the personal challenges by these individuals is also illustrated. For decades, clinicians have struggled to provide accurate diagnoses and effective treatment to returning Servicemembers and Veterans while frequently reporting that the diagnostic presentation is confounding, nomenclature inadequate, and recommended treatment is only marginally effective. Specifically, issues of comorbidity, 
treatment efficacy, and other statistical trends for program and treatment completion rates illustrate a potential disconnect between our current understanding of the phenomenon based on prevailing diagnostic criteria and nomenclature and the lived experience of clinicians in the field. These clinical challenges result in frustration for both providers and clients as well as present barriers to successful treatment and reintegration.

\section{Problem Statement Summary}

In the decades following the Vietnam War, lessons have been learned. Arguably, the greatest lesson learned is that failure to provide timely, appropriate, and effective care for this population leads to pain and suffering for individuals and families for generations to come. This failure also contributes to an array of social problems including domestic violence, child abuse, incarceration, substance abuse, unemployment, and homelessness. It is as imperative today as it was generations ago to take an objective new look at this problem to understand the comprehensive needs of our Servicemembers and Veterans as they struggle to reintegrate into society. Far too many warriors are dying - not from combat— but from the consequences of our inability to effectively address their comprehensive needs. In an address to the National Suicide Prevention Conference, Admiral Mike Mullen stated that he is "frustrated and disappointed with the slow pace of treatment for Post-Traumatic Stress and other "unseen" combat injuries. After eight years of war military officials should have better answers" (Shane, 2009, p.1). The time has come to develop a comprehensive model of assessment and treatment inclusive of recognizing the depth to which trauma can injure all facets of the individual including the physical, mental, and emotional as well as the personal moral core. 
Decades of research and practice supporting the diagnosis of Post-Traumatic Stress Disorder have transpired since it was formally included in the DSM-III (1980) following the conclusion of the Vietnam War (APA, 1980). However, returning Servicemembers and Veterans indicate that this diagnosis is inadequate to capture the full extent of their pain and experience of existential transformation following war. A common complaint heard from this population is the sense that something deep in the core of their being has been profoundly changed. For some, this transformation is reported to have been unexpected and the source of significant distress. Yet, to date, no empirically supported definition has been adopted to adequately address or examine this phenomenon. Research related to this concept is sparse and challenged by the lack of consensus about the conceptual definition of this invisible wound. Directives published across military \& Veterans' settings to promote the provision of holistic care, yet fall short in providing a clear definition or guidance.

\section{Purpose of this Study.}

Litz, et. al. (2009) states, "Moral Injury in Servicemembers and Veterans appears to be a distinct phenomenon warranting its own line of inquiry and development of special intervention strategies." He recommended a two-pronged approach to investigate and address this concept. First, he recommended the development of psychometric instruments to reliably assess Moral Injury. Subsequently, the Moral Injury Events Scale (Nash, et. al., 2013) and the Moral Injury Questionnaire - Military Version (Currier, Holland, Drescher \& Foy, 2015) were developed to assess for the potential of Moral Injury based on a measure of potentially morally injurious experiences per self-report. 
In the testing phase of the instrument, the findings indicated that individuals who score high on the measure of Morally Injurious Experiences Scale (MEIS) also showed a significant correlation with impairments in work/social functioning, PTSD, depression, and suicide risk. While these instruments have been validated to assess for the existence of a potentially morally injurious experience, neither were designed to identify which specific individuals are also experiencing symptoms associated with the concept of Moral Injury. It is this facet of inquiry that is recommended by Litz as the second prong for research - the need to delve deeper into the phenomenology of the constructs of Moral Injury to better understand the lived experience of these individuals. It is this facet which has yet to been explored empirically.

Little is known at this time about how the concept of Moral Injury may also related to PTSD, DESNOS or EWB. The diagnosis of PTSD has been so intrinsically entwined within the military population, that assumptions related to this diagnosis tend to overshadow the presence of other mitigating factors that may be confounding accurate diagnosis and, therefore, effective treatment. It would appear that the intense internal conflict associated with Moral Injury reaches beyond our current paradigm of PostTraumatic Stress Disorder (PTSD) and may serve to illuminate the gaps that continue to exist in our understanding and broaden the discussion of the complex symptoms reported. In addition, a cursory exploration of the descriptors of Moral Injury appear to share common features of the DESNOS sub-domain structure. Exploring these commonalities may provide a foundation for establishing a symptomological assessment of the presence of Moral Injury. And, finally, the commonly cited hallmark characteristics of Moral Injury often include reports of enduring changes in sense of self and loss of personal 
meaning and purpose. These concepts are clearly similar to the primary premise of Existential Well-Being (or lack thereof). Exploring the relationship between the proposed construct of Moral Injury and a measure of Existential Well-Being could provide valuable insights as well.

Therefore, the purpose of this study is two-pronged. The first prong is to build upon the descriptions offered by previous studies regarding the proposed symptomology of Moral Injury to construct a symptomological model of the construct through content analysis and comparison to other validated constructs. The conceptualization will be examined within the context of prevailing diagnostic frameworks including Disorders of Extreme Stress Not Otherwise Specified (DESNOS) and Post-Traumatic Stress Disorder (PTSD), and closely related construct, Existential Well-Being (EWB). The second prong of this study was to then examine the constructs to explore the relationships between the parent constructs as well as at the sub-domain level to gain a deeper conceptual understanding of the intersections between these constructs.

This inquiry will be accomplished by exploring the concept of post-deployment reintegration to facilitate a more comprehensive understanding of how these constructs have developed over time and have been historically entwined with war and its aftermath for the individual. The literature review will not only explore the concepts across a broad historical perspective, but will also consider the theoretical and conceptual paradigms associated with the models presented. Behavioral factors associated with PTSD, DESNOS, and Moral Injury will be identified to operationally describe these constructs. Based on the behavioral descriptions from assessment and self-report, these constructs will be compared to assess the extent to which they are unique or overlapping domains. 
To clarify terms for this study, the author will be using the term, Moral Core, (at times also referenced in the literature as the spiritual or existential domain) to refer to the “core, inner sanctum of the ego and the self of a person" (Wilson, 2004, p. 110). This refers to the part of the self that is thought to hold the individual's deeply seated values, beliefs, morality and purpose, and the perception of the self in relation to society. This domain is distinguishable conceptually from the physical (referring to the body or biological processes) or the cognitive/emotional (referring to emotions or cognition such as memory).

The term Moral Injury (as defined by Litz et. al. (2009) and discussed further in Chapter II), will refer to the post-deployment phenomenon often reported by returning Servicemembers and Veterans, in which they report feeling a deep sense of personal or existential transformation. Litz and Nash propose that Moral Injury occurs when the individual's Moral Core (values, beliefs, purpose) is overwhelmed by prolonged stress, trauma or crisis, especially in a morally ambiguous experience, the very foundation of the individual's sense of self can be radically transformed. While the term has some inherent limitations and misleading connotations, it appears to be the term that is becoming more widely accepted in the field and has informed empirical research.

\section{Research Questions.}

In consideration of the numerous challenges faced by returning Servicemembers and Veterans following deployment, and the implications for personal, social, and societal dysfunction, it behooves us to continue seeking answers to increase our understanding of this experience and the complex nature of this injury. Currently, little is empirically known about how the emerging construct, Moral Injury, is defined from an 
operational or behavioral perspective, how it may be related to previous

conceptualizations such as PTSD or DESNOS, and if it could be connected to Existential Well-Being.

A cursory review of the emerging literature suggests that this construct may hold the context for which to identify and describe the phenomenon of deep personal existential transformation so often reported by this population. It is also noted that Moral Injury appears to encapsulate many of the same descriptive factors as DESNOS which suggests that the two constructs may be highly related, co-morbid, or potentially indicative of one comprehensive construct. In addition, it is unclear how this construct may be related to the diagnosis of PTSD. Therefore, this study will begin by exploring the literature to address the following questions:

1. What are the proposed indicators of Moral Injury found in in the literature?

2. What is the relationship between the behavioral or observable indicators of PTSD, DESNOS \& Moral Injury?

3. How are these constructs related to the concept of Existential Well-Being? 


\section{CHAPTER II}

\section{LITERATURE REVIEW}

As discussed in the previous chapter, the prevailing conceptualization of the complex bio-psycho-social-spiritual challenges faced by returning military personnel and Veterans continues to be heavily influenced by a single, trauma-based diagnostic paradigm. This perspective tends to focus on the impact of traumatic experiences on the emotional and, to a lesser degree, biological and cognitive domains yet fails to address, or at times even acknowledge, the impact of these experiences on the individual's spiritual domain or existential well-being.

Recent shifts in the focus of inquiry regarding the impact of war on the whole person have begun to challenge the limited previously held paradigms, illuminating the need for further inquiry into this realm. Since the first waves of Servicemembers returned from the current era of war, fifteen years of raw data have been gathered by a variety of sources, yet empirical studies to support this emerging conceptual framework are lacking. The validity and utility of many preliminary reports are contingent on several factors including the population available for study, the source of the research, and the ability to integrate sufficient rigor in the design. Field and opportunistic studies produce observational trends, but have inherent limitations for generalizability, replication or comparison between studies due to the general lack of consensus about operational and conceptual definitions across studies. Much of the assumptions applied to the current 
generation of Servicemembers are inferred from previous war-era studies, available raw data, and historical data trends - the most recent pertaining to the Servicemembers who returned from the Vietnam War (1961-1973). As introduced in Chapter 1, and discussed in greater detail in the following section, ever-changing theories and terminology related to the topic of post-deployment reintegration have created barriers to providing a consistent thread of understanding across history.

Presented in three sections, this chapter will present a review of pertinent literature pertaining to the issue of post-deployment reintegration across a historical, theoretical, and epidemiological perspective. This subject will be examined across several generations of war eras, and theory iterations, to extract common themes to inform this study. Section one follows the observations of common post-war symptomology and etiological conceptualizations for the post-war reintegration phenomenon, as well as provides a review of the diagnostic classification and terminology that prevailed during each era. Section two will illustrate the progression of several theoretical and/or conceptual models that have influenced diagnosis and treatment of post-deployment distress from a variety of relevant paradigms. Finally, section three explores more recent contemporary models that have emerged which provide a more inclusive explanation of the complexity of post-deployment distress more directly related to the subject of inquiry in this study.

\section{Historical Review}

Examining the issue of reintegration distress from the reports of those who have lived it and observations of clinicians across a historical perspective provides a strong foundation for understanding the experience of Veterans as a timeless and universal 
phenomenon. Accounts of Servicemembers returning from combat illustrates that their narratives change very little across the generations while the theoretical and conceptual models used to explain their pain tends to change with each era. The relationship between periods of war and the subsequent development of etiological explanations is as clear throughout history as it is today.

Ancient Warriors.

As far back as 800 B.C.E. (Before Current Era), Homer chronicled the reintegration obstacles faced by the ancient Greek warrior Odysseus during his 10-year journey to make his way home after the Trojan Wars. In this classic epic, Homer effectively illustrates the similarities between this iconic warrior and modern-day Veterans. After enduring and overcoming many challenges and barriers along his journey, including navigating through trials of self-doubt and fear, he arrives home to find that his wife and closest friends do not know him. While his appearance is changed by the years and battles, it is his demeanor and spirit they do not recognize. This story is played out repeatedly in the homes of returning Veterans whose family members state that they are not the same person they used to be - that the experiences of combat has changed them into someone they do not recognize. Resounding the comments of the Servicemembers presented in the prologue, we hear this theme conveyed by Veterans and family members alike as they try to describe being fundamentally changed at the core of their being.

A historical literature review reveals a long history of attempts to describe and explain the invisible wounds of war. The $5^{\text {th }}$ century Greek historian, Herodotus, talks of an Athenian soldier who was "wounded in no part of his body," but completely lost his 
vision after witnessing his comrade killed in battle (Meagher, 2007, p.13). Far from focusing on fear, anxiety or stress reactions, these early accounts of post-war transition recognize the existence of a deep, internal psychic conflict.

\section{The Civil War era (1861-1865).}

The term Nostalgia, previously coined in 1688 by Johanne Hofer (Kardiner, 1941) to describe the condition observed in Swiss mercenaries, was instrumental in shaping the initial responses to the wounded warriors of the Civil War. According to Hofer, Nostalgia referred to a severe case of homesickness that was capable of making the individual physically ill and included fainting, fever, gastrointestinal issues, and even causing death. Military physicians and commanders regarded this condition as a serious danger and tried to mitigate the effects, believing it to be due to severe homesickness. However, some regarded this as a "disease of moral turpitude" and attributed it to character flaws (Dr. John Taylor of the $3^{\text {rd }}$ Missouri Cavalry; Friedman, 2012).

During the Civil War, there were over 281,000 walking wounded - those who were considered to have minor physical wounds, but were adversely affected none-theless by their service (Leland and Oboroceanu, 2010). Desertion and alcoholism were rampant on both sides of the battle (Cruden, 1973). Those who were broken by the experiences of battle were regarded as malingerers or cowards and execution was the recommended course of 'treatment' (Meagher, 2007, p.15). Documented accounts of Veterans reporting anxiety, paranoia, psychosis, memory problems and a sunken countenance (Dean, 1997) following battle were common.

Following the end of the war, Jacob DaCosta (1871) proposed that these Veterans' symptoms resulted in a physiological condition affecting the heart and coined 
the term, Irritable Heart Syndrome which was later to be called DaCosta's syndrome or Soldier's Heart (Shepherd, 2000). If psychotic symptoms were reported, they were dismissed as insanity and no treatment was specifically recommended. These individuals wandered home to be cared for by ill-equipped family members and most suffered for the rest of their lives.

\section{World War-I Era (1914-1919).}

Veterans of World War I experienced trench warfare and massive explosions in addition to mortal hand-to-hand combat. Along with the symptoms previously mentioned, literature from that era describes reports of a hollow stare, violent tremors, psychogenic blindness or deafness, and paralysis. In 1917, British psychologist, Charles Myers, referred to this collection of symptoms as shell shock (Meyers, 1940). He observed that many soldiers returned displaying hysteria, anxiety, paralysis, blindness or deafness, nightmares, insomnia, heart palpitations, depression, dizziness, disorientation and loss of memory (Myers). Myers believed that the concussive nature of experiencing the vibrations of explosions were to blame for possible changes within the brain, most likely what we now understand to be the effects of Traumatic Brain Injury. Meyers was also instrumental in advocating for efforts to delve into the underlying psychological and emotional aspects of trauma, but sufferers of this era were still regarded as "weak moral invalids" (Shepherd, 2000).

\section{The World War-II era (1939-1941).}

Veterans of World War II continued to be plagued by shame, guilt, psychosis and memory problems. Menninger stated that, "for every four men wounded, there would be one psychiatric casualty" $(1948$, p. 11); a statistic that continues to ring true in the most 
recent research on the incidence and prevalence of PTSD (RAND, 2008). Awareness that the experience of battle was directly related to many of the common complaints was increasing. The terms battle fatigue and war neurosis (Kardiner, 1941 \& 1947) began to emerge in the wake of World War-I and throughout World War-II to describe the collection of symptoms reported by Veterans when returning from battle. For Kardiner, the manifestation of symptoms was a result of the individuals' struggles to adapt to the painful changes to their "external and internal worlds" and efforts to control or eliminate these symptoms (Linder, 2004, p. 26). Kardiner's work was also instrumental in illuminating the phenomenon that the effects of war neuroses were "no longer likely to be confined to combatants" (Kardiner, p. v) and that the symptoms were "the commonest neurotic disturbance of war" (p.3). While the terminology has evolved, these words, written amid the World War-II era, continue to be a controversial and relevant subject of discussion across the Department of Defense and Veterans Administration. Kardiner recognized, over 70 years ago, that a significant feature of post-war dysfunction was that the individual's "conception of the outer world and his own capacities to deal with it have undergone a profound change" (1941, p. 232).

\section{Diagnostic and Statistical Manual of Mental Health Disorders (1952): Stress Response Symptoms.}

William Menninger, founder of the Menninger Foundation and Chief Consultant in Neuropsychiatry to the Surgeon General of the United States from 1943-1946, was instrumental in the development of the first standardized classification for mental disorders. Working closely within the military environment to integrate psychiatric practices into the medical care of soldiers, he outlined several challenges and obstacles 
observed during World War-II regarding the delivery of mental health care for soldiers and Veterans during and immediately following deployment (Menninger, 1948).

Between 1940 and 1945, an interdisciplinary joint sub-committee of the recently formed American Psychiatric Association convened to develop a standardized classification system to resolve the discrepancies, inconsistencies and misnomers prevalent across multiple interdisciplinary fields. In 1946, the first Standard Classified Nomenclature was published (Menninger, 1948). The psychiatric portion of this classification system differentiated Transient Reactions to Stress from the more pervasive psychoneurotic disorders. Within the framework of the Transient Reactions to Stress, the term Combat Exhaustion Disorder (as identified and postulated by the military) referred to the post-combat symptoms as opposed to the symptoms related to Anxiety Reaction, Dissociative Reaction (pp. 557-571), or from the effects of physical trauma (Figley, 1978). This classification system remained the standard until 1952 when, in the midst of the Korean War (1950-1953), the first Diagnostic and Statistical Manual for Mental Disorders (1952) was published. Under this new guidance, the collection of symptoms related to war trauma were referred to as Stress Response Syndrome under the broad heading of Gross Stress Reactions (APA 1952).

\section{Korean War (1950-1953).}

Less is known about the after effects of the Korean War than many of the other worldwide engagements. Referred to as 'the forgotten war," it appears to have been lost between WWII and the Vietnam era. However, studies indicate that the Korea War Veterans who engaged in combat showed the same symptom profile of their WWII peers including depression, hysteria, and hypochondriasis (Archibald, 1965). Of note, there was 
an emphasis on researching the long-term effects of being a prisoner of war (POW). The atrocities of POW treatment during the Korean conflict, were considered to be cruel and inhumane. These including beatings, starvation, torture and execution and were suspected to be a factor in studies of the chronicity of war trauma (Sutker and Winstead,1991).

In addition, widespread atrocities and massacres of civilians were committed by both the North and South Korean armies throughout the Korean war. It is estimated that at least 500,000 civilians were executed by North Korean Army. In addition, this was the first US engagement in which enemy guerrillas hid among refugees in order to attack and kill UN forces. U.S. troops resorted to a "shoot-first-ask-questions-later" policy against any civilian refugee approaching U.S. battlefield positions. The moral dilemmas of witnessing, experiencing, and/or participating in war atrocities, has been strongly associated with the construct of Moral Injury.

\section{The Vietnam War Era (1954-1975; U.S. entered in 1960).}

The classification and ideology of the first edition of the Diagnostic and Statistical Manual prevailed throughout most of the Vietnam War (1964-1973) in spite of the outcry and lobbying efforts of Veterans and military providers, during and immediately following the Vietnam War. Providers maintained that the diagnosis and criteria for Gross Stress Reaction were not sufficient to describe or explain the collection of symptoms they were observing in their Veteran clients. While the psychological effects of war were beginning to achieve some validation, the symptoms continued to be explained as the result of the individuals' maladaptive reaction to a situational stressor (war trauma). To revisit the issues and attempt to further clarify the classification system, a new multi-disciplinary revision committee was assembled and met throughout much of 
the Vietnam War era. This committee produced the first substantial revision to the DSM in 1968 at the height of the Vietnam War as countless Veterans were already returning to communities with the invisible wounds of war (Lifton, 2005).

\section{Diagnostic and Statistical Manual of Mental Health Disorders -II (1968): Transient Stress Reaction.}

Despite overwhelming need presented by returning combat Veterans, the second edition of the Diagnostic and Statistical Manual DSM-II continued to regard combatrelated stress as a transient reaction to the "fear associated with military combat, manifested by trembling, running and hiding" (American Psychiatric Association, 1968). Regardless of the complexity or severity of the presenting symptoms (to include psychotic symptoms), this edition defined the phenomenon as non-specific Adult Adjustment Reaction under the heading of Transient Situational Disturbance and removed the term, Gross Stress Reaction (Figley, 1978). This manual broadened the scope of diagnosis to include many different types of trauma (beyond war-related) and identified several types of reactions to exposure to extreme emotional stress.

Disturbances to mental functioning were referred to as 'reactions' rather than specific pathology and were considered transient; meaning that there was an expectation that the symptoms would subside once the stressor was removed. When the symptoms failed to subside, the individual was diagnosed with Transient Situational Personality Disturbance and thought to be a condition that was due to underlying inadequacies of the individual (American Psychiatric Association, 1968). Linder, through her extensive survey of literature, interviews, and documented accounts of the historical development of the diagnosis of PTSD, emphasizes that the diagnosis of Transient Situational Disturbance was the only diagnostic classification available to clinicians working with the Vietnam 
Veterans despite the reality of increased substance abuse, homelessness, violence, and suicides (2004). Matthew Friedman, current director of the National Center for PTSD observed, "People were flooding into clinics, demanding that we do something for their distress. We had no clinical terminology for what we were seeing” (Meagher, 2004, p.19).

The DSM-II Reactive Disorders Committee formed to investigate the need for revisions to the nomenclature. Still operating from the stance that the symptom constellation was a single phenomenon resulting from exposure to a specific stressor (hence, the name of the workgroup), the intention was to investigate Veteran specific issues. Initially referred to as "post-combat disorder," this groups set out to explore and validate the specific existence of a condition shared by military combat Veterans.

The newly formed Vietnam Veterans Work Group (VVWG), a largely civilian advocacy group, presented the revision committee with criteria that included diagnoses for Brief Situational Psychotic disorder, Brief Situational Non-Psychotic Disorder, Acute Catastrophic Stress Disorder, Chronic Catastrophic Stress Disorder, and Delayed Catastrophic Disorder (Figley, 1978, p. xviii-xix ).Their findings revealed evidence that this complex constellation of symptoms was not exclusive to combat Veterans but may be shared with survivors of other disasters or catastrophes. The scope broadened, the name changed to Catastrophic Stress Disorder, and the focus began to shift away from specifically military population and generalized the symptoms to other groups as well (Linder, p. 28). With political and social pressure mounting, there was a sense of urgency to address the identified discrepancies and appease the providers, Veterans, and lobbyists who were demanding a competent, comprehensive diagnosis for Vietnam Veterans. Amid 
conflicting theories and lack of empirical data, the development and inclusion of what was to become Posttraumatic Stress Disorder, based largely on descriptive and phenomenological data documented following experiences of "extreme stress" such as war, disasters, and the Holocaust (Keane, 1993, p. 100). Ironically, the substantiating research came after the diagnosis was adopted.

\section{Diagnostic and Statistical Manual of Mental Health Disorders -III (1980): Emergence of Post-Traumatic Stress Disorder as an Anxiety Disorder.}

The Diagnostic and Statistical Manual (DSM)-III committee on Reactive Disorders remained divided over the criteria structure, symptomatology, and placement of this diagnosis (Linder, 2004). Depending on which symptom cluster was the focus of attention, some members felt that the constellation of symptoms was the result of the anxiety and fear produced by a specific overwhelming stressor or traumatic experience. Other members of the committee argued that this classification was insufficient and failed to address the highly co-morbid complaints of depression and dissociative features (flashbacks, numbing, and identity crisis). In the end, despite much debate, and working under professional and political pressure, the committee settled on placing the diagnosis of Posttraumatic Stress Disorder and established the basic premise regarding the etiology of PTSD as an anxiety disorder (due to a traumatic event). (American Psychiatric Association, 1980), published seven years after the end of the Vietnam War, and there it has resided ever since. Following this decision, Linder reports that, "a few issues were left unresolved"' (2004, p. 31).

The foundation for the current four-factor diagnosis was laid by emphasizing the commonly reported presence of re-experiencing, hyper-arousal, and avoidance/numbing, on which all subsequent assessment tools and treatment modalities are based. To address 
the other co-morbid symptomatology, this edition included a section of associated features in which the common confounding symptoms (including depression, compulsive behavior, memory problems, emotional liability, and survivor's guilt) were placed. This edition also recognized the potential for delayed onset, and that impairment could range from mild to severe affecting multiple areas of life (American Psychiatric Association, 1980). The publication of the DSM-III has significantly shaped our impression of the presentation of the vast constellation of symptoms seen in returning warriors as a single, trauma-related; yet this has resulted in a narrow view of the complexity of this issue thereby perpetuating the practice of ignoring the severity and presence of the other symptoms.

\section{Diagnostic and Statistical Manual of Mental Health Disorders - IV (1993) The Controversy Continues.}

In 1993, just prior to the publication of the Diagnostic and Statistical Manual-4 ${ }^{\text {th }}$

edition, Dr. Elizabeth Brett, an advisor to the revision committee commented that, "PTSD sits uneasily in its present classification as an anxiety disorder" (1993, p. 191), and cited two reasons that the classification of this disorder should be revised. Recognizing the omission of many of the key symptoms commonly reported by Veterans, she points to the intense historical controversy over whether PTSD was an anxiety or dissociative disorder and the unanimous vote of the DSM-IV advisory subcommittee on PTSD to classify the diagnosis under a new stress response category. Furthermore, multiple studies investigating the comorbidity of PTSD with other diagnoses such as anxiety, depression, and substance abuse, indicate that PTSD and anxiety are likely to co-occur based more upon the nature of the stressor, but that the relationship between PTSD and anxiety is "modest at best" (Brett, p. 194). 
During this time, Bessell van der Kolk had been conducting field trials as a part of the DSM-IV diagnostic review committee testing the viability of the construct, Disorders of Extreme Stress Not Otherwise Specified classification structure as potential, more comprehensive, alternative to PTSD. DESNOS will be covered more fully in section three of this chapter.

Despite promising findings in the field trials and advisory committee recommendations for the inclusion of the DESNOS classification structure, the American Psychiatric Association (APA) rejected the concept (Shay, 2014) and the Diagnostic and Statistical Manual-IV (1993) was published maintaining PTSD as an anxiety disorder. The published criteria continued to be inadequate to provide additional, differential classification adequate to resolve the issues raised regarding the dissociative and significant changes to personal perception of identity. Instead, perhaps as a compromise, the associated features section was expanded to include potential dissociative states, diminished interest in activities, feelings of detachments from other people, issues with intimacy, tenderness and sexuality, guilt, interpersonal conflict, divorce, and loss of job. Also, identified for the first time, were concepts far beyond anxiety including (a) feelings of ineffectiveness, shame, despair, and hopelessness, (b) feeling of being permanently damaged, (c) loss of previously sustained beliefs, and (d) pervasive change from the individual's previous personality characteristics (Davidson and Foa, 1993).

\section{Diagnostic and Statistical Manual of Mental Health Disorders - 5 (2013): A Paradigm Shift.}

Attempting to address many of the reported controversies with the DSM-IV and align more closely with the International Classification of Diseases ICD-10 coding system used by the medical field, the DSM-5 was published (May, 2013). Among many changes 
to the classification system, one of the most significant was to the diagnostic category and criteria for Post-Traumatic Stress Disorder. Recognizing the limitations of the previous classification as an anxiety-based disorder, the entire diagnostic category was removed from the Anxiety Disorders section and placed in a new category, Trauma and Stressor Related Disorders. Disorders residing in this new section include those in which experiencing a known stressor as a central diagnostic criterion. In addition to the classification change, significant changes were made to the core criteria for diagnosis. While the first criterion maintains that the individual must have been exposed to severe trauma, it now clarifies that the trauma may be actual or threatened and may be experienced directly, witnessed, learned of a tragedy to close friend or loved one, or due to repeated, extreme stress.

The previous DSM IV criterion requiring that the individual report feelings of extreme fear, helplessness or horror was removed. This change represents a significant shift to diagnosing the military or Veteran population who traditionally denied feelings of helplessness or fear which would prohibit them from receiving a diagnosis of PTSD. They often report that they were trained and competent and expected to experience or witness the horrors of war. Based on these criteria, some clinicians who went strictly would refrain from diagnosing PTSD for these Servicemembers because they would not endorse feeling "helpless" in self-report. So, while it remains to be seen how these new criteria will be embraced by clinicians who work with this population, it should significantly expand the number of military or Veteran patients who are accurately diagnosed with the PTSD disorder based solely on the change in the etiology language. Another factor to consider is that the requirement of the individual to have a specific trauma event as in the DSM-IV- 
TR, but that they were exposed to repeated extreme trauma or stress. In some cases, individuals previously may not have been diagnosed with PTSD if they had not been exposed to an "event" that they continued to re-experience and could identify as the source of the PTSD. It is now being recognized that the deployment itself, with the prolonged, constant exposure to extreme stress can result in the manifestation of the other symptoms of distress.

The core symptoms previously associated with PTSD (re-experiencing, avoidance, and hyper-vigilance) have been maintained as the core diagnostic categories, but have been broken out into four categories instead of the previous three (Numbing has been separated from Avoidance and is included in the new Criterion “D”). Although these criteria may prove to be more inclusive for the military population, they continue to be limited in their ability to address the pervasive change to the core self so often reported following deployment and is not sufficient or comprehensive enough to capture the degree of distress.

Conversely related to this theme of Moral Injury is the report of some returning Veterans who describe feeling as though they have been transformed in a positive way because of their experiences. Still a significant shift in the personal inner core self, some individuals acknowledging the trials of war, trauma and sacrifice, but report that they feel that they have experienced a beneficial change in their sense of self. In contract to the phenomenon of Moral Injury, the phenomenon known as Post Traumatic Growth is also measured across three domains often associated with Moral Injury: changes in selfperception, changes in inter-personal relationships, and a changed philosophy of life (Tedeschi and Calhourn, 1996). The construct of Post-Traumatic growth points to the 
human potential for resilience and healing in the face of adversity and provides further evidence of the capacity of traumatic experiences to transform the individual at the core.

It remains to be seen whether the new classification criteria embody a more comprehensive diagnostic explanation for the complex array of complaints voiced by returning Servicemembers and Veteran. Instruments based on the new criteria are only just recently being published, validated and put into use. Therefore, most existing data available are based on the DSM-IV criteria.

\section{Historical Review Summary.}

This section followed the issue of post-deployment transition across history providing an abbreviated overview of the on-going relationship between the experiences of military personnel returning from war and the theories and terminology postulated to explain the resulting distress. From this historical review, two broad themes emerge; the commonality of self-reports from returning Servicemembers and, the reactionary response of the mental health field to attempt to define and understand.

\section{Same Story - Different War.}

With regard to the first theme, the review of the literature illustrates how common the reported post-war experiences of the returning Servicemembers and Veterans are across the generations, in spite of the fact that the nature of war differs greatly from era to era, (cause, location, and type of warfare). These common reports of the personal lived experience of distress voiced by Veterans appear to fall into two distinct categories; emotion-based changes and identity-based changes. As noted in the historical literature review above, reports of extreme changes in the experience and expression of emotion, including pervasive anxiety, was clearly prominent across descriptions of all eras. For 
example, following the Civil War era, reports of fear, desertion, and tremors were noted along with reports of anxiety, hysteria, mood instability, and depression. These same complains of emotional lability were found to be reported across each of the war eras and still hold true for the most recent combat Veterans. It has been these symptoms which has garnered the most attention, research and treatment modalities. Also, clearly prevalent following each war era were reports of significant changes in individual's sense of core identity or ensuing existential crisis. Feelings of self-doubt, shame, guilt, inner conflict, sunken countenance, an empty hollow stare, inferiority, despair, loss of previously sustained beliefs, and dissociation from former self marked by deep internal conflict were commonly reported. These complaints have proven to be more difficult to conceptualize, quantify and study.

\section{Clinical Reaction.}

The second theme that emerged from the historical review is the reactionary response that each generation of researchers developed in their attempt to better explain this complex presentation. Each era had its share of conflict and controversy about the etiology, diagnostic classification, treatment and prognosis - disagreements that continue to permeate the discussion of post deployment mental health to this day. Also prevalent throughout the historic review, was a common thread of awareness of the concept of an invisible wound that was capable of adversely affecting the successful transition and reintegration of returning warriors. Yet, throughout the literature, our predecessors struggled to understand or define this concept.

This concept of an invisible wound was documented as far back as the Civil War, when individuals who were unable to adjust back to civilian life were said to have a 
condition known as Nostalgia (Kardiner, 1941). At the time, this condition was thought to be a result of severe, debilitating homesickness - but was regarded as a disease of moral turpitude. Throughout the subsequent modern war eras, new terms have continued to be postulated including Soldier's Heart, Shell Shock, War Neuroses, and Transient Stress Reaction. Post-Traumatic Stress Disorder, the most recent widely accepted term, has dominated the field of post-deployment mental health for over four decades.

While this review is far from exhaustive, it illustrates that many theorists regarded the post-war condition to be a result of experiencing the trauma of war, while others viewed the changes as an indication of inherent weakness in the character of the individual-- referring to those who suffered as weak moral invalids. Across the generations, some have called into question the moral character, or moral identity, of the individual as a potential factor in the inability to overcome their war experiences. This division appears to support the secondary theme above which allude to two paths of injury - an emotional injury and an injury to the moral core that leads to a pervasive identity change.

As previously discussed, the diagnostic criteria for Post-Traumatic Stress Disorder has dominated the field of military and Veteran care for decades. This single diagnosis, used as a post-deployment catch-all, continues to miss the mark for adequately acknowledging and addressing the reports of profound changes to the core identity of the individual in lieu of focusing on the emotional responses related to trauma and anxiety. Although the criteria for PTSD has expanded over the past three major iterations of the Diagnostic and Statistical Manual of Mental Disorders, attempts to include facets of identity change such as shame, guilt, and the loss of previously sustained beliefs, have 
not advanced to sufficiently explain this phenomenon or to allow for the alleviation of problems reported across the wide spectrum of stress indicators. Attempting to address this deficit of understanding, several alternative theories or models have been postulated to provide a more comprehensive explanation for the common cluster of complains voiced by Veterans. A sampling of some of the most relevant to this study will be explored and discussed in section two.

\section{Influencing Theories.}

As mentioned above, the explanation for the reintegration challenges commonly reported by Veterans during a particular era is predicated on the dominant conceptual frameworks of the time period. Often, these lacked the ability to fully explain the depth and complexity of the post-deployment experience across all domains; physical, emotional, cognitive and spiritual. Over time, several theoretical models attempted to more fully describe the issue of post-deployment distress discussed in Chapter 1 and further outlined above. The following theories discussed in this section have been included to provide a platform for further exploration of the post-deployment distress phenomenon from a developmental, constructivist and existential framework. While not intending to be an exhaustive review, this section will present a sampling of prevailing models that seek to explain the concept of identity and to address how it can be affected by extreme stress or trauma. Each model and its relevance to the topic of postdeployment transformation will be presented, followed by a discussion of how these models have addressed the gaps in understanding and led to further exploration. 


\section{Developmental/Constructivist Models.}

\section{Erikson's stages of identity.}

Erikson's stages of identity development (1980) provide a relevant framework for understanding the formation and transformation of identity across the lifespan, as well as a contextual model for examining the disintegration of personal identity following trauma. Speaking specifically of Veterans, Erikson stated,

What impressed me most was the loss in these men of a sense of identity. They knew who they were; they had a personal identity. But it was as if, subjectively, their lives no longer hung together - and never would again. There was a central disturbance of ...ego identity. (Erikson, 1963, p. 42)

Awareness of the stages and tasks of normal identity development is relevant to enhance understanding of the military population due to the point at which many individuals initially join the military. As Rebecca Silverstein points out, the modal age of combat duty is about 19 years and occurs at a time when the identity is just beginning to crystallize (1994). During this stage of psychosocial development, many individuals have navigated through the first 5 or 6 developmental stages, while others may still be in the process of working through the stages associated with establishing industry (competence), identity (self) and intimacy (relationships). In many ways, the military lifestyle provides an environment and opportunity for individuals to successfully navigate these stages by allowing them the ability to seek a sense of purpose, bond with others, and achieve a sense of belonging and sense of self. However, this environment also holds the potential for these individuals to experience extreme stress or trauma which can undermine and unravel the developmental tasks previously attained. During this 
vulnerable stage, traumatic experiences can shatter existing schema resulting in developmental regression and identity diffusion seen in many returning combat Veterans (Silverstein, 1994). In many returning military personnel struggling to adjusted after deployment, the breakdown of the fundamental virtues of previous developmental stages (i.e. Trust/Hope, Autonomy/Will, and Initiative/Purpose) are evident. For the warrior who has experienced extreme stress or trauma, the core of individual being--where these virtues reside, may become fragmented and development regressed to earlier stages.

\section{Piaget's concept of schemas.}

According to constructivist theory, based heavily on the work of Piaget, humans actively create "increasingly complex cognitive structures" over their lifespan; developing schemas (or cognitive maps) that allow the individual to organize their experiences in accordance with processes of assimilation and accommodation of new information. Janoff-Bulman (1992) described the concept of schema as our "assumptive" world. "Most generally, at the core of our assumptive world are abstract beliefs about ourselves, the external world, and the relationship between the two (Janoff-Bulman, 1992, p.51). Generally, Janoff-Bulman asserted that human beings seldom consider these assumptions until they are "stretched too far" in a time of extreme crisis when these core values are challenged and shattered resulting in disillusionment (p 52). Judith Lewis Herman (1997) adds, "The belief in a meaningful world is formed in relation to others and begins early in life...traumatized people suffer damage to the basic structures of the self. Their sense of self has been shattered and can only be rebuilt as it was built initially, through connections with others (p.61). 


\section{Horowitz view of trauma.}

Similarly, Horowitz defines schema as an "organized composite of multiple features that persists unconsciously to organize mental processes (1999, p.257).

Individuals have multiple schemas with regard to their sense of personal identity, sense of relationships, and about the world around them (Horowitz, 1997, p. 10). Constructivist theory regards the "self" as the "seat of individual identity and inner life" (McCann and Perlman, 1990, p. 14). Traumatic experiences are 'encoded' in the construction of the self as a means of survival but can overwhelm their existing belief system, disrupt all parts of the self, and shatter existing schema (p. 17). Trauma shatters the person's view of self and the belief in a "meaningful, orderly world" (p. 61). Even vicarious trauma can shatter existing schema.

\section{Existential/Humanistic Models.}

Departing from the traditional pathology based explanation for post deployment reintegration issues, the Department of Defense, Veterans Health Administration, National Center on PTSD (Friedman, 2000), have moved toward a whole health, patientcentered, recovery model of care. These directives recognize that injury and disintegration can occur across multiple domains of an individual's life and provide examples of a shift toward integrated and progressive models of care that embrace a comprehensive and multi-dimensional continuum of care for returning Servicemembers. While treatment protocol for returning Servicemembers is clear on ways to address biological, environmental, and mental needs, valid and empirically based interventions shown to be effective to address injuries to Servicemembers' personal or moral identity are lacking. 


\section{The soul wound.}

Many theorists not only acknowledge that the spiritual or moral domain exists, and have made attempts to describe it, they also suggest that this domain can be injured or wounded, resulting in an array of emotional, social, and behavioral outcomes. In War and the Soul (2005), Dr. Edward Tick details the theory derived from his extensive work with Vietnam Veterans stating that, "every vital human characteristic that we attribute to the soul may be fundamentally reshaped...war invades, wounds, and transforms our spirit" (2005, p.1). Focusing on post-war related symptoms, Tick asserted that, "PTSD . . . is best understood as an identity disorder and soul wound, affecting the personality at the deepest levels" (p.5). Tick refers to this transformation of the personality as a 'psycho-spiritual death' and contends that the pathology we see in many returning Veterans is a result of their becoming disconnected from their souls. According to Tick, the soul holds awareness, experience, creativity, ethics, aesthetic values, love, and is that which distinguishes good from evil. The spiritual domain, when seen as the core of the individual, is intertwined and inseparable from the whole, each layer being influenced by every other layer, and therefore, cannot (and, arguably, should not) be isolated. Rather, this domain is best regarded as a vital, integral component of the whole being that can be injured and changed. (p. 102).

\section{The broken spirit.}

Jonathan Shay asked, "When a soldier is broken by combat, what breaks?" (1994, p. 165). "The broken spirit is a metaphor for the fracturing of the soul, self, and identity" (Wilson, 2004, p.110). While this concept has had many names (soul, self, life energy), Wilson regard the spirit as the "core, inner sanctum of the ego and the self of a person" 
(Wilson, p.110). Wilson contends that when this human domain becomes fragmented, it results in the loss of coherency and continuity in the being. What is broken is the sense of connection with the "critical dimensions of [human] existence" (Wilson). These include one's connection with the self and others, nature and the sacred, hopes for the future and sources of meaning in life. Disintegration of these virtues (to borrow a term from Erikson) occurs when the self is shattered by trauma or extreme stress. Wilson outlined several possible manifestations of this continuum from the "empty self" characterized by significant disintegration of the identity, to the "cohesive self" which is characterized by ability to "spring back" from trauma demonstrating resiliency. Between the empty and cohesive selves are several variations of the "fragmented self" that are characterized by "traits of identity diffusion, fragility, and strong feelings of discontinuity within themselves and with others and are prone to dissociation" ( $p$ 123).

\section{Heimler's Social Functioning.}

Eugene Heimler, a survivor of the Holocaust, developed the theory of social functioning following his own tragic experiences while in concentration camps (Heimler, 1959). In his book, Mental Illness and Social Work (1967), Heimler brings together his experiences in concentration camps and discusses how these early experiences have colored his attitudes toward mental health and treatment. He observed that in the "face of completely meaningless tasks, people started to lose their sanity" Heimler stated, "It was clear that meaningless tasks and pointless work destroyed people” (p. 108). Heimler developed a strong belief in the necessity of a sense of meaning and purpose in life. He recognized that anyone can become "out of balance" when they reach a "point in which their frustrations overwhelm them" and stated that, "it appeared that those who 
functioned in society, as opposed to those who did not function, had the common feature of a subjectively felt satisfaction that corresponded with their level of bearable frustration" (p. 8). According to Heimler, the role of the therapist is to guide the individual in "externalizing and disentangling" their stressors. He developed the Heimler Scale of Social Functioning to assess five domains that lend meaning to life: (a) work or interests, (b) financial security, (c) friendship and social relationships, (d) family, and (e) sexuality (Heimler, 1975).

\section{Frankl's Existential Vacuum.}

Very similar in nature to Heimler's theory, Franklian Psychology (also known as Logotherapy) developed throughout the $20^{\text {th }}$ century by Viktor Frankl, also a Holocaust survivor. Logotherapy (Logos referring to "meaning") is often referred to as the Third Viennese School of Psychotherapy is based on the premise that the greatest human motivator is the quest for personal purpose or meaning. Franklian Psychology is founded on the premise that life has meaning under all circumstances stating that human beings are motivated to search for their own unique meaning in their lives and have the freedom (and responsibility) to discover meaning in all that they do or experience--even in the face of great suffering (Frankl, 1988, p. 16). Frankl recognized that suffering is inevitable and that all human beings will experience the "tragic triad" of pain, guilt, and death. But, as human beings, Frankl posited that we have the ability to reflect on our suffering and strive to discover personal meaning in the experience. Frankl viewed individuals as being comprised of three domains: the physical self (Soma), the mental self (Psyche), and the spiritual self (Noos). He regarded the Soma and Psyche as "what we have" but the Noos as "what we are" (Frankl, 1969). According to this model, the Noos is the unique 
individual essence of the being that holds all of the values, beliefs, experiences, preferences, hopes, dreams, goals, and inspiration. For Frankl, these three dimensions are inseparable and unified. He stated that "if one is disregarded, we do not get a complete human being, but a shadowy two-dimensional projection” (Graber, 2004, p.68).

Frankl differentiates between the emotional discomfort felt when searching for meaning (which he views as being a desired human trait) and the potentially pathological emptiness or void he calls the "existential vacuum" (Frankl, 1988). According to Frankl, emotional illness and depression are the result of the individual's inability to find or create their own sense of meaning in life, leading to an internal emptiness and disconnection with one's sense of personal meaning. The loss of this personal connection with personal meaning or purpose causes a chain reaction of existential crises, which leads to a shattering of the connection with the Noos or spiritual/existential domain. What was once a cohesive construct become fragmented or dis-integrated. This dis-integration affects the individual's sense of who they are as a person (or who they perceived themselves to be); their individual sense of purpose; and ultimately their ability connect with others or find meaning in their new lives. According to Franklian theory, it is this ability to remain connected within one's self in the face of adversity that leads the individual toward resiliency, recovery and growth (Frankl, 2006).

Applying this theoretical framework of existential models to the plight of returning Servicemembers and Veterans, one can see that the transition from Soldier to Civilian could bring about the makings of an existential crisis. As a Soldier, being in combat or deployed can provide a strong sense of identity and purpose. The individual has a clear and purposeful mission with other's depending on them in life and death 
situations. Coming home to Civilian life often means losing that sense of purpose, possibly being jobless or returning to a mundane job. Sometimes, the individual feels disconnected from their families and relationships and unsure of themselves. According to Frankl, this existential crisis can lead to emptiness and despair.

Table 1 provides an overview of the models presented herein including the elements, terms and descriptors proposed to describe the construct of injury to this moral domain.

Table 1

Summary of Theoretical Models, Terms and Descriptors

\begin{tabular}{|c|c|c|c|c|}
\hline MODEL & THEORIST & ELEMENTS OF MORAL DOMAIN & TERMS & DESCRIPTORS \\
\hline \multirow{2}{*}{ Developmental } & Erikson (1980) & $\begin{array}{l}\text { Purpose (industry), Relationships } \\
\text { (Intimacy) }\end{array}$ & Ego Identity & Disintegrated \\
\hline & $\begin{array}{l}\text { Silverstein } \\
\text { (1994) }\end{array}$ & $\begin{array}{l}\text { Virtues of trust, hope, autonomy, } \\
\text { initiative \& purpose }\end{array}$ & Identity Schema & Unravel \\
\hline \multirow{3}{*}{ Constructivist } & $\begin{array}{l}\text { Janoff-Bulman } \\
\text { (1992) }\end{array}$ & $\begin{array}{l}\text { Core values, beliefs about self and } \\
\text { world }\end{array}$ & $\begin{array}{l}\text { Assumptive inner } \\
\text { world }\end{array}$ & Shattered \\
\hline & Herman (1997) & Beliefs, meaning, connection to others, & Self & Damaged self \\
\hline & $\begin{array}{l}\text { Horowitz } \\
\text { (1999) }\end{array}$ & $\begin{array}{l}\text { Seat of identity, belief in meaningful } \\
\text { orderly world }\end{array}$ & Self & Shattered \\
\hline \multirow{4}{*}{$\begin{array}{l}\text { Existential/ } \\
\text { Humanistic }\end{array}$} & Tick (2005) & Values, love, ethics, beliefs of good/evil & Soul/Spirit & Disconnected \\
\hline & Shay (1994) & $\begin{array}{l}\text { Core, critical dimensions of human } \\
\text { existence }\end{array}$ & Soul/Spirit & Broken/Fractured \\
\hline & Wilson (2004) & Virtue & $\begin{array}{l}\text { Core, inner } \\
\text { sanctum }\end{array}$ & Empty Self \\
\hline & Frankl (1988) & Relationships, Purpose, Beliefs & Noos/Spirit & Existential Vacuum \\
\hline
\end{tabular}




\section{Quantifying the Moral Domain.}

One challenge to researching a concept as intangible as the Moral or Existential domain, is operationally defining such an elusive concept as well as developing reliable, empirical methods to measure it. Few validated tools exist which assess the existential or moral identity while also being widely accepted in the field of research. Far from being an exhaustive list, the following present a few examples for consideration.

\section{Existential Anxiety Questionnaire.}

Weems, Costa, Dehon and Derman (2004) explored Paul Tillich's theory of existential anxiety (1952) and used his conceptual model to develop and validate the Existential Anxiety Questionnaire. The theory of Existential Anxiety is conceptualized as an "apprehension about the ultimate meaning of life and death...revolving around three related domains of apprehension" (p.383): fate $\&$ death, emptiness \& meaninglessness, and guilt and condemnation. According to Tillich, the anxiety related to the emptiness is based on an "apprehension that specific beliefs no longer have the meaning" and "meaninglessness is an absolute concern and is about the loss of the significance of life, the future, the world, and everything" (p.385). The researchers hypothesized that "existential anxiety is an important human phenomenon that has important implications for understanding emotional functioning and may be linked to symptoms of depression and general anxiety" (p.387). A diverse sample of 225 college students (ages ranging from 18-44) were assessed with the Existential Anxiety Questionnaire (EAQ, developed for this study) along with demographics and the Symptom Checklist-90-revised. The EAQ began as 21 questions designed to assess Tillich's three domains. Eight items were found to be flawed and were removed leaving 13-items, which corresponded to 2 items 
for each of the 6 concepts within the 3 domains (although fate had 3 items). Reported reliability indicated a strong internal consistency (coefficient alpha $=0.71$ ) and test-retest reliability (of a sub-sample) of $(\mathrm{r}=0.72)$. Confirmatory factor analysis was used to determine that the data was represented well in a three-factor model. This study also found that symptoms of anxiety and depression were significantly associated with the overall EAQ as well as all three domain subscales (Weems, 2004).

\section{Qualitative Existential Social Work Model.}

Regarding the Veteran population, Lantz \& Greentree (1990) conducted a study in which they developed an existential social work model for working with Vietnam Veterans. Through a presentation of case studies, their model, based on the "belief in the central, core importance of helping the Vietnam Veteran perceive, discover, and experience a sense of meaning in both their Vietnam memories and in their present and future life," illustrates the connection of existential suffering with the commonly reported symptoms of anesthesia, rage, anxiety, depression, re-experiencing, and substance abuse. Based heavily on the work of Krill's existential social work (1978), the authors offer basic concepts in existential treatment including, existential reflection, network intervention, social skills training, that correspond with Frankl's model of finding meaning through the ability to reflect and find purpose and meaning, develop connections with others and seek a new sense of purpose (Frankl, 1969). While this is heavily anecdotal and based on practice research, conceptual models and individual case studies, it offers a clear connection to its utility with this population. Lantz went on to further develop his theory and promote existential social work practice, while continuing to strive to validate this connection through empirical means, but found this to be difficult. 
As he observed, implementing systematic experimental research methods to evaluate existential concepts was often met with resistance from practitioners. Quantitative instruments were scarce and lacked the ability to capture the richness of the lived experiences of the respondents. For this reason, he concluded that the most appropriate methods to study this phenomenon tended to be qualitative techniques such as participatory action, case study, single subject case research and grounded theory methods (Lantz, 2004).

\section{Existential Well-Being Scale.}

The Existential Well-Being Scale (EWBS), developed by Raymond Paloutzian (1982), consists of a 10-question subscale of the Spiritual Well-Being Scale (SWB). It is designed to assess the individual's sense of individual life purpose and overall life satisfaction. The respondent chooses an answer that most closely matches his or her agreement with a series of statements such as: I don't know who I am, where I came from, or where I am going; Life doesn't have much meaning; or I feel very fulfilled and satisfied with life. Negative statements are reverse scored to obtain the overall score of existential well-being. Higher scores (from 40-60) indicate an intact sense of Existential Well-Being while scores under 40 suggest that there may be concerns with the individual's sense of his or her existential wellness. This scale has been validated based on data from over 900 participants in seven different studies, with an internal consistency of $\alpha=.73$ to .98 .

The theoretical models, instruments, and surveys presented illustrate the difficulty inherent to attempting to quantify a concept that is so very subjective and culturally defined. And, with nearly as many definitions as there are tools created to measure or 
assess the elusive domain of the moral core, comparison of results from one study to another are futile. However, extracting the common threads amongst these concepts helps to crystalize this concept across these diverse definitions. The following table provides an overview of the elements and terms used to describe the profound changes to the core identity of the individual following extreme trauma or prolonged extreme stress and the adjectives use to describe the result of this injury. The following table provides an overview of the instruments presented with a summary of the primary elements of inquiry.

\section{Table 2}

Overview of Relevant Assessment Instruments

\begin{tabular}{|c|c|c|c|}
\hline THEORIST & BASED ON & ASSESSMENT & ELEMENTS \\
\hline Weems, 2004 & $\begin{array}{c}\text { Paul Tillich's } \\
\text { Theory of } \\
\text { existential anxiety } \\
\text { (1952) }\end{array}$ & $\begin{array}{c}\text { Existential Anxiety } \\
\text { Questionnaire }\end{array}$ & $\begin{array}{l}\text { Apprehension about fate/death; emptiness/ } \\
\text { meaninglessness; guilt/condemnation }\end{array}$ \\
\hline Lantz (1990) & Vietnam Veterans & $\begin{array}{c}\text { Existential Social Work } \\
\text { model }\end{array}$ & $\begin{array}{l}\text { Connection of existential suffering with } \\
\text { commonly reported symptoms of rage, } \\
\text { anxiety, depression, re-experiencing and } \\
\text { substance abuse. }\end{array}$ \\
\hline $\begin{array}{c}\text { Paloutzian } \\
\text { (1982) }\end{array}$ & $\begin{array}{l}\text { Spiritual Well- } \\
\text { Being Scale }\end{array}$ & $\begin{array}{c}\text { Existential Well-Being } \\
\text { Scale }\end{array}$ & $\begin{array}{c}\text { Loss of personal identity, meaning and } \\
\text { values }\end{array}$ \\
\hline
\end{tabular}

\section{Influencing Theories Summary.}

Section one of this chapter reviewed the progression of military events, post deployment symptomology, and etiological theories that led to the development and adoption of the diagnosis of Post-Traumatic Stress Disorder as the primary post deployment, trauma-based explanation for the presenting issues. While this classification structure has been validated for decades to effectively address the emotion-based changes 
following deployment (specifically anxiety, depression and anger), it fails to adequately account for the commonly reported identity-based changes such as reports of loss if sense of self, values, beliefs and purpose.

Recognizing these limitations to adequately identify, describe, and address this complex phenomenon, other theoretical models were developed or adapted in attempts to better understand, explain, and treat this deeply painful condition. The theorists discussed in this section largely shared the theoretical assumption that all human beings develop or possess a core self (referred to by many names including spirit, soul, identity) and that it is this domain that contains the moral core where values, beliefs, sense of right and wrong, and personal sense of life meaning and purpose are held. Collectively, these theories maintain that this moral core can be injured by experiencing extreme and/or prolonged trauma or stress that shatters the individual's sense of self and their place or purpose in the world. When that occurs, the terminology used by the theorists presented to describe the resulting condition include, breaking, fragmenting or fracturing of the core part of the self, resulting in profound identity changes. The identification of the common elements above point to a central shared assumption across theories that within every individual exists a core domain where values, beliefs, schema of self and the world, and sense of personal meaning and purpose are held. Also common is the assertion that trauma is capable of wounding and breaking this core and transforming the identity at the core. While no one term has risen to be widely accepted by the field, the term Moral Injury (Litz, 2009) is beginning to gain traction and will be discussed in greater detail in section three. 
Clearly many limitations exist when attempting to develop, utilize, or compare instruments which purport to quantify an unobservable, and yet to be defined, construct such as a Moral Core or Moral Identity. Since it can only be assessed through the individual's subjective report of their internal experience, results can be skewed by their interpretation of the concept being assessed, and their own values and beliefs. However, in spite of these limitations and the various definitions employed, the examples provided in this section have interesting commonalities that further support the collective assumptions. The assessments presented strive to assess the respondent's perception of a personal life meaning and future oriented life significance. This sense of life meaning or significance, when intact is believed to support a sense of personal well-being and functioning in the world. However, the loss of a sense of personal meaning or significance is strongly associated with anxiety, depression and a loss of personal identity. This phenomenon, or invisible wound, is described in the literature and research as both an existential and a moral identity crisis. Or, when fragmented by extreme stress or trauma is referred to as an existential or Moral Injury. This will be explored more fully in the next section.

\section{Emerging Theories}

The first section of this chapter followed the progression of theory related to post deployment reintegration and illustrated how both war, and the necessity of responding to the needs of Veterans, have propelled the field of post deployment mental health forward in sporadic increments from one era to the next. Extremes in conceptualization of the nature of this phenomenon have ranged from regarding the distress as a sign of moral turpitude during the Civil War, to creating the highly structured diagnostic classification 
of PTSD during the Vietnam conflict. War, and its aftermath, have historically created a societal imperative that could not be ignored. This urgency to understand and respond to the needs of the returning Servicemembers motivates inquiry and advances the fields of medicine, psychology and science in response to meeting the need of Veterans and society. Now, as we find ourselves faced with striving to meet the post-deployment needs of over two million returning combat Veterans, researchers are again striving to address the gaps in understanding that have been discussed in the previous sections.

Building upon previous studies and current observation of the limitations of the diagnosis of PTSD to adequately explain the complexity of symptomology reported by a sub-set of individuals who return from war, alternative conceptual models have been developed to explain the complex and diverse symptoms observed for this population. The following section will explore the progression of alternative theoretical models that have influenced recent developments of contemporary theory which will be discussed later in the chapter.

\section{Complex PTSD.}

Soon after the inclusion of the diagnosis of PTSD in the DSM-III (1982), amid much controversy in the field, researchers and practitioners recognized that there continued to be symptoms and complaints reported by patients who were not effectively described in the PTSD criteria. "From its inception, it has been suggested that PTSD captures only a limited aspect of posttraumatic psychopathology and despite the ubiquitous occurrence of numerous posttraumatic problems other than PTSD, the relationship between PTSD and these multiple other symptoms has received surprisingly little attention" (van der Kolk, 2005). While there have been many attempts to explain the 
etiology and phenomenology of these variations, one of the leading theorists to focus her attention on the symptoms that tend to fall out of the PTSD filter, is Judith Herman. Based on her extensive research and clinical work with trauma survivors, Herman observed that not all trauma experiences are the same--and not all "victims" present in the same way. In Trauma and Recovery (1997), Herman states that the existing diagnostic criteria for PTSD "do not fit accurately enough" (p. 118). She postulated, "there is a spectrum of traumatic disorders, ranging from the effects of a single overwhelming event to the more complicated effects of prolonged and repeated abuse" (p. 3). Furthermore, she believed that the presentation of individuals who have experienced prolonged, persistent or repeated trauma differed qualitatively from those who had experienced a single traumatic event. Herman began to explore the profound transformation that occurs in the individual who experiences extensive trauma. She asserted that traumatic experiences breach attachments with others, shatters constructs of the self, destroys sense of safety in the world and ability to trust, undermines and violates existing belief and faith systems that give life meaning, and leads to a state of existential crisis (p. 51). This recognition of the effects of trauma on the individual's sense of self and sense of meaning provided the foundation for further inquiry to connect experiences of trauma with profound changes in the moral core.

\section{Disorders of Extreme Stress Not Otherwise Specified.}

Expanding further upon the work of Herman, Bessel A. van der Kolk, developed an alternate classification system referred to as Disorders of Extreme Stress Not Otherwise Specified (DESNOS). Similar to Judith Herman's classification structure for Complex PTSD (C-PTSD), DESNOS recognized observable alterations in mood/affect regulation, 
concentration, self-perception, relationships and personal systems of meaning. To these, van der Kolk added the criterion of somatization--a significant observation for providing a holistic and comprehensive diagnosis for military personnel who often report multiple somatic complaints that tend to have no physiological origin (fatigue, generalized pain, digestive problems, erratic heart rate, and sexual dysfunction, among many others). Another differentiating factor between C-PTSD and DESNOS is Herman's assumption of the etiology of prolonged or repeated abuse in which the victim reports feeling helpless and/or controlled by the abuse or abuser. While also strongly associated with experiences of prolonged trauma or stress, "DESNOS is not predicated on a specific traumatic experience," (p. 375) and therefore is much more generalizable to many populations stating that it can be the result of any "history of interpersonal victimization, multiple traumatic events, and/or traumatic exposure of extended duration" (p. 375).

Van der Kolk sought a classification structure that would be more readily generalizable to many types of extreme, prolonged, trauma or stress experiences. His classification structure, Disorders of Extreme Stress - Not Otherwise Specified, addressed alterations across six domains as shown in Table 3 below.

\section{Table 3}

Classification of Disorders of Extreme Stress Not Otherwise Specified

\section{Alteration in regulation of affect and impulses}

2. Alteration in attention or concentration

3. Alterations in self-perception

4. Alterations in relations with others

5. Somatization

6. Alterations in systems of meaning

As previously stated in section two, the DESNOS classification structure was considered for possible inclusion in the DSM-IV iterations (1990 and 1992). During the field trials, the Structured Interview of Disorders of Extreme Stress (SIDES) assessment 
tool was developed and validated (Pelcovitz, D. et.al., 1997; Scoboria, Ford \& Lin, 2008). Using the Structured Clinical Interview for DESNOS, the study found that the diagnosis of DESNOS could be identified independently of PTSD in a small number of cases. However, it failed to empirically conclude whether DESNOS symptoms were a comorbid but separate disorder, or some variation of PTSD. Through this process, the existence and prevalence of these complex symptoms was substantiated and DESNOS was considered for inclusion in the DSM-IV revision either as a stand-alone diagnosis or sub-category of PTSD. However, due to resistance to changing the already controversial PTSD diagnosis, a compromise was reached. The DESNOS name was omitted and the symptoms became known as the "associated features" of PTSD - which provides a catch all to throw in everything that doesn't fit under the specific classification structure of PTSD. The DESNOS nomenclature was again considered for potential inclusion in the recently published DSM-5; however, while some of the nuances that DESNOS brings to light were embedded within the new criteria for PTSD, it was not included as a standalone diagnosis.

Subsequent research using the SIDES tool with military personnel has shown that DESNOS and PTSD are highly co-morbid yet are distinct (Ford, 1999). Although it is small, this study is unique in that it was one of the first to explore the topic of differentiating DESNOS symptoms from PTSD in a population of Veterans. Ford interviewed 85 Veterans who had been admitted to a specialized PTSD residential rehabilitation program and found that of $31 \%$ met the criteria for both PTSD and DESNOS, 28\% were diagnosed with PTSD alone, 28\% with DESNOS alone and 13\% met the criteria for neither (1999). This study provides valuable information to infer that 
the DESNOS symptoms significantly hang together within the Veteran population and are distinct, yet highly co-morbid with PTSD. While this initial study was small, in conjunction with the field trials and continued research, the evidence suggests that the collection of DESNOS symptoms may be related to, but extend beyond PTSD. It is also believed that DESNOS is strongly associated with individual who have experienced prolonged extreme stress rather than a specific traumatic event. Van der Kolk's research suggests the existence of a condition that is prevalent and sustaining in similar populations over generations and settings and is separate from (yet comorbid with) PTSD. While this departure proved to be a significant finding, DESNOS was unfortunately not selected for inclusion in the DSM-IV (1993) as a separate classification from PTSD. The conceptualization of DESNOS as a stand-alone diagnostic structure was abandoned as the field continued to be predominately influenced by diagnosis of PTSD, but many of the associated symptoms of DESNOS were incorporated into the diagnostic criteria for PTSD and the ever-expanding "associated features" section of the PTSD classification.

\section{Moral Injury.}

Many theorists have turned their attention to exploring the concept how trauma transforms the individual at the core of their being - leading to pervasive changes to their identity. While this interest appears to wax and wane over time, it has recently been revived yet again by the increase in returning Servicemembers who are reporting that they are experiencing this all-too-familiar psycho-spiritual phenomenon. While many terms have been used in the past to refer to this deep existential change, the term that is gaining acceptance in recent years is Moral Injury. 
The concept of a Moral Injury is not new (Nash, 2013). It was formally introduced by Jonathan Shay_clinician, researcher, and author of Achilles in Vietnam (1994) and Odysseus in America (2002). Shay worked extensively with Vietnam-era Veterans in the VA clinics and community. He has written prolifically about the psychosocial and psycho-spiritual challenges Veterans face when coming home (Shay, 2014). Yet it was Vietnam Marine Veteran, Camillo "Mac" Bica, who is credited with coining the term, Moral Injury, in his journals and letters written during and after the war. Through his writing, he explored the "moral anguish" he felt as he reflected on the transgressions to basic moral identity experienced during extreme trauma (Brock and Lettini, 2012). More recently, discussion is emerging among mental health experts working in the field of military trauma, stating that the concept of Moral Injury as the "least acknowledged form of combat stress" (Walker, 2010,4) and recommend further study and discussion. Moral Injury is thought to be caused by the individual experiencing a situation or event that fundamentally challenges, or transgresses, their previously held values and belief system, shattering the core psyche (Wilson, 2004) and leads to an existential crisis.

Brett Litz, a clinician and researcher in the Boston VA medical system, has been exploring the concept of Moral Injury as it relates to the Veterans he serves. Litz, and his colleagues, have conducted several studies to define and better understand this phenomenon. Litz defines Moral Injury as "a construct that describes the deleterious long-term effect of morally injurious experiences leading to significant and pervasive disruption in an individual's sense of personal morality leading to highly aversive and haunting states of inner conflict and turmoil across emotional, psychological, behavioral, 
spiritual and social domains." Events are considered potentially morally injurious if they "transgress deeply held moral beliefs and expectations". Thus, the key precondition for Moral Injury is an act of transgression which shatters moral and ethical expectations that are deeply rooted in religious or spiritual beliefs or cultural-based rules about fairness, the value of life, and so forth.” (Litz, 2009).

\section{The presentation of Moral Injury.}

Expounding on the theme set forth by the three narratives presented in the prologue, Fred Minnick, an Army journalist armed with only a camera during his tour of duty in Iraq, writes that he felt prepared for war, but unprepared for the changes he would endure in his sense of self. After several months embedded within a combat unit, he was scheduled to go on leave. He describes how he dreaded it, "I had become so involved and entrenched with the daily dose of fear and adrenaline, coupled with boredom and stress, that I was terrified of a normal day" $(2009$, p. 93). From the first day of leave, he described wanting nothing more than to be left alone, and to go back to Iraq. He was irritable and distant from his family and they commented that he "didn't seem like himself" (p. 97). These hauntingly familiar refrains heard among returning Servicemembers point to the existence of a significant personal struggle to reintegrate the many facets of their identity and self-perception during the months or even years following military service.

Interviews, survey responses, and literature related to the challenges of Veterans returning from deployment are prolific with the phrases, I am not the person I used to be and I don't know who I am anymore. This pervasive personal transformation is described as so dramatic that it is apparent to family members and friends who report feeling as if 
one person left but another returned. Family members also feel a sense of loss and grief over this change. "You think if they come back in one piece, everything is going to be all right" as a mother explains that she "never imagined that [her son] would come back somebody different” (Halliday, 2010, p.2).

These comments, voiced repeatedly by current-era Veterans and their families, echo the expression voiced by generations of war Veterans who have come before. Often these stories are woven throughout the many outlets that individuals who return from deployment have found to expressing this life-changing struggle of coping with the aftermath of war. They often engage in art, music, writing poetry, books, public speeches, and web-logs as an outlet for expressing their unaddressed pain. In the stories shared by returning Servicemembers, Veterans, and their family members, a richer and more personal glimpse into the lived experience begins to shed light on deeper issues.

\section{Proposed indicators of Moral Injury.}

As described by Litz, Dreschler, \& Nash (2013), the experience of a Moral Injury results in new learning and alteration of the view of self (in the world). This new view of the self is described as rigid and the changes to the self and core beliefs are described as rigid and damaging (Litz, 2009, p. 701). Common indicators used to describe the presentation or lived experience of Moral Injury in the individual found in the literature include:

$\begin{array}{lll}\text { Anger } & \text { Anxiety } & \text { Confusion/Bewilderment } \\ \text { Shame } & \text { Guilt } & \text { Remorse } \\ \text { Inability to trust } & \text { Self-Condemnation } & \text { Enduring changes in sense of self } \\ \text { Demoralization } & \text { Withdrawal/Isolation } & \text { Loss of personal meaning/purpose }\end{array}$




\section{Theoretical Assumptions.}

The concept that an individual could sustain a transformative shift or injury to the moral core domain of identity, resulting in what is referred to as Moral Injury is predicated on essentially two primary theoretical assumptions. According to Litz, Moral Injury is only possible in individuals who are able to experience moral dissonance - those who have/had a strong moral code to break in the first place. It is recognized that the ability to feel "anguish, guilt, and shame" following an experience that transgresses one's moral code indicates that one has a moral conscience to transgress (p.701). By extension, this assumption leads to a recognition that even the presence of Moral Injury can be viewed as a strength and evidence of the "goodness" of the individual, and would constitute a normal (rather than a pathological) reaction to abnormal events. This assumption also serves to inform a paradigm for intervention strategies.

The second assumption on which this construct is predicated is that exposure to morally injurious experiences does not have to be a direct experience (personal action/inaction or participation), but can also occur from indirect experience (witnessing or knowing about the actions of others) - and that either may produce the same effect. Evidence suggests that the effects of Moral Injury can occur as a result of an individual's own experiences or in association with a group.

\section{Etiology of Moral Injury.}

As previously discussed, Moral Injury is thought to be precipitated by the experience of potentially injurious situations in which individual "perpetrates, fails to prevent, or is witness to acts that transgress deeply held moral beliefs and expectations, emotionally, psychologically, behaviorally, socially and spiritually.” (Litz, 2009, p. 700) 
It is assumed that this experience is "incongruent and discrepant with fundamental beliefs and assumptions about how the world operates" and causes psychic "dissonance and inner conflict."

According to Litz' model to conceptualize the etiology of Moral Injury, when faced with a potentially morally injurious experience with a transgression sufficient enough to cause moral dissonance, the individual faces the challenge to either reconcile the moral dissonance or remain stuck in an existential vacuum (to borrow a term from Frankl (1969)) of shame and self-doubt. Those who are effectively able to assimilate the experience by allowing themselves to feel remorseful, are inspired to work through their dissonance by correcting or repairing the source of the guilt are ultimately able to achieve forgiveness and stability. However, individuals who are unable to navigate through this task, may internalize guilt leading to self-blame and feel shameful, believing themselves to be "unforgiveable". This harmful self-perception leads to withdrawal and isolation, inability to trust others, helplessness and hopelessness.

\section{Figure 1}

Conceptual model of Etiology of Moral Injury adapted from Litz (2009, p.700)

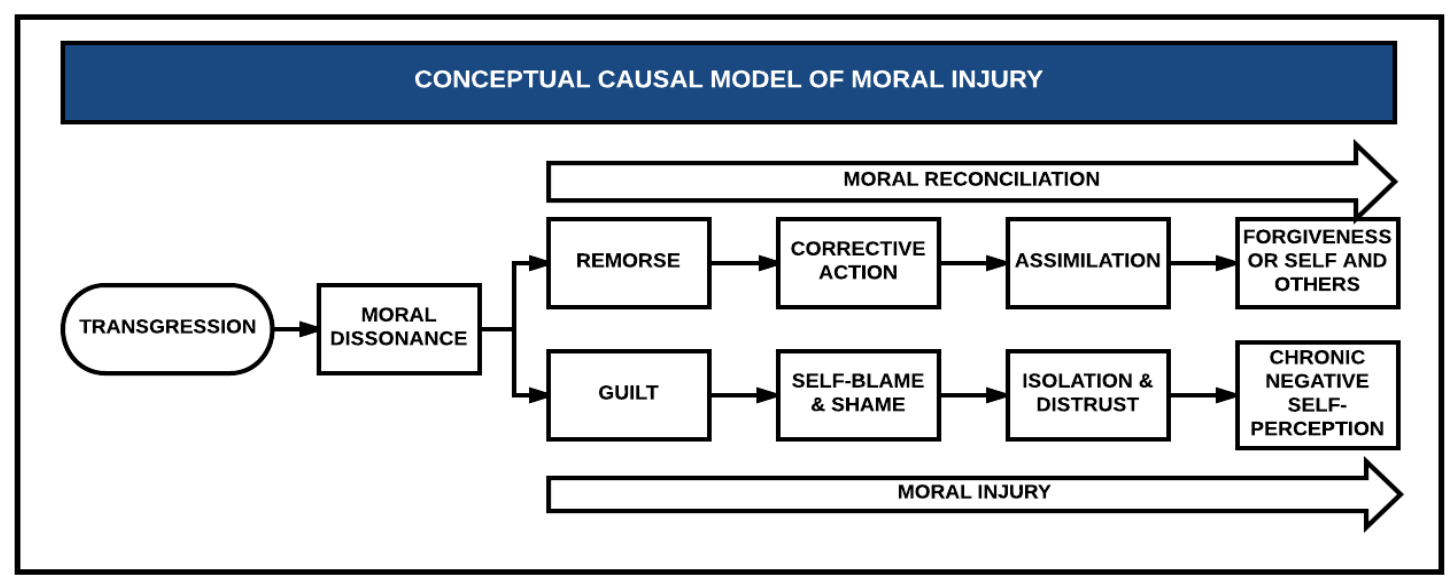




\section{Assessing Moral Injury.}

Prior to this recent research, no validated psychometric assessment tools to assess the concept of Moral Injury or morally injurious experiences existed. Based on their preliminary research on post-war experiences of Veterans and military personnel, Nash, et. al. (2013) focused attention on developing an assessment for identifying those who had experienced situations in which Moral Injury could result. The team first developed a pool of questions based on content analysis gleaned from an extensive review of literature. From this pool, an 11-item scale was constructed. The initial questions described perpetrating, failing to prevent, bearing witness to, learning about or being the victim of acts that contradict deeply held beliefs and expectations. Of the initial 11 items, two were eventually deleted due to low correlations leaving 9 items that were subjected to factor analysis. Two sub-scales emerged from the analysis, perceived transgressions and perceived betrayals. The instrument was then constructed on a 6-point Likert scale which asked the respondents to assess the extent to which they agreed or disagreed with statements about their experiences. (see figure 2 below)

The assessment was then administered to two of four cohorts in the Marine Resiliency Study at post deployment (Cohort $1 \mathrm{~N}=533$ \& Cohort $2 \mathrm{~N}=506$ ). Other scales, such as the Beck Anxiety Inventory, Combat Experiences Scale, and PTSD checklist were used to assess the validity and reliability of the MEIS. The internal consistency for the MEIS was excellent (Cronbach's 0.90) and the item-total correlations averaged .65

This, and a closely related instrument created by Currier, Holland, Drescher and Foy, the Moral Injury Questionnaire - Military (MIQ-M, 2015), offer the first attempts to assess the experiences of war as a possible factor in the identification of individuals who 
may be experiencing a Moral Injury. However, both instruments "confound exposure to transgressive acts with the effects of exposure" and are unable to identify individuals who may be suffering from what Frankfurt and Frazier have referred to as, Moral Injury

Syndrome (2016, p.318).

Figure 2

Example of the Moral Injury Experiences Scale (MEIS)

\begin{tabular}{|c|c|c|c|c|c|c|c|}
\hline \# & Item & $\begin{array}{l}\text { Strongly } \\
\text { Disagree }\end{array}$ & $\begin{array}{l}\text { Moderately } \\
\text { Disagree }\end{array}$ & $\begin{array}{l}\text { Slightly } \\
\text { Disagree }\end{array}$ & $\begin{array}{l}\text { Slightly } \\
\text { Agree }\end{array}$ & $\begin{array}{c}\text { Moderately } \\
\text { Agree }\end{array}$ & $\begin{array}{l}\text { Strongly } \\
\text { Agree }\end{array}$ \\
\hline 1 & $\begin{array}{l}\text { I saw things that were morally } \\
\text { wrong. }\end{array}$ & 1 & 2 & 3 & 4 & 5 & 6 \\
\hline 2 & $\begin{array}{l}\text { I am troubled by having witnessed } \\
\text { others' immoral acts. }\end{array}$ & 1 & 2 & 3 & 4 & 5 & 6 \\
\hline 3 & $\begin{array}{l}\text { I acted in ways that violated my } \\
\text { own moral code or values. }\end{array}$ & 1 & 2 & 3 & 4 & 5 & 6 \\
\hline 4 & $\begin{array}{l}\text { I am troubled by having acted in } \\
\text { ways that violated my own morals } \\
\text { or values. }\end{array}$ & 1 & 2 & 3 & 4 & 5 & 6 \\
\hline 5 & $\begin{array}{l}\text { I violated my own morals by } \\
\text { failing to do something that I felt I } \\
\text { should have done. }\end{array}$ & 1 & 2 & 3 & 4 & 5 & 6 \\
\hline 6 & $\begin{array}{l}\text { I am troubled because I violated } \\
\text { my morals by failing to do } \\
\text { something that I felt I should have } \\
\text { done. }\end{array}$ & 1 & 2 & 3 & 4 & 5 & 6 \\
\hline 7 & $\begin{array}{l}\text { I feel betrayed by leaders who I } \\
\text { once trusted. }\end{array}$ & 1 & 2 & 3 & 4 & 5 & 6 \\
\hline 8 & $\begin{array}{l}\text { I feel betrayed by fellow service } \\
\text { members who I once trusted. }\end{array}$ & 1 & 2 & 3 & 4 & 5 & 6 \\
\hline 9 & $\begin{array}{l}\text { I feel betrayed by others outside the } \\
\text { U.S. military who I once trusted. }\end{array}$ & 1 & 2 & 3 & 4 & 5 & 6 \\
\hline
\end{tabular}


The work of Litz, Nash and others discussed in this section has clearly brought the concept of Moral Injury forward as a viable construct in which to describe the injury or transformation experienced by returning Servicemembers and Veterans. The framework opens the door to examining the deep personal domain of the moral core and how it can be injured by experiences that transgress previously held moral beliefs or assumptions about the self and the world. The development of the Moral Injury Experiences Scale to identify the experiences that can lead to injury to the moral core is a valuable first step but it does not have the capacity to identify which individuals are experiencing symptoms that may be associated with Moral Injury. What is still lacking at this time, is the second prong of investigation suggested by Litz, which is to delve deeper into the epidemiological foundation of Moral Injury which has not yet been explored empirically.

\section{Literature Review Summary}

This chapter followed the progression of observations and theoretical models employed to guide diagnosis and practice in post deployment mental health over the past several decades. Since the adoption of Post-Traumatic Stress Disorder in the DSM-III (1980), the scope of most studies addressing post-deployment distress has been heavily influenced by this prevailing trauma/anxiety-based nomenclature. However, ample evidence in the form of Veterans' narratives and clinician observation suggest that this paradigm is limited in its ability to sufficiently address the complex nature of the reintegration stress. More recently, contemporary models which embrace a holistic or comprehensive paradigm have emerged. These studies suggest that experiences of prolonged stress or extreme trauma can impact the core identity of the individual and lead 
to an existential crisis of identity marked by a variety of disturbances such as identity diffusion or a shattering of previously held beliefs about the self and the world as well as a loss of personal meaning and purpose. Steeped in constructivist and existential theory, these models recognize the potential of war to transform the individual at their deepest core of the self - referred to as the Moral Core. The concepts, Disorders of Extreme Stress Not Otherwise Specified and Moral Injury, have been proposed as promising constructs to address this elusive domain, to further discussion, and promote inquiry. However, while raw data on this subject are abundant, a body of valid empiricial evidence to support these constructs are scarce. This presents a challenge, not only to research, but ultimately to developing effective treatment and intervention to assist Veterans in their personal journey of healing.

To begin to answer the questions posed in Chapter I, the literature and existing scales related to the assessment of PTSD, DESNOS \& MI were reviewed. From these, a comprehensive list of items associated with each construct was extracted for initial comparison to identify thematic differences and similarities. The established subdomains for PTSD taken directly from the DSM-IV \& DSM-5 diagnostic categories were used to establish a known and validated structure of assessment for comparison. The sub-domains associated with DESNOS were taken directly from the broad categories proposed by van der Kolk (1999) - see full description in Table 4 .

The available literature was mined to identify a common list of proposed descriptors to provide a conceptualization for the construct of Moral Injury. Upon initial observation, many of the Moral Injury items appear to aligned thematically with the broad categories of DESNOS - refer to Table 4 below. 
Table 4

Comparison of DESNOS \& Moral Injury Proposed Indicators and Domains

\begin{tabular}{|c|c|c|}
\hline \multicolumn{3}{|c|}{ DESNOS AND MORAL INJURY ITEM COMPARISON } \\
\hline \multicolumn{2}{|r|}{ DESNOS } & MORAL INJURY ITEMS \\
\hline $\mathbf{I}$ & $\begin{array}{l}\text { Alterations in regulation of affect } \& \\
\text { impulses (A and } 1 \text { of } B-F \text { required): }\end{array}$ & \\
\hline$A$ & Affect regulation & \multirow{6}{*}{$\begin{array}{c}\text { Anger } \\
\text { Self-harm \& punishment }\end{array}$} \\
\hline$B$ & Modulation of Anger & \\
\hline$C$ & Self-Destructive & \\
\hline$D$ & Suicidal Preoccupation & \\
\hline$E$ & $\begin{array}{l}\text { Difficulty modulating sexual } \\
\text { involvement }\end{array}$ & \\
\hline$F$ & Excessive Risk Taking & \\
\hline II & $\begin{array}{l}\text { Alterations in attention and } \\
\text { Consciousness (A or B required): }\end{array}$ & \\
\hline$A$ & Amnesia & \multirow{2}{*}{$\begin{array}{c}\text { Bewilderment* } \\
\text { Confusion* }\end{array}$} \\
\hline$B$ & $\begin{array}{l}\text { Transient Dissociative Episodes and } \\
\text { Depersonalization }\end{array}$ & \\
\hline III & $\begin{array}{l}\text { Alterations in Self-Perception (Two of } \\
\text { A-F required): }\end{array}$ & \\
\hline$A$ & Ineffectiveness & \multirow{6}{*}{$\begin{array}{c}\text { Self-Blame \& Condemnation } \\
\text { Enduring changes in self } \\
\text { Guilt \& Remorse } \\
\text { Shame } \\
\text { Isolating \& Withdrawal }\end{array}$} \\
\hline$B$ & Permanent damage & \\
\hline$C$ & Guilt and responsibility & \\
\hline$D$ & Shame & \\
\hline$E$ & Nobody can understand & \\
\hline$F$ & Minimizing & \\
\hline IV & $\begin{array}{l}\text { Alterations with relations with others } \\
\text { (One of A-C required): }\end{array}$ & \\
\hline$A$ & Inability to trust & \multirow[t]{3}{*}{ Inability to trust } \\
\hline$B$ & Revictimization & \\
\hline$C$ & Victimizing others & \\
\hline $\mathbf{V}$ & Somatization & Not assessed in MI \\
\hline VI & $\begin{array}{l}\text { Alterations in systems of meaning (A } \\
\text { or B required): }\end{array}$ & \\
\hline$A$ & Despair and hopelessness & Demoralization \\
\hline$B$ & Loss of previously sustaining beliefs & $\begin{array}{c}\text { Loss of personal sense of life } \\
\text { purpose or meaning }\end{array}$ \\
\hline
\end{tabular}

* In the initial comparison, it appeared that MI items, confusion and bewilderment would thematically match the DESNOS subdomain of Alterations in attention and concentration. But this was questionable due to the more internalized connotations related to the meaning and interpretation of the term within the MI construct as being more closely related to being bewildered and confused about the self and not a cognitive impairment of actual memory, concentration, processing or psychotic dissociation. Conceptually, these may fit more accurately within the Alterations of Self-Perception sub-domain. 
A review of the table above illustrates the potential fit of several identified MI items with the sub-domain structure of DESNOS. In many cases the items are thematically very similar or using the same language (i.e. shame, guilt, loss of meaning, etc.). However, in other cases, the fit is not as obvious or clean and the literature had to be explored further to identify the best initial fit based on availability of additional information in the literature and application of practice wisdom. However, this step was meant as a means to view and organize the content to produce a model that could be subject to further analysis and not meant to be a concise portrayal of empirically supported relationship. Further analysis may indicate the need to re-conceptualize some of the items that do not quite fit the preliminary model.

Next, this item-level comparison was extended to looking at how the DESNOS and MI descriptive items related to the classification structure of PTSD. Due to the fact that the DSM-5 (2013) revised diagnosis was not yet published at the time of the data collection phase of this study, and assessment tools in current use have not been revised to reflect the added assessment items, the DSM-IV daignostic criteria will be used for the remainder of analysis for this study. However, the DSM-5 (2013) criteria was added to the final content analysis to explore the differences and aid in potential recommendations for future research.

The visual overview of the comparison of these three constructs is provided in Appendix A which provides a preliminary depiction of how these three major concepts may relate on an item-to-item level, and where they may be found to diverge. Across the spectrum of these three major constructs, ten sub-domains were identified. Figure 3 that 
follows illustrates the relationship and strength of association (at the shared item-level)

for each of the constructs examined.

Ten sub-domains across the spectrum of PTSD, DESNOS and Moral Injury constructs:

1. Affect regulation

2. Cognitive/Memory changes

3. Changes in Self-Perception/Identity

4. Alterations of Relationships with others

5. Somatic Complaints

6. Alteration of sense of personal Meaning/Purpose

7. Re-experiencing (related to Trauma event)

8. Avoidance (related to Trauma event)

9. Numbing/Negative Alterations in Cognition and Mood

10. Hyper-arousal

\section{Figure 3}

Comparison of Sub-domains of the Constructs PTSD, DESNOS and MI

COMPARISON OF SUB-DOMAINS OF THE CONSTRUCTS PTSD, DESNOS \& MORAL INJURY

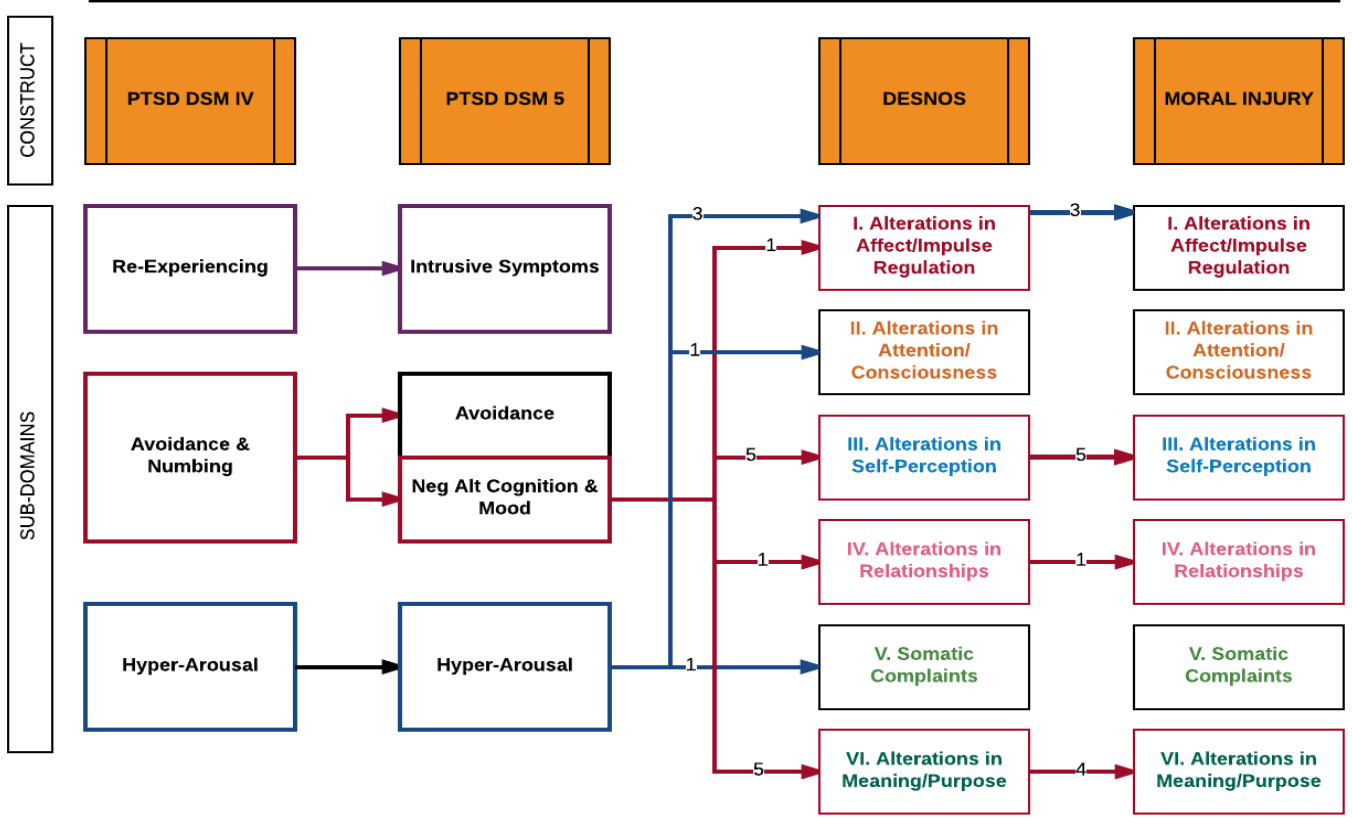

Note: The numbers indicate the number of items shared between the constructs.

\section{Discussion of Similarities and Differences between the constructs.}

As the graphic above illustrates, a great deal of association is evident between and across both PTSD diagnostic classification structures, and DESNOS and MI proposed 
diagnostic structures at the sub-domain level. And, there are clearly areas in which there are no observable intersections. These similarities and differences will be outlined below.

\section{Similarities.}

This analysis of the content extracted from the literature review supports the initial observation that a degree of commonality exists across the constructs of Post Traumatic Stress Disorder (PTSD), Disorders of Extreme Stress Not Otherwise Specified (DESNOS) and Moral Injury (MI). Specifically, common themes include:

1. DESNOS and Moral Injury share 4 of the 6 DESNOS categories: Alterations in Regulation of Affect/Impulse, Alterations in Self Perception, Alterations in Relations w/Others, and Alterations in Meaning/Purpose with the strongest connection between Alterations in Self-Perception and Alterations in Meaning/Purpose. Note: Due to the interpretation of the items Bewilderment and Confusion in MI being describe more within the context of being bewildered/confused due to the changes in self-perception rather than the interpretation of the description in DESNOS in which the focus was on impaired memory, cognition or processing, these were moved to the category of Alterations in Self-Perception which collapsed the potential sub-domain categories for MI into four. This, of course was a judgement call and is subject to further interpretation and analysis.

2. The non-avoidance indicators in DSM-IV PTSD (or Numbing indicators) and Negative Alterations of Cognition \& Mood in the DSM-5 PTSD classification overlap strongly on 4 of 5 initial items. 
3. The non-avoidance indicators in DSM-IV PTSD and Negative Alterations of Cognition \& Mood in the DSM-5 PTSD also appear to overlap with four of the DESNOS sub-domains (Alterations in Regulation of Affect \& Impulse; Alterations in Self-Perception; Alterations in Relations with Others; and Alterations in Meaning/Purpose), and three or the related Moral Injury sub-domains (Alterations in Self-Perception; Alterations in Relations with Others; and Alterations in Meaning/Purpose).

4. The PTSD category, Hyper-arousal, overlaps very weakly on two DESNOS subdomains (Somatic and Alterations in Attention) with only one item in common for each sub-domain, but it overlaps slightly more with Alterations in Affect \& Impulsivity with 3 indicators in common with both DESNOS and MI.

5. Somatic complaints are reflected in both PTSD descriptions and DESNOS (but not present in Moral Injury - see differences below).

6. PTSD has more sub-domains in common with DESNOS than Moral Injury.

\section{Differences.}

Several differences between the constructs can also be noted. Specifically, areas in which the sub-domains appear to diverge include:

1. The category of Re-experiencing/Intrusive Symptoms is exclusive to PTSD (IV \& 5) and absent in DESNOS and Moral Injury.

2. The DSM-IV PTSD category of Avoidance \& Numbing is split into two categories (Avoidance and Negative Alterations of Cognition \& Mood) in the DSM-5 version. Indicators related to the sub-domain, Avoidance is exclusive to PTSD (IV \& 5) and not reflected in DESNOS or MI. Somatic complaints are not present in Moral Injury. 
3. Of the remaining "non-avoidance" items contained in category " $\mathrm{C}-$ Avoidance \& Numbing" in the DSM-IV PTSD classification, the C-7 item ("feeling as if your future is somehow cut short") was omitted from the new DSM-5 classification. In its place were added three new items (having strong negative feelings about self, others and the world; blaming self or others for the traumatic experiences, and having strong negative feelings such as fear, horror, guilt or shame). On the surface, the new items appear to be aligned with the DESNOS \& MI sub-domain Alterations in Self-Perception.

4. The category of Alteration in Meaning \& Purpose may be exclusive to DESNOS/MI (not explicitly reflected in PTSD) and appears to be more prevalent in Moral Injury. It is important to note that of the constructs in question, PTSD is the only established and validated diagnosis supported by decades of empirical research and founded by specific criteria while Moral Injury is regarded as a dimensional problem with no known clinical threshold (Nash, 2009). In addition, the hallmark etiological event that is associated with PTSD is the experience of a traumatic event while the hallmark etiological event related to the potential presence of Moral Injury is the experience of a significant transgression of moral beliefs or expectations.

Figure 4 provides a simplified depiction of the relationship between the sub domains of PTSD (DSM-IV, 1980) and the four sub-domains proposed to be associated with Moral Injury (potentially conceptualized as a sub-scale of the DESNOS classification structure). From this illustration, it would appear that the PTSD sub-domain, $R e$ experiencing (Criterion B), is not associated with Moral Injury and is exclusive to PTSD. The solid blue arrow between the PTSD sub-domain, Hyper-arousal (Criterion D) 
indicates an association with the Moral Injury sub-domain Alterations in Affect/Impulse Regulation. However, there are two additional items associated with this Moral Injury domain that do not quite fit the DSM-IV PTSD description of Hyper-Arousal and four PTSD items are not reflected in the Moral Injury domain (as noted by the total number of items included in each domain in parentheses).

Within the PTSD sub-domain, Avoidance and Numbing (Criterion C), no Moral Injury items appear to be similar to the Avoidance items in the PTSD sub-domain. However, several items, representing three Moral Injury sub-domains, appear to potentially correspond with the non-avoidance items in PTSD or those associated with Numbing behavior. These domains include: Alterations in Relationships with Others, Alterations in Self-Perception, and Alterations in Meaning and Purpose. The latter two are only tentatively thought to be similar to the concept of Numbing/Avoidance (as indicated by the dotted lines) pending results of analysis.

\section{Figure 4}

Item Comparison of PTSD (DSM-IV) and Moral Injury Dub-domains

\section{CORRELATIONS BETWEEN PTSD (DSM-IV) \& MORAL INJURY SUB-DOMAINS}

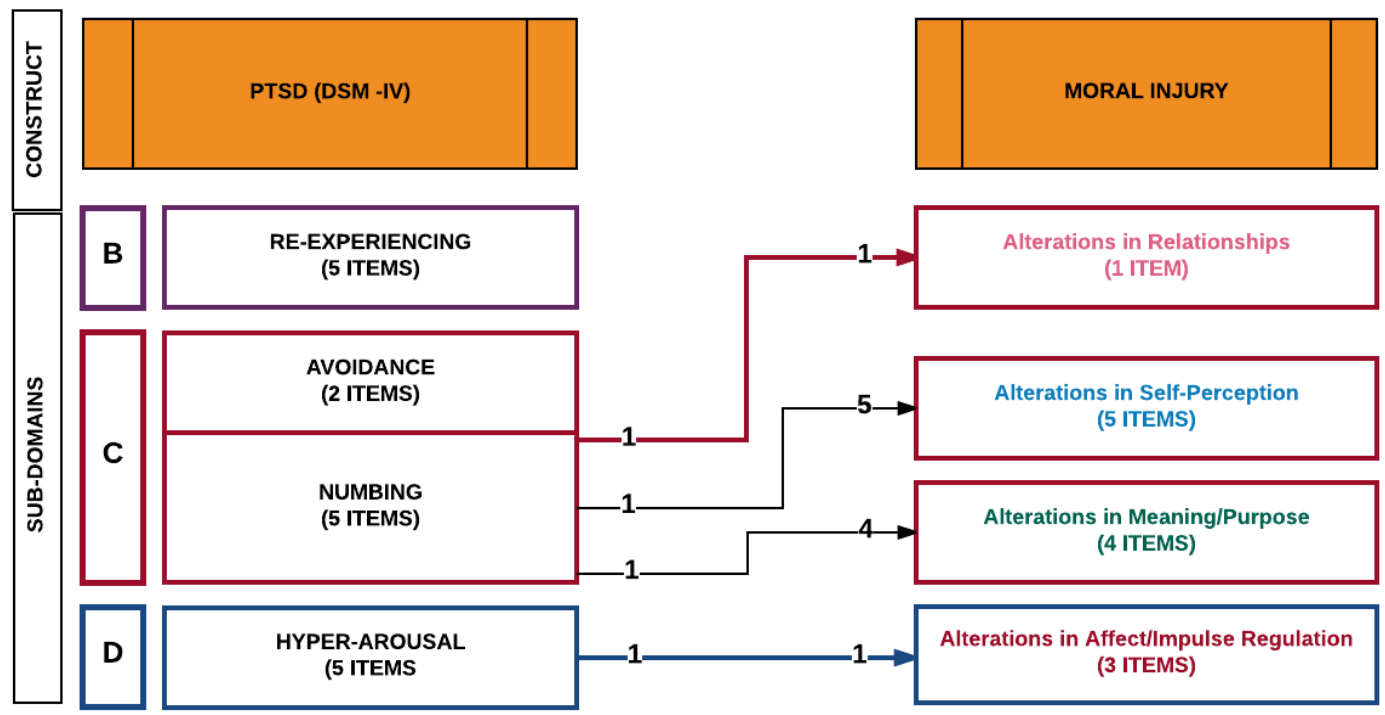




\section{Discussion of Content Analysis with Refined Research Questions.}

Through this content analysis the development of the relational model was completed to attempt to address the first two questions posed in Chapter I were addressed illustrating the relationships, similarities, and differences between PTSD, DESNOS and the symptomological conceptualization of Moral Injury. While this offers a clearer picture of how entwined these constructs can be, the third broad question, how are these constructs related to the concept of Existential Well-Being, has not been effectively addressed. As previously discussed, the prevalence of Servicemembers and Veterans reporting that they feel profoundly changed at the core of their being indicates a need to more fully explore this phenomenon of post deployment existential crisis within the context of the constructs of Moral Injury. Yet, to date this connection has not been empirically investigated. Therefore, this study will endeavor to fill this gap in research.

The methodology used to address this remaining question will be described in the following chapter as the following specific research questions are addressed.

1. How are the sub-domains of PTSD and Moral Injury related within and across sub-domains?

2. How well do the existing constructs, PTSD and Moral Injury, assess issues with Existential Well Being?

3. To which Moral Injury sub-domain is low to moderate Existential Well-Being more closely related?

4. To which PTSD sub-domain is low to moderate Existential Well-Being more closely related? 


\section{CHAPTER III}

\section{METHODOLOGY}

As stated in Chapter I, and illustrated throughout the literature review in Chapter II, returning Servicemembers struggle with countless challenges as they attempt to reintegrate into civilian life. Those who fail to successfully overcome these challenges may find themselves dealing with an array additional psycho-social outcomes including homelessness, substance abuse, unemployment, incarceration, and/or suicide (Shay, 2014). There is a growing trend in the healthcare and mental health fields recognizing the impact of the spiritual or existential domain as a mitigating construct to help explain the intense suffering experienced by some individuals, as well as to explain the phenomenon of human resiliency and growth in the face of adversity (Frankfurt, 2016). Many leading national researchers have recommended the inclusion of spiritual or existential assessment to identify those who may be struggling to reintegrate or are at-risk of failing to successfully adapt. However, to date, no empirical studies have emerged to support a universally accepted construct to identify this phenomenon.

\section{Purpose of this study}

Given the significance of the topic of post-deployment mental health, the scarcity of information concerning the relationship between one's existential condition and postdeployment distress, this study aims to fill a void in the current body of literature by exploring the differences and similarities between the constructs of Post-Traumatic Stress 
Disorder, DESNOS, and Moral Injury in relation to an individual's perceived sense of Existential Well-Being. To date, no study has specifically examined the proposed indicators of Moral Injury in relation to the concept of Existential Well-Being (Frankfurt, 2016) and the information obtained from this analysis may help to provide a more holistic understanding of the injuries suffered by returning Servicemembers. In addition, predictors and/or risk factors may be identified that could be developed in to screening tools to identify those who are struggling with Moral Injury concerns. As stated in Chapter II, this study proposes the following broad research question:

How are the constructs PTSD \& Moral Injury related to t each other and to the self-perceived issues related to Existential Well-Being?

\section{Research Hypotheses}

Based on an examination of the items associated with each of the constructs in question (PTSD, DESNOS, MI, and EWB), as well as the content analysis presented in Chapter II, one would expect that the proposed construct, Moral Injury, more effectively assesses reported changes in self-perception and/or personal sense of meaning or purpose than the more commonly used PTSD criteria.

With the strong emphasis contained within Moral Injury to assess key components of Existential Well-Being, such as dealing with a sense of changed identity, and loss of meaning or life purpose, one would also expect to find that Moral Injury will correlate strongly with the Existential Well-Being scale and that this will be higher than the correlation between PTSD and the EWB which is expected to be small or negligible. Further, one would expect to find this relationship to be strongest with certain related indicators within the Moral Injury total score, specifically the Alterations in Self- 
Perception and Alterations in Meaning/Purpose component. The findings from this investigation may indicate the ability screen for the presence of Moral Injury or loss of Existential Well-Being. To address these assumptions, the following hypotheses will be tested:

1. The Existential Well-Being total score will correlate higher with the Moral Injury total score than with the PTSD total score.

2. The magnitude of correlation between Existential Well-Being and PTSD will be small and negligible.

3. The magnitude of correlation between Existential Well-Being and Moral Injury is not small nor negligible.

4. The Existential Well-Being total score correlates higher with Alterations in Meaning and Purpose (MI) items of Moral Injury than with remaining items in the Moral Injury scale.

5. The Existential Well-Being total score will correlate moderately with the items related to Alterations in Self Perception of the Moral Injury Scale.

\section{Research Design}

This study utilized raw data from a pre-existing data set originally collected at the Warrior Transition Battalion (Fort Knox, KY) during a 6-month trial period in which the revised assessment and screening tool was being implemented (October 1, 2010 and March 31, 2011). The instrument, the Spiritual Attitudes Inventory - Revised (2010), was administered by the Warrior Transition Battalion Chaplain's office to every Soldier admitted during the six-month pilot period. The original purpose of data collection was to assess the efficacy of the new instrument which was later adopted for continued use. 
The original pilot study was a cross sectional, one-shot design employed during the timeframe in which the assessment instrument was being tested. The raw data collected from this self-assessment tool was entered into Excel for the purpose of assessing the revised instrument for efficacy and potential continued use by the Battalion's Chaplain office. The data from the spreadsheet was scrubbed for personal identifiers and then converted to SPSS for formal analysis. While the number of responses in the original data set was small $(\mathrm{N}=173)$, the information that could be gleaned from this investigation was helpful to inform practice and intervention while improving understanding about this population. The original purpose of the instrument was for the screening and identification of returning Soldiers who were experiencing spiritual or existential crisis or stress and may be in need of intervention by the Chaplain or social work services.

\section{Population setting and Sampling Methods.}

\section{Setting - The Warrior Transition Battalion}

The Warrior Transition Battalion (WTB)was a unique military battalion structure that was an extension of the Army hospital command. It was implemented in 2006 in order to provide comprehensive, interdisciplinary military and medical support to military personal who were ill, injured or wounded, most of which were coming directly to the battalion from deployment. Others may be injured while serving in support of the mission or during training accidents. While at the WTB, the Soldier was expected to maintain military routine and had a squad, company, and battalion structure with cadre to oversee the military needs and compliance with treatment. Each Soldier also was assigned to a inter-disciplinary team consisting of a medical provider, nurse case 
manager, social work case manager and other support personnel. Their mission, while assigned to the unit was to either heal and return to duty, or to return to the community as a Veteran should their illnesses or injuries be found to be permanent or severe enough to prohibit them from continuing to serve. If that became the case, a medical evaluation board would be initiated to medically discharge the Soldier.

The mission of the battalion team of cadre and civilian providers was to work together to assess and treat the comprehensive needs of the Soldier. This started with a multi-tier admission and on-going assessment process. The SAI-R was one of many screening instruments the Servicemembers were required to complete upon admission and orientation to the battalion and its purpose was to identify any potential psychosocial-spiritual issues that would warrant further support or intervention.

Once completed, the SAI-R was then submitted to the Chaplain during the oneon-one orientation interview. The results or responses of the individual assessments were not recorded or transmitted in any form for further analysis by the Chaplain or the Army Command and were not included in the Servicemembers' individual health records or files. However, for the purposes of assessing the revised tool during the 6-month pilot phase, the raw, unidentifiable data was entered into a separate database for recordkeeping and to examine the data for trends. During the process, the Chaplain evaluated the utility of the tool (administration, completion, and ability to scan for assessment). No formal protocol was provided by the Department of the Army to use or analyze this data in aggregate. 


\section{Instrument.}

Original Spiritual Attitudes Inventory (SAI, 2009).

The Spiritual Attitudes Inventory (SAI, Appendix B) was created by the United States Army Center for Health Promotion and Preventative Medicine (USACHPPM) in 2009 to "assist chaplains, behavioral health professionals and other clinician with the assessment of spiritual needs, to facilitate discussion relation to spirituality and/or track an individual's spiritual beliefs over time (such as pre- or post-deployment) as a part of a comprehensive approach to wellness." (Pg. 1) The original SAI as published in 2009 by USACHPPM, consisted of a total of 28-items constructed from four validated measures including the Duke Religion Index (DUREL, Koenig, 1997); Negative Religious Coping Scale (NRCOPE, Pargament, 2000); the Multiple Health Locus of Control Scale (MHLC, Wallston, 2005); and the Existential Well-Being Scale (EWBS, Paloutzian, 1982). Of these, this study will only be using the EWBS described below.

\section{Revised Spiritual Attitudes Inventory (SAI-R, 2010).}

Soon after implementation of the original instrument, it became clear that several functional problems existed. Specifically, the format was difficult for respondents to complete, and for Chaplains to score for use as a real-time screening tool. In fact, no scoring mechanism was originally provided. The instrument also lacked response fields for the provision of information that would aid in identifying additional issues of concern or need for Chaplain Services, such as demographics or issues of distress.

To enhance the quality and utility of this assessment, a revised version was developed and implemented as a pilot program at the Fort Knox, Kentucky Warrior Transition Battalion in the fall of 2010. The format of the instrument was modified to be 
presented in a grid format to allow for easy completion and to reduce completion errors and missing data fields. This also improved the ease by which the assessment could be scored including a means to score the sub-scales as well as a total SAI-R score. The new format was structured so that areas of endorsement or concern could be identified at-aglance without having to obtain a score to proceed.

The revised instrument, the Spiritual Attitudes Inventory - Revised (Appendix C), retained the four sub-scales previously described. To these, a short demographics section was added as well as checklist of Military Stress Indicators (which will be described in greater detail in the Independent and Dependent Variables section). This revised tool was implemented for a 6-month trial period during which time the data used for this study was collected.

\section{Conceptual and Operational Definitions of Independent Variables.}

\section{Demographics.}

The Spiritual Attitudes Inventory-Revised (Appendix C) included a section of independent demographics variables that were added to assist the chaplain during 1:1 interviews. It was determined to be helpful to the Chaplain and the Battalion leadership to collect information on Servicemembers' rank, Military Occupations Specialty (MOS), and recent deployment histories to better understand the respondents' experience. In addition, information related to marital status, and children enabled the Chaplain to reach out to the families as well as to consider potential protective factors mentioned in recent research. These independent variables (described in Table 4 in the procedures section below) provide additional information from which to conduct differential analysis of this 
population. Descriptive analyses provide information about the distribution of the population as well as generating grouping variables.

\section{Conceptual and Operation Definitions of Dependent Variables.}

For the purpose of this study, the scale variables may be considered dependent by virtue of being subject to study or change based on other factors (i.e. number of deployments). However, during analysis, they may also be treated as independent variables when exploring the relationship between the constructs measured.

\section{Existential Well-Being Scale.}

As previously discussed in Chapter II, studies across a variety of fields have recognized the importance of embracing a holistic approach to research and treatment and supporting the inclusion of the existential domain in research and treatment. However, the operational and conceptual definitions for this concept vary widely from study to study, and a unifying definition across studies is non-existent. Therefore, within the context of this study, this construct is operationally defined and measured by the Existential Well-Being Scale (EWBS; Paloutzian, 1982). The EWBS is a ten-item subscale of the Spiritual Well-Being Scale designed to measure perceived existential well-being. Based on data from over 900 participants in seven different studies from which internal consistency coefficients of $\alpha=.73$ to .98 were reported. Higher scores indicate greater existential well-being while lower score may be an indication of existential angst or crisis.

\section{Military Stress Indicator (MSI) checklist (with sub-scales).}

The Military Stress Indicator checklist consists of 34 items within which two embedded sub-scales are contained and a third construct is extrapolated. The two sub- 
scales contained within the MSI are the Post-Traumatic Stress Disorder Checklist Military Version (PCL-M) and the Disorders of Extreme Stress Not Otherwise Specified classification criteria. The third sub-scale that was extracted from this data is the proposed Moral Injury Scale - derived from the DESNOS classification.

The MSI checklist can be scored in its entirety as an overarching scale to determine overall level of distress, or the sub-scales can be scored independently to assess for PTSD, DESNOS, or Moral Injury-related symptoms. The checklist directs the respondent to endorse any conditions that they have experienced over the previous 30day period. If tallied in total, one would be able to assess for a general level of distress or to isolate specific items indicating concern.

\section{PCL-M sub-scale.}

Within the total 34-item checklist, 17 items are from the Post-Traumatic Disorder Checklist - Military version (PCL-M) which screen for PTSD-related symptomology. The PCL-M version that was used at the time of the study was based on the DSM-IV-TR criteria developed by Weathers (1993) and was the screening and diagnostic tool endorsed in DoD \& VA practice guidelines (NCPTSD). The PCL-M has a test-retest reliability of $96 \%$ and is used as both a screening tool and baseline diagnostic assessment. The 17-items assess for facets of the 4 core diagnostic criteria (re-experiencing, hyperarousal, avoidance and numbing) which is consistent with the core diagnostic criteria also included in the DSM-5.

The PCL-M has a test-retest reliability of $96 \%$ and is used as both a screening tool and baseline diagnostic assessment. The original PCL-M is scored based on responses to a 5-point Likert scale that ranges from $1=$ Not at all to 5=Extremely, with a usual time 
frame of In the past month. The range of the possible scores is $17-85$. While many cut-off scores have been suggested for a positive endorsement, for the general population a score of 50 (Forbes, 2001) is the standard for a positive screening, warranting referral for further assessment. However, the suggested cut off score adopted for Active Duty Military is set at 28 (NCPTSD, 2010) to build more sensitivity into the screening. The DoD and the VA have endorsed the use of the PCL-M as a preliminary screening, as well as a diagnostic, tool. The 17-items assess for facets of the 4-core diagnostic criteria (reexperiencing, avoidance and numbing, and hyper-arousal) which is consistent with the core diagnostic criteria also published in the DSM-5 (2013).

For ease of use and completion in the intake screening process, the 17 items from the PCL-M are presented in a yes/no checklist format rather than in the original Likertscale form. This format has been used in practice by the author and found to be less intimidating and easier to complete in a self-report format and during the pilot phase it was found to be successful as a screening tool. The instructions direct respondent to check only those items that they have experienced at a moderate level or above for the past 30 days. Therefore, any item checked will be considered a positive endorsement for scoring. The cut off score suggested for combat Veterans is 28 of 85 or $32.9 \%$. Converting this ratio to the 17 possible points in the new scale, this equates to 5.59 items needed to consider a positive screening for PTSD symptoms (rounded to 6 items out of the possible 17) is considered a positive result for the PTSD sub-scale response.

\section{DESNOS Sub-Scale.}

In addition to the 17-items from the PCL-M the remaining 17-items were adapted from the criteria for Disorders of Extreme Stress - Not Otherwise Specified (DESNOS) 
as defined by van der Kolk (1996). DESNOS consists of six symptom clusters: (a) alterations in regulation of affect and impulses, $(b)$ alterations in attention/concentration, (c) alterations in self-perception, $(d)$ alterations in relations with others, (e) somatization, and $(f)$ alterations in systems of meaning. The classification of DESNOS was validated in DSM-IV field trials conducted by van der Kolk, et. al. (1996) and found to more effectively capture the extraneous symptoms often reported by victims of prolonged or extreme stress. In 1999, Ford administered the SIDES to a group of military personnel, he found that the DESNOS criteria were endorsed independently from PTSD symptoms in $28 \%$ of cases while reported to be separate but co-morbid in $31 \%$ of the cases. Based on these criteria, a 17-item scale was developed to assess for the presence of DESNOS. Similar to the PCL-M checklist, a positive endorsement of DESNOS will be made if a respondent endorses 6 or more of the 17 items (35\% endorsement). The other 17 -items within the total checklist are taken from the criteria for Disorders of Extreme Stress - Not Otherwise Specified (DESNOS) as defined by van der Kolk (1996). These 17 DESNOSrelated items encompass all 6 symptoms clusters including alterations in regulation of affect and impulses, attention/concentration, self-perception, relations with others, somatization, and systems of meaning.

\section{Moral Injury Sub-Scale.}

As illustrated in the content analysis presented in Chapter II, the proposed indicators of the construct of Moral Injury appear to align across four of the categories of DESNOS criteria: alterations in regulation of affect and impulses, alterations in selfperception, alterations in relations with others, and alterations in systems of meaning. 
The following two DESNOS categories do not appear to be related to the construct of Moral Injury: alterations in attention/concentration, and somatization.

For the purpose of analysis for this study, the items associated with the four categories DESNOS which are also related to Moral Injury will constitute the third subscale to measure the construct Moral Injury.

\section{Ethics \& Safety Issues.}

This study used existing data collected in routine assessments through the chaplain's office as directed by U.S. Army Medical Command. No surveys were identified; only de-identified raw data responses were processed and analyzed.

\section{Institutional Review Board.}

The original pilot study was developed in conjunction with the Fort Knox Ireland Army Community Hospital and Walter Reed Defense Research Institute. The protocol was submitted and reviewed by the Institutional Review Boards over both agencies as well as through the University of Louisville.

\section{Walter Reed Army Medical Center Institutional Review Board.}

The protocol was submitted through the military chain of command on multiple levels (Chaplain, Warrior Transition Battalion Commander, and Ireland Army Hospital Commander) before finally being submitted to the Institutional Review Board at the Walter Reed Army Medical Center Research. The study was declared exempt due to the use of anonymous, retrospective existing data. Approved December 4, 2012).

\section{University of Louisville Institutional Review Board.}

The proposal was then submitted to the University of Louisville Institutional Review Board and reviewed as an exempt study - March 25, 2013. 


\section{Procedures}

\section{Data Entry, Evaluation, Cleaning and Recoding. Data Entry and Evaluation.}

The raw, de-identified data set from the original pilot project was provided to the researcher in an Excel spreadsheet. The data file and code book were then created in Predictive Analytics Software Gradpack 17.0 (PASW, 2009) component of the Statistical Package for Social Science (SPSS) software program to exactly match the variables in the SAI-R (2010) instrument. The data were then entered into the SPSS data file. The data entry and conversion to SPSS was then checked twice for transcription accuracy and reviewed for errors.

\section{Data Cleaning \& Recoding.}

The Active Duty Military respondents had been very thorough when completing the forms and, subsequently, very little data were missing. There were a few instances in which entire sub-scale responses were omitted and were omitted from the analysis. The remaining data were scrubbed for inconsistencies and evaluated for parametric and nonparametric tendencies.

\section{Recoding of Independent Variables.}

The original variables were analyzed to review frequencies and basic descriptive characteristics. Due to the small $\mathrm{N}=173$, several of the demographic variables were collapsed and recoded to provide a clearer view of the sub-categories. These are presented Table 5 below. 


\section{Table 5}

Original and Recoded Independent Variables

\begin{tabular}{|c|c|c|c|}
\hline Variable \# & $\begin{array}{l}\text { Variable Name } \\
\text { (Original data level } \\
\text { of measurement) }\end{array}$ & Original Response Value & Recoded Variable Values \\
\hline \multirow{3}{*}{1} & \multirow{3}{*}{ Rank (nominal) } & \multirow{3}{*}{ Open Response } & 1 - Lower Enlisted \\
\hline & & & 2 - Upper Enlisted \\
\hline & & & 3 - Officers \\
\hline 2 & MOS (nominal) & Open Response & NOT USED \\
\hline \multirow{3}{*}{3} & \multirow{3}{*}{ Component (nominal) } & 1 - Active Duty & 1 - Active Duty \\
\hline & & 2 - National Guard & \multirow{2}{*}{2 - NG \& Reserves } \\
\hline & & 3 - Reserves & \\
\hline 4 & Age (ratio) & Open Response & Not Recoded \\
\hline \multirow{6}{*}{5} & \multirow{6}{*}{$\begin{array}{l}\text { Race/Ethnicity } \\
\text { (nominal) }\end{array}$} & 1 - Caucasian & \multirow{3}{*}{1 - Caucasian } \\
\hline & & 2 - Black & \\
\hline & & 3 - Hispanic & \\
\hline & & 4 - Asian & \multirow{3}{*}{2 - Non-Caucasian } \\
\hline & & 5 - Native American & \\
\hline & & 6 - Other & \\
\hline \multirow{5}{*}{6} & \multirow{5}{*}{$\begin{array}{l}\text { Marital Status } \\
\text { (nominal) }\end{array}$} & 1 - Married/Partnered & \multirow{2}{*}{1 - Married/Partnered } \\
\hline & & 2 - Single & \\
\hline & & 3 - Separated & \multirow{3}{*}{2 - Non-Married/Partnered } \\
\hline & & 4 - Divorced & \\
\hline & & 5 - Widowed & \\
\hline \multirow{2}{*}{7} & \multirow{2}{*}{ Gender (nominal) } & 1 - Male & \multirow{2}{*}{ No Change } \\
\hline & & 2 - Female & \\
\hline 8 & $\begin{array}{l}\text { Service Entry Date } \\
\text { (ratio) }\end{array}$ & Open Response & NOT USED \\
\hline \multirow{6}{*}{9} & \multirow{6}{*}{$\begin{array}{c}\text { Number of } \\
\text { deployments (ratio) }\end{array}$} & 0 & \multirow{3}{*}{$0=$ no deployments } \\
\hline & & 1 & \\
\hline & & 2 & \\
\hline & & 3 & \multirow{3}{*}{$1=$ one or more } \\
\hline & & 4 & \\
\hline & & 5 & \\
\hline \multirow{7}{*}{10} & \multirow{7}{*}{ Number of Children } & 0 & \multirow{4}{*}{$0=$ no children } \\
\hline & & 1 & \\
\hline & & 2 & \\
\hline & & 3 & \\
\hline & & 4 & \multirow{3}{*}{$1=$ one or more } \\
\hline & & 5 & \\
\hline & & 6 or more & \\
\hline
\end{tabular}




\section{Recoding of Dependent Variables.}

The original Dependent Variables - the domain scales, included the Existential Well-Being Scale; Military Stress Indicator Total Checklist with the Post-Traumatic Stress Disorder Checklist and DESNOS sub-scales. These original variables were analyzed to review frequencies and basic descriptive characteristics. Due to the small $\mathrm{N}=173$, and for further analysis to answer the research questions for this study, these variables were transformed and recoded to create new variables which more effectively captured the characteristics of each domain (see Table 6 below).

Given that the Existential Well-Being Scale measures the degree of well-being perceived by the respondent, it was necessary to determine the what values would indicate poor or lack of Existential Well-Being. The literature indicates that a score of 4060 indicate strong, healthy existential well-being (Paloutizian, 1982). Therefore, this variable was recoded to create a new variable that only contained the scores that were under 40 and indicative of low to moderate Existential Well-Being. The remaining scales (PCL-M and DESNOS) were recoded to eliminate those cases which did not endorse a single item in the scale, thereby creating a new variable for each that contained only those cases in which at least one item was endorsed.

A new variable, Moral Injury, was created by combining the four DESNOS subscales found through content analysis to be strongly associated with the proposed indicators of Moral Injury. Finally, each of the constructs, PTSD and Moral Injury were broken down into their categorical elements to allow for internal analysis as well as cross domain analysis. 
Table 6

Table of Recoded Dependent Variables

\begin{tabular}{|c|c|c|c|}
\hline Original Variable & Original Sub Scales & New Variable & New Sub-Scales \\
\hline \multirow{8}{*}{ Military Stress Indicator } & \multirow{4}{*}{ PCL-M - Total } & \multirow{4}{*}{ PCL-M - YES } & Re-Experiencing \\
\hline & & & Avoidance \\
\hline & & & Numbing \\
\hline & & & Hyper-Arousal \\
\hline & \multirow{4}{*}{ DESNOS Total } & \multirow{4}{*}{ MORAL INJURY YES } & Affect \& Impulsivity \\
\hline & & & Relationships \\
\hline & & & Self-Perception \\
\hline & & & Meaning \& Purpose \\
\hline Existential Well-Being & EWB Total & EWB - YES & N/A \\
\hline
\end{tabular}

\section{Data Analysis}

\section{Power.}

The power of a statistical test refers to the "probability that effects that actually exist have a chance of producing statistical significance" (Taabachnick) and assesses the probability of making Type II errors, which is failing to reject a false null hypothesis (Rubin \& Babbie, 1997). The required sample size given alpha of .05 and power of .95 given a small effect size (Spearman rho) of .3 and a non-centrality parameter $\Delta=3.3133$, a critical $t=1.66$ is $n=111$. Based on this test, the sample size of this study, $N=173$, is sufficient.

\section{Frequencies \& Descriptive Analyses.}

Descriptive statistics were performed on all demographic and recoded variables to better understand the respondent population and data set description. The total scores for the composite scales and sub-domain scales were examined individually to determine the descriptive characteristics of the data sample including the mean, mode 
and range of scores for this population.

\section{Correlational Analysis.}

Bi-variate (Pearson), two tailed correlational analyses were performed to address the previously stated research questions and hypotheses. This analysis measures the strength and direction of linear relationships between pairs of continuous variables, represented by $r$, correlation coefficient, value. For larger analyses involving multiple calculations, ad hoc Bonferroni calculation adjustment approach was conducted to correct for the distribution of the significance level across the multiple calculations. This is meant to minimize the possibility of making a Type I error which would be accept a false positive based on a deflated significance level. However, there is ample evidence in research literature that cautions against the overuse or overinterpretation of the Bonferroni adjustment stating that its use in some cases could over compensate leading to a Type II error (a false negative result) leading to potentially missing subtle significant findings (Perniger, 1998). For this study, the findings of the significance of the relationships reported in Chapter IV for the larger calculations will be presented with and without the Bonferroni calculation adjustment for comparison and discussion since the focus of this study is the exploratory identification of relationships between the variables.

Research questions, hypotheses and methods outlined:

1. Question: How are the constructs, PTSD \& MI, and their sub-domains related within and across the domains?

Hypothesis: Based on an examination of the items associated with each of the constructs in question (PTSD, DESNOS, MI, and EWB), as well as the content analysis presented in Chapter II, one would expect that the proposed construct, 
Moral Injury, more effectively assesses reported changes in self-perception and/or personal sense of meaning or purpose than the more commonly used PTSD criteria.

Analysis: For this analysis, the total scores for the recoded scale variables for the PCL-M and MORAL INJURY as well as the scores for each of their subdomain scales will be used to measure the magnitude of the correlation between the parent variables, as well as the associations between the sub-domain variables.

2. Question: How well do the existing constructs, PTSD and Moral Injury, assess the concept of Existential Well-Being?

Hypothesis: With the strong emphasis contained within Moral Injury to assess key components of Existential Well-Being, such as dealing with a sense of changed identity, and loss of meaning or life purpose, one would expect to find that Moral Injury will correlate strongly with the Existential Well-Being scale and that this will be higher than the correlation between PTSD and the EWB which is expected to be small or negligible.

Analysis: For this analysis, the total scores for the recoded scale variables for the PCL-M, DESNOS, MORAL INJURY (those cases which had at least one endorsed item) and EWB (recoded to include the low to moderate endorsement indicating a lack of perceived Existential Well-Being) will be used to measure the magnitude of the correlation between the parent variables.

3. Question: To which Moral Injury sub-domain is low to moderate Existential Well-Being more closely related? 
Hypothesis: One would expect to find the relationship to be strongest between low-moderate Existential Well-Being and certain sub-domains within the Moral Injury total score. Specifically, the Existential Well-Being total score correlates higher with Alterations in Meaning and Purpose (MI) items of Moral Injury than with remaining items in the Moral Injury scale and that the Existential Well-Being total score will correlate moderately with the items related to Alterations in Self Perception of the Moral Injury Scale.

Analysis: For this analysis, the total score for EWB (recoded to include the low to moderate endorsement indicating a lack of perceived Existential Well-Being) and the recoded variables for each of the four sub-domains of the construct Moral Injury (Alternations in Relationships; Alterations in Affect/Impulses; Alternations in Self-Perception; and Alterations in Meaning \& Purpose) were used to measure the magnitude of the correlation. Then, each of the sub-domain variables were measured independently of the others to explore which sub-domains were more strongly correlated with the construct of EWB.

4. To which PTSD sub-domain is low to moderate Existential Well-Being more closely related?

5. Hypothesis: One would expect to find the relationship between low-moderate Existential Well-Being and certain sub-domains within the PCL-M total score to be correlated more strongly than others. Specifically, the Existential Well-Being total score will correlate moderately with the Numbing Category of PCL-M than with remaining items in the PCL-M scale and that correlation with the remaining items will be small or negligible. 
Analysis: For this analysis, the total score for EWB (recoded to include the low to moderate endorsement indicating a lack of perceived Existential Well-Being) and the recoded variables for each of the four sub-domains of the construct PTSD (Re-experiencing; Avoidance; Numbing; and Hyper-Arousal) were used to measure the magnitude of the correlation. Then, each of the sub-domain variables were measured independently of the others to explore which sub-domains were more strongly correlated with the construct of EWB.

\section{Methodology Summary}

Using an existing data set gathered during the pilot implementation of the Spiritual Attitudes Inventory - Revised (2010), the purpose of this study and data analysis plan was to examine the relationship between variables which measure aspects of post-deployment distress. Specifically, the association between the Post-Traumatic Stress Checklist - Military Version (PCL-M), and the proposed construct of Moral Injury (as measured by combining four domains taken from the Disorders of Extreme Stress Not Otherwise Specified (DESNOS) classification domains) were explored. Additionally, the relationship between these variables and the concept of Existential Well-Being (or lack thereof) was a central question in the study. The following Chapter will present and discuss the results of this analysis. 


\section{CHAPTER IV}

\section{RESULTS}

In this chapter, the results of the data analyses are presented. The data, collected as described in Chapter III, were analyzed with the objective of addressing each of the research questions posed in Chapters I and II. These results will be discussed and interpreted in the final chapter.

\section{Demographics and Descriptive Data Findings}

The ages of the respondents in this study ranged from 19-59 years old with an average age of 33.74. The racial composition of the respondents was: Caucasian, 78\%; Black, 13.9\%; Hispanic, 5.2\%; Asian, 1.7\%; and Native American, 1.2\%. The gender distribution of the population was male $88.4 \%$ and female, $11.6 \%$. Nearly all ranks were represented in the sample, however the largest segment of the population were the upper enlisted (E-4 through E-8) which made up $83.8 \%$ of the sample. The majority were active duty (41.6\%), followed by Army Reserves (30.6\%), and National Guard (27.7\%). Most had been deployed at least once $(82.1 \%)$.

The demographic distribution of the Fort Knox data set was compared to that of the Army at large at the time of the pilot to determine if it was similar across a number of variables. According to the Army profile for FY 2009, there were 1,133, 699 members of

the U.S. Armed Forces (DoD, Personnel and Procurement Statistics, 2010). Of that total, there were 49\% Active Duty, 32\% National Guard, and 18\% Reservists. Regarding additional descriptive variables, $85 \%$ were male, $61 \%$ Caucasian and over $58 \%$ were 
married. The chart below illustrates this comparison. Even though the $\mathrm{N}$ for the pilot was very small and it is not suggested that the findings could be generalized to the larger population, it is of interest to note that the distribution across the primary descriptive variables of this study were similar to the population of the Army as a whole (Table 7).

Table 7

Demographic comparison between study population and Army at time of data collection.

\begin{tabular}{|c|c|c|c|c|}
\hline \multicolumn{5}{|c|}{ POPULATION COMPARISON BETWEEN STUDY \& GENERAL POPULATION OF THE ARMY } \\
\hline \multirow[b]{2}{*}{ VARIABLE } & \multicolumn{2}{|c|}{ GENERAL ARMY POP } & \multicolumn{2}{|c|}{ STUDY N } \\
\hline & $\mathbf{N}$ & $\%$ & $\mathbf{N}$ & $\%$ \\
\hline \multicolumn{5}{|l|}{ COMPONENT } \\
\hline Active Duty & 555,512 & 49 & 72 & 41.6 \\
\hline National Guard & 374,121 & 33 & 48 & 27.7 \\
\hline Reserves & 204,066 & 18 & 53 & 30.6 \\
\hline \multicolumn{5}{|l|}{ GENDER } \\
\hline Male & 963645 & 85 & 153 & 88.4 \\
\hline Female & 170055 & 15 & 20 & 11.6 \\
\hline \multicolumn{5}{|l|}{ ETHNICITY } \\
\hline Caucasian & 691557 & 61 & 135 & 78 \\
\hline non-white & 442143 & 39 & 38 & 22 \\
\hline \multicolumn{5}{|l|}{ MARITAL } \\
\hline Married & 657546 & 58 & 114 & 65.9 \\
\hline Single/Divorced/Widowed & 476154 & 42 & 59 & 34.1 \\
\hline \multicolumn{5}{|l|}{ DEPLOYMENT } \\
\hline Deployed & 827600 & 73 & 142 & 82.1 \\
\hline Non-Combat & 306100 & 27 & 31 & 17.9 \\
\hline TOTAL & 1133699 & & 173 & \\
\hline$*$ of active duty component & & & & \\
\hline
\end{tabular}

http://www.rand.org/pubs/research_reports/RR145.html 
Table 8

Summary of Descriptive Findings for Independent Variables (Original \& Re-coded)

\begin{tabular}{|c|c|c|c|c|c|}
\hline $\begin{array}{c}\text { Variable } \\
\quad \#\end{array}$ & $\begin{array}{l}\text { Variable Name } \\
\text { (Original data level } \\
\text { of measurement) }\end{array}$ & $\begin{array}{c}\text { Original Response } \\
\text { Value }\end{array}$ & $\begin{array}{c}\text { \% reported by } \\
\text { sample }\end{array}$ & $\begin{array}{c}\text { Recoded Variable } \\
\text { Values }\end{array}$ & $\begin{array}{c}\% \\
\text { reported } \\
\text { by sample }\end{array}$ \\
\hline \multirow{3}{*}{1} & \multirow{3}{*}{ Rank (nominal) } & \multirow{3}{*}{ Open Response } & \multirow{3}{*}{$\begin{array}{l}\text { Too many } \\
\text { responses }\end{array}$} & 1 - Lower Enlisted & $12.2 \%$ \\
\hline & & & & 2 - Upper Enlisted & $83.8 \%$ \\
\hline & & & & 3 - Officers & $4.0 \%$ \\
\hline 2 & MOS (nominal) & Open Response & N/A & NOT USED & N/A \\
\hline \multirow{3}{*}{3} & \multirow{3}{*}{$\begin{array}{l}\text { Component } \\
\text { (nominal) }\end{array}$} & 1 - Active Duty & $41.6 \%$ & 1 - Active Duty & $41.6 \%$ \\
\hline & & 2 - National Guard & $27.7 \%$ & \multirow{2}{*}{2 - NG \& Reserves } & \multirow{2}{*}{$58.4 \%$} \\
\hline & & 3 - Reserves & $30.6 \%$ & & \\
\hline 4 & Age (ratio) & Open Response & $\begin{array}{c}\text { Mean } 35.2 \text { yrs. } \\
\text { old }\end{array}$ & Not Recoded & N/A \\
\hline \multirow{6}{*}{5} & \multirow{6}{*}{$\begin{array}{l}\text { Race/Ethnicity } \\
\text { (nominal) }\end{array}$} & 1 - Caucasian & $78.0 \%$ & \multirow{3}{*}{1 - Caucasian } & \multirow{3}{*}{$78.0 \%$} \\
\hline & & 2 - Black & $13.9 \%$ & & \\
\hline & & 3 - Hispanic & $5.2 \%$ & & \\
\hline & & 4 - Asian & $1.7 \%$ & \multirow{3}{*}{2 - Non-Caucasian } & \multirow{3}{*}{$22.0 \%$} \\
\hline & & 5 - Native American & $1.2 \%$ & & \\
\hline & & 6 - Other & N/A & & \\
\hline \multirow{5}{*}{6} & \multirow{5}{*}{$\begin{array}{l}\text { Marital Status } \\
\quad \text { (nominal) }\end{array}$} & 1 - Married/Partnered & $65.9 \%$ & \multirow{2}{*}{1 - Married/Partnered } & \multirow{2}{*}{$65.9 \%$} \\
\hline & & 2 - Single & $21.4 \%$ & & \\
\hline & & 3 - Separated & $0.6 \%$ & \multirow{3}{*}{$\begin{array}{l}2 \text { - Non- } \\
\text { Married/Partnered }\end{array}$} & \multirow{3}{*}{$34.1 \%$} \\
\hline & & 4 - Divorced & $11.6 \%$ & & \\
\hline & & 5 - Widowed & $0.6 \%$ & & \\
\hline \multirow{2}{*}{7} & \multirow{2}{*}{ Gender (nominal) } & 1 - Male & $88.4 \%$ & \multirow{2}{*}{ No Change } & \multirow{2}{*}{$\begin{array}{l}\text { No } \\
\text { Change }\end{array}$} \\
\hline & & 2 - Female & $11.6 \%$ & & \\
\hline 8 & $\begin{array}{l}\text { Service Entry Date } \\
\text { (ratio) }\end{array}$ & Open Response & N/A & NOT USED & N/A \\
\hline \multirow{6}{*}{9} & \multirow{6}{*}{$\begin{array}{c}\text { Number of } \\
\text { deployments (ratio) }\end{array}$} & 0 & $17.9 \%$ & \multirow{3}{*}{$0=$ no deployments } & \multirow{3}{*}{$17.9 \%$} \\
\hline & & 1 & $47.4 \%$ & & \\
\hline & & 2 & $19.7 \%$ & & \\
\hline & & 3 & $12.1 \%$ & & \\
\hline & & 4 & $2.3 \%$ & $1=$ one or more & $82.1 \%$ \\
\hline & & 5 & $0.6 \%$ & & \\
\hline & & 0 & $34.1 \%$ & & \\
\hline & & 1 & $22.0 \%$ & $0-$ no children & $341 \%$ \\
\hline & & 2 & $19.7 \%$ & $0=110$ cintuleti & $34.1 \%$ \\
\hline 10 & Number of Children & 3 & $15.0 \%$ & & \\
\hline & & 4 & $5.2 \%$ & & \\
\hline & & 5 & $1.7 \%$ & $1=$ one or more & $65.9 \%$ \\
\hline & & 6 or more & $2.3 \%$ & & \\
\hline
\end{tabular}


Several of the demographic variable factors were collapsed to gain a clearer profile of the respondent population for consideration. Most the respondents were Caucasian (78\%), male (88.4\%), upper enlisted (88.3\%), National Guard/Reserved (58.3\%), age (mean age 35.2), married/partnered (65.9\%), have children (65.9\%), and have been deployed at least once (82.1\%). A summary of the descriptive results for the Independent Variables as shown in Table 8 above.

\section{Dependent Variable Data Findings}

Bi-variate (Pearson), two tailed correlational analyses were performed to measure the strength and direction of linear relationships between the constructs in order to answer the posed research questions. The constructs identified for analysis include: PostTraumatic Stress Disorder (as measured by the PCL-M items); Moral Injury (as measured by the 4 sub-domains of DESNOS found during the content analysis to be thematically similar); and issues related to existential angst (as measured by moderate to low scores on the Existential Well-Being scale). The strength of the association between the variables is represented by $r$, correlation coefficient, value. The results will be presented in the order they were performed to answer the specific questions posed.

\section{How are the constructs, PTSD \& MI, and their sub-domains related within and across the domains?}

To answer these questions, the Pearson correlation coefficient was calculated for the PCL-M and Moral Injury constructs, total scores recoded to contain all cases which endorsed at least one factor as a positive endorsement. Based on the output of the analysis, a strong positive relationship was found $(r=.832, p<.001)$ indicating a significant linear relationship between the two variables and suggesting respondents who report having increased issues related to PTSD (as measured by the PCL-M), also report 
having increased issues with Moral Injury constructs (as measured by the DESNOS subdomains).

The four sub-domains that comprise the two parent constructs (PCL-M and MI) were then used to explore the relationships at the sub-domain level - see Table 9. These variables had also been recoded to include only those cases which endorsed at least one item of the domain. The four sub-domains of the PCL-M include Re-Experiencing which consisted of 5 items on the survey, Avoidance which consisted of 2 items, Numbing which consisted of 5 items, and Hyper-Arousal which consisted of 5 items (making up the total 17-item scale for the PCL-M). The four sub-domains associated with Moral Injury include Alterations in Regulation of Affect/Impulses which consisted of 4 items, Alterations in Relations with Others which consisted of only 1 item, Alterations in SelfPerception which consisted of 5 items, and Alterations in Meaning/Purpose which consisted of 5 items. Due to the sub-domain Alterations in Relations with Others only having one item, this analysis was omitted from the table.

Due to the multiple calculations required for this analysis, the Bonferroni calculation adjustment approach was conducted ad hoc to minimize the possibility of making a Type I error which would be accept a false positive based on a deflated significance level. Both sets of alpha levels will be reported for comparisons so as not to over-compensate and ultimately commit a Type II error (a false negative result) by not recognizing very subtle relationships which may be of interest from an exploratory standpoint. 
Table 9

\section{PCL-M and Moral Injury sub-domain correlation analysis}

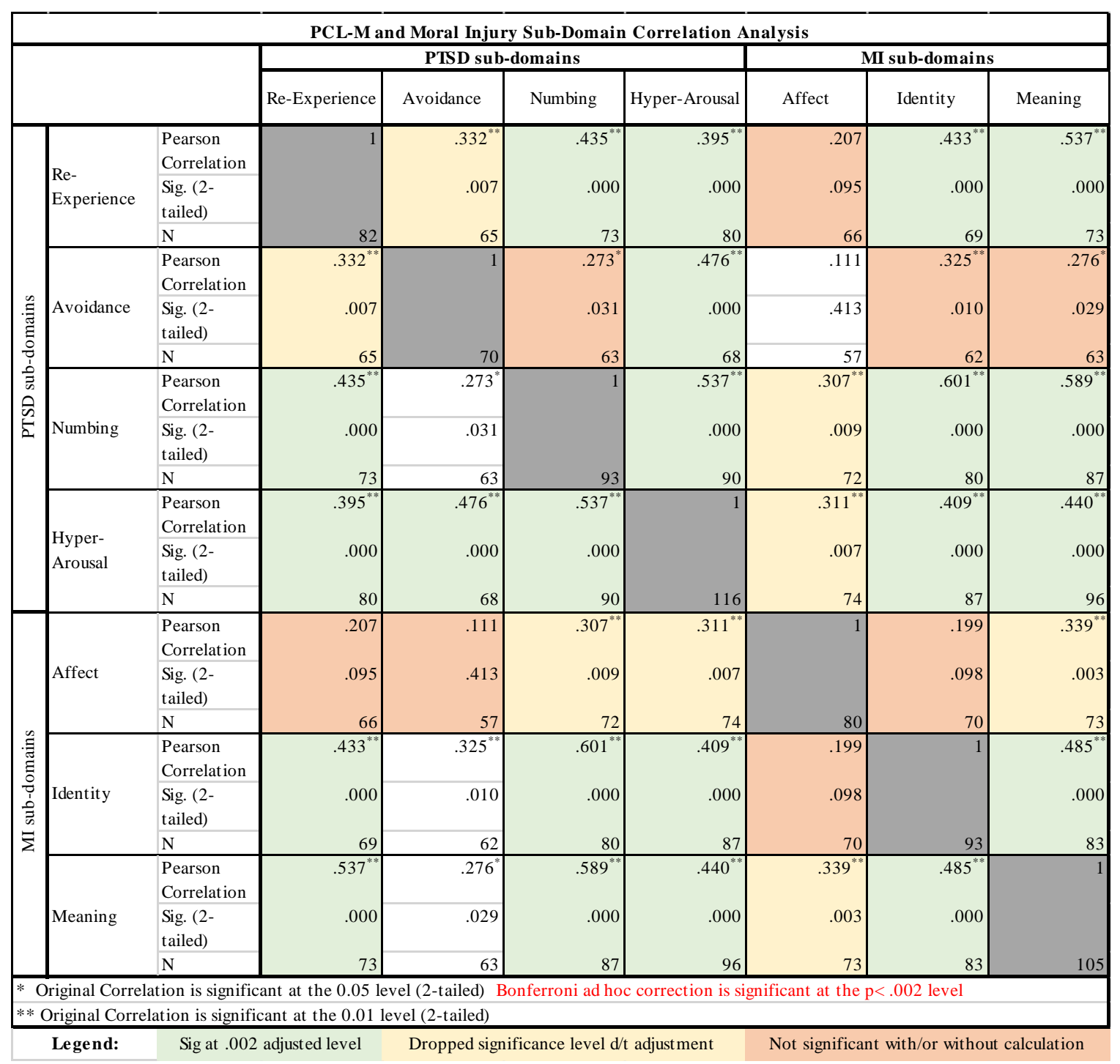

Based on the original output shown in Table 9 (prior to the ad hoc Bonferroni

calculation adjustment), there appears to be a range of statistically significant

relationships found between most of the sub-domain variables. The strongest positive

relationship was between the PCL-M sub-domain, Numbing, and the MI sub-domain

Alterations of Self-Perception (Identity) which was $r=.601, p<.001$ indicating a very

strong linear relationship between the two variables. This finding is consistent with the 
content analysis assumptions as shown in the comparison chart in Appendix A. Conversely, the weakest significant relationship was between the PCL-M sub-domain, Avoidance and the MI sub-domain Alterations of Meaning \& Purpose $(\mathrm{r}=.276, \mathrm{p}<.05)$. The sub-domain Numbing also had a moderate relationship with the MI sub-domain, Alterations in Meaning and Purpose $(r=.589, p<.001)$. In addition, a significant relationship was found between the two MI sub-domains, Alterations in Affect/Impulse and Alterations in Self-Perception/Identity $(r=.199, p<.001)$.

Several variable pairs were found not to have a significant relationship. The PCLM sub-domains Re-Experiencing and Avoidance were shown to lack statistical significance with the MI sub-domain, Alterations in Affect/Impulse ( $r=.207$ and .111 respectively). This analysis illustrates the complexity of relationships that exist between the constructs at the sub-domain level.

After applying the Bonferroni adjustment, due to the number of calculations conducted, the significance level was deflated to $\mathrm{p}<.002$. While the correlation coefficient was not affected showing the strength of relationships between several variables, the calculation adjustment did cause a number of cells to fail to meet the threshold for statistical significance. The following pairs were no longer considered significant Re-experience/Avoidance; Numbing/Affect; Hyper-Arousal/Affect; Identity/Meaning. For the purpose of this study, it would appear that using this adjustment could cause an overcompensation of reliance on significance leading to a potential Type II error overlooking a potential informative relationship. This calculation should be taken into consideration when interpreting results. 


\section{How well do the existing constructs, PTSD and Moral Injury, assess issues with Existential Well-Being?}

For this analysis, the total scores for the constructs, Existential Well-Being (recoded to contain only those cases which fell in the moderate to low category to indicate mild to moderate issues with EWB), and the PCL-M and Moral Injury scores (recoded variables containing only those cases which had at least one endorsed item) were used to measure the magnitude of the correlation between these parent variables.

\section{Table 10}

Correlation between EWB, PCL-M and MI Total Scores (Positive cases only)

\begin{tabular}{|c|c|c|c|c|}
\hline \multicolumn{5}{|c|}{ Relationship between Low Existential Well-Being, PTSD \& MI } \\
\hline & & $\begin{array}{c}\text { Low to Moderate } \\
\text { Existential Well-Being }\end{array}$ & PTSD & Moral Injury \\
\hline \multirow{3}{*}{$\begin{array}{l}\text { Low to Moderate } \\
\text { Existential Well- } \\
\text { Being }\end{array}$} & $\begin{array}{l}\text { Pearson } \\
\text { Correlation }\end{array}$ & 1 & $-.349^{* * *}$ & $-.384^{* *}$ \\
\hline & Sig. (2-tailed) & & .001 & .000 \\
\hline & $\mathrm{N}$ & 116 & 91 & 94 \\
\hline \multirow{3}{*}{ PTSD (PCL-M) } & $\begin{array}{l}\text { Pearson } \\
\text { Correlation }\end{array}$ & $-.349^{* *}$ & 1 & $.832^{* *}$ \\
\hline & Sig. (2-tailed) & .001 & & .000 \\
\hline & $\mathrm{N}$ & 91 & 119 & 110 \\
\hline \multirow{3}{*}{ Moral Injury } & $\begin{array}{l}\text { Pearson } \\
\text { Correlation }\end{array}$ & $-.384^{* *}$ & $.832^{* *}$ & 1 \\
\hline & Sig. (2-tailed) & .000 & .000 & \\
\hline & $\mathrm{N}$ & 94 & 110 & 121 \\
\hline
\end{tabular}

Table 10 indicates a very strong positive relationship between PTSD (PCL-M) and Moral Injury total scores $(r=.832, p<.001)$ as previously reported. There is a significant but only weak to moderate negative relationship between Existential WellBeing (recoded to consist of only those cases endorsing low to moderate Existential Well-Being $)$ and Moral Injury $(r=-.384, p<.001)$ or PTSD $(r=-.349, p<.001)$. This negative correlation indicates that the higher the respondents' reports of Existential Well- 
Being, the lower their reports of PTSD or Moral Injury. Conversely stated, when Existential Well-Being is low, the PTSD and Moral Injury scores are high. These findings support the posed hypothesis that expected these constructs to be related. This will be discussed further in the next chapter.

\section{To which Moral Injury sub-domain is low to moderate Existential Well-}

\section{Being more strongly related?}

For this analysis, the total score for EWB (recoded to include the low to moderate endorsement indicating a lack of perceived Existential Well-Being) and each of the four sub-domains of the construct Moral Injury (Alterations in Relationships; Alterations in Affect/Impulses; Alterations in Self-Perception; and Alterations in Meaning \& Purpose) were used to measure the magnitude of the correlation between the construct of EWB and the sub-domains (Table 11). As previously stated, the Moral Injury sub-domain Alterations in Relations with Others was removed due to inability to compute.

The output shown in Table 11 indicates a weak but statistically significant negative relationship between low Existential Well-Being and the Moral Injury subdomains Alterations in Meaning/Purpose $(r=-.231, p<.005)$ and Alterations in SelfPerception $(r=-.231, p<.005)$. There was no significant correlation between EWB and Alterations of Affect/Impulse $(r=-.086)$. These finding indicate that the Moral Injury subdomain Alterations in Meaning \& Purpose is more strongly related to low Existential Well-Being than the other MI sub-domains. 


\section{Table 11}

Correlation between EWB and MI sub-domains (Positive cases only)

\begin{tabular}{|c|c|c|c|c|c|}
\hline \multicolumn{6}{|c|}{ Relationship between Low Existential Well-Being and Moral Injury Sub-Domains } \\
\hline & & $\begin{array}{c}\text { Low } \\
\text { Existential } \\
\text { Well-Being }\end{array}$ & $\begin{array}{l}\text { Affect/ } \\
\text { Impulse }\end{array}$ & $\begin{array}{l}\text { Self-Perception } \\
\text { (Identity) }\end{array}$ & Meaning/ Purpose \\
\hline \multirow{3}{*}{$\begin{array}{l}\text { Low } \\
\text { Existential } \\
\text { Well-Being }\end{array}$} & $\begin{array}{l}\text { Pearson } \\
\text { Correlation }\end{array}$ & 1 & -.086 & $-.268^{*}$ & $-.231^{*}$ \\
\hline & $\begin{array}{l}\text { Sig. (2- } \\
\text { tailed) }\end{array}$ & & .477 & .018 & .033 \\
\hline & $\mathrm{N}$ & 116 & 70 & 77 & 86 \\
\hline \multirow[t]{3}{*}{$\begin{array}{l}\text { Affect// } \\
\text { Impulse }\end{array}$} & $\begin{array}{l}\text { Pearson } \\
\text { Correlation }\end{array}$ & -.086 & 1 & .199 & $.339^{* *}$ \\
\hline & $\begin{array}{l}\text { Sig. (2- } \\
\text { tailed) }\end{array}$ & .477 & & .098 & .003 \\
\hline & $\mathrm{N}$ & 70 & 80 & 70 & 73 \\
\hline \multirow{3}{*}{$\begin{array}{l}\text { Self- } \\
\text { Perception } \\
\text { (Identity) }\end{array}$} & $\begin{array}{l}\text { Pearson } \\
\text { Correlation }\end{array}$ & $-.268^{*}$ & .199 & 1 & $.485^{* *}$ \\
\hline & $\begin{array}{l}\text { Sig. (2- } \\
\text { tailed) }\end{array}$ & .018 & .098 & & .000 \\
\hline & $\mathrm{N}$ & 77 & 70 & 93 & 83 \\
\hline \multirow[t]{3}{*}{$\begin{array}{l}\text { Meaning/ } \\
\text { Purpose }\end{array}$} & $\begin{array}{l}\text { Pearson } \\
\text { Correlation }\end{array}$ & $-.231^{*}$ & $.339^{* *}$ & $.485^{* *}$ & 1 \\
\hline & $\begin{array}{l}\text { Sig. (2- } \\
\text { tailed) }\end{array}$ & .033 & .003 & .000 & \\
\hline & $\mathrm{N}$ & 86 & 73 & 83 & 105 \\
\hline
\end{tabular}

To explore these relationships further, a series of analyses were performed to determine the strength of the relationship between the two significant findings above independent of the other variables. First, low Existential Well-Being, Alterations in SelfPerception and Non-Self-Perception (the other 3 Moral Injury sub-domains) were used to determine the extent of the relationship between the constructs (Table 12). Next, low Existential Well-Being, Alterations in Meaning/Purpose and Non-Meaning/Purpose (the other 3 Moral Injury sub-domains) were used to determine the extent of the relationship between those constructs (Table 12). 


\section{Table 12}

Correlation between EWB, Alterations in Self-Perception (Identity) and Non-SelfPerception (Identity)

\begin{tabular}{|c|c|c|c|c|}
\hline \multicolumn{5}{|c|}{ Existential Well-Being and (MI) Self-Perception/Non-Self-Perception } \\
\hline & & $\begin{array}{l}\text { Low Existential } \\
\text { Well-Being }\end{array}$ & $\begin{array}{l}\text { Self-Perception } \\
\text { (Identity) }\end{array}$ & $\begin{array}{l}\text { Non-Self- } \\
\text { Perception } \\
\text { (Identity) } \\
\end{array}$ \\
\hline \multirow[t]{3}{*}{$\begin{array}{l}\text { Low Existential Well- } \\
\text { Being }\end{array}$} & $\begin{array}{l}\text { Pearson } \\
\text { Correlation }\end{array}$ & 1 & $-.268^{*}$ & -.074 \\
\hline & Sig. (2-tailed) & & .018 & .600 \\
\hline & $\mathrm{N}$ & 116 & 77 & 53 \\
\hline \multirow[t]{3}{*}{ Self-Perception (Identity) } & $\begin{array}{l}\text { Pearson } \\
\text { Correlation }\end{array}$ & $-.268^{*}$ & 1 & $.412^{* *}$ \\
\hline & Sig. (2-tailed) & .018 & & .002 \\
\hline & $\mathrm{N}$ & 77 & 93 & 55 \\
\hline \multirow[t]{3}{*}{$\begin{array}{l}\text { Non-Self-Perception } \\
\text { (Identity) }\end{array}$} & $\begin{array}{l}\text { Pearson } \\
\text { Correlation }\end{array}$ & -.074 & $.412^{* *}$ & 1 \\
\hline & Sig. (2-tailed) & .600 & .002 & \\
\hline & $\mathrm{N}$ & 53 & 55 & 57 \\
\hline \multicolumn{4}{|c|}{ * Correlation is significant at the 0.05 level (2-tailed) } & \\
\hline
\end{tabular}

Table 12 indicates that there is a much stronger and statistically significant negative relationship between low Existential Well-Being and the Moral Injury subdomain Alterations in Self-Perception (Identity) than with the other sub-domains combined. This suggests that the relationship, while somewhat weak at $r=-.268$ is still significant at $p<.005$. The relationship between EWB and non-self-perception/identity is not significant $(r=-0.74)$.

Table 13 indicates that there is a much stronger and statistically significant negative relationship between low Existential Well-Being and the Moral Injury subdomain Alterations in Meaning/Purpose than with the other sub-domains combined (nonmeaning/purpose). This suggests that the relationship, while somewhat weak at $r=-.231$ 
is still significant at $p<.005$. The relationship between EWB and non-meaning/purpose is not significant $(r=-.130)$.

\section{Table 13}

Correlation between Existential Well-Being, Moral Injury sub-domain Alterations in Meaning/Purpose, and MI Non-Meaning/Purpose domains

\begin{tabular}{|c|c|c|c|c|}
\hline \multicolumn{5}{|c|}{ Existential Well-Being and (MI) Meaning/Purpose/Non-Meaning/Purpose } \\
\hline & & $\begin{array}{l}\text { Low Existential } \\
\text { Well-Being }\end{array}$ & Meaning/ Purpose & $\begin{array}{l}\text { Non-Meaning/ } \\
\text { Purpose }\end{array}$ \\
\hline \multirow{3}{*}{$\begin{array}{l}\text { Low Existential Well- } \\
\text { Being }\end{array}$} & Pearson Correlation & 1 & $-.231^{*}$ & -.130 \\
\hline & Sig. (2-tailed) & & .033 & .357 \\
\hline & $\mathrm{N}$ & 116 & 86 & 52 \\
\hline \multirow[t]{3}{*}{ Meaning/ Purpose } & Pearson Correlation & $-.231^{*}$ & 1 & $.474^{* *}$ \\
\hline & Sig. (2-tailed) & .033 & & .000 \\
\hline & $\mathrm{N}$ & 86 & 105 & 55 \\
\hline \multirow{3}{*}{$\begin{array}{l}\text { Non-Meaning/ } \\
\text { Purpose }\end{array}$} & Pearson Correlation & -.130 & $.474^{* *}$ & 1 \\
\hline & Sig. (2-tailed) & .357 & .000 & \\
\hline & $\mathrm{N}$ & 52 & 55 & 55 \\
\hline \multicolumn{5}{|c|}{ * Correlation is significant at the 0.05 level (2-tailed) } \\
\hline$* *$ Correlation is signifi & ant at the 0.01 level (2 & & & \\
\hline
\end{tabular}

\section{To which PTSD sub-domain is low to moderate Existential Well-Being more closely related?}

To answer this research question, the total score for EWB (recoded to include the low to moderate endorsement indicating a lack of perceived Existential Well-Being) and the recoded variables for each of the four sub-domains of the construct PTSD (Reexperiencing; Avoidance; Numbing; and Hyper-Arousal) were used to measure the magnitude of the correlation. Then, each of the sub-domain variables were measured independently of the others to explore which sub-domains were more strongly correlated with the construct of EWB. 


\section{Table 14}

Correlation between EWB and PCL-M sub-domains (Positive cases only)

\begin{tabular}{|c|c|c|c|c|c|c|}
\hline \multicolumn{7}{|c|}{ Existential Well-Being and PTSD Sub-Domains } \\
\hline & & $\begin{array}{l}\text { Low Existential } \\
\text { Well-Being }\end{array}$ & Re-Experiencing & Avoidance & Numbing & Hyper-Arousal \\
\hline \multirow[t]{3}{*}{$\begin{array}{l}\text { Low Existential } \\
\text { Well-Being }\end{array}$} & $\begin{array}{l}\text { Pearson } \\
\text { Correlation }\end{array}$ & 1 & -.090 & -.069 & $-.450^{* *}$ & $-.320^{* *}$ \\
\hline & Sig. (2-tailed) & & .460 & .598 & .000 & .002 \\
\hline & $\mathrm{N}$ & 116 & 69 & 61 & 76 & 88 \\
\hline \multirow[t]{3}{*}{ Re-Experiencing } & $\begin{array}{l}\text { Pearson } \\
\text { Correlation }\end{array}$ & -.090 & 1 & $.332^{* *}$ & $.435^{* *}$ & $.395^{* *}$ \\
\hline & Sig. (2-tailed) & .460 & & .007 & .000 & .000 \\
\hline & $\mathrm{N}$ & 69 & 82 & 65 & 73 & 80 \\
\hline \multirow[t]{3}{*}{ Avoidance } & $\begin{array}{l}\text { Pearson } \\
\text { Correlation }\end{array}$ & -.069 & $.332^{* *}$ & 1 & $.273^{*}$ & $.476^{* *}$ \\
\hline & Sig. (2-tailed) & .598 & .007 & & .031 & .000 \\
\hline & $\mathrm{N}$ & 61 & 65 & 70 & 63 & 68 \\
\hline \multirow[t]{3}{*}{ Numbing } & $\begin{array}{l}\text { Pearson } \\
\text { Correlation }\end{array}$ & $-.450^{* *}$ & $.435^{* *}$ & $.273^{*}$ & 1 & $.537^{* *}$ \\
\hline & Sig. (2-tailed) & .000 & .000 & .031 & & .000 \\
\hline & $\mathrm{N}$ & 76 & 73 & 63 & 93 & 90 \\
\hline \multirow[t]{3}{*}{ Hyper-Arousal } & $\begin{array}{l}\text { Pearson } \\
\text { Correlation }\end{array}$ & $-.320^{* *}$ & $.395^{* *}$ & $.476^{* *}$ & $.537^{* *}$ & 1 \\
\hline & Sig. (2-tailed) & .002 & .000 & .000 & .000 & \\
\hline & $\mathrm{N}$ & 88 & 80 & 68 & 90 & 116 \\
\hline
\end{tabular}

Table 14 indicates a moderate and statistically significant negative relationship between low Existential Well-Being and the PTSD sub-domains Numbing $(r=-.450, p<$ .001) and less moderate, yet still statistically significant sub-domain Hyper-Arousal ( $r=-$ $.320, p<.005)$. There was no significant correlation between EWB and PCL-M Avoidance $(r=-.069)$ or Re-experiencing $(r=-.090)$. These findings indicate that PCLM sub-domain Numbing and Hyper-Arousal are significantly related to the concept of low Existential Well-Being.

To explore these relationships further, a series of analyses were performed to determine the strength of the relationship between the two significant findings above 
independent of the other variables. First, low Existential Well-Being, Numbing and Non-Numbing (the other 3 PCL-M sub-domains) were used to determine extent of the relationship between the constructs (Table 15). Next, low Existential Well-Being, HyperArousal and Non-Hyper-Arousal (the other 3 remaining PCL-M sub-domains) were used to determine extent of the relationship between those constructs (Table 16).

\section{Table 15}

Correlation between EWB, PCL-M sub-domain Numbing and Non-Numbing Domains

\begin{tabular}{|c|c|c|c|c|}
\hline \multicolumn{5}{|c|}{ Existential Well-Being and Numbing/Non-Numbing } \\
\hline & & $\begin{array}{l}\text { Low Existential } \\
\text { Well-Being }\end{array}$ & Numbing & Non-Numbing \\
\hline \multirow{3}{*}{$\begin{array}{l}\text { Low Existential } \\
\text { Well-Being }\end{array}$} & Pearson Correlation & 1 & $-.450^{* *}$ & -.106 \\
\hline & Sig. (2-tailed) & & .000 & .446 \\
\hline & $\mathrm{N}$ & 116 & 76 & 54 \\
\hline \multirow[t]{3}{*}{ Numbing } & Pearson Correlation & $-.450^{* *}$ & 1 & $.560^{* *}$ \\
\hline & Sig. (2-tailed) & .000 & & .000 \\
\hline & $\mathrm{N}$ & 76 & 93 & 57 \\
\hline \multirow[t]{3}{*}{ Non-Numbing } & Pearson Correlation & -.106 & $.560^{* *}$ & 1 \\
\hline & Sig. (2-tailed) & .446 & .000 & \\
\hline & $\mathrm{N}$ & 54 & 57 & 63 \\
\hline
\end{tabular}

Table 15 indicates that there is a much stronger and statistically significant negative relationship between low Existential Well-Being and the PCL-M sub-domain Numbing than with the other sub-domains combined (Non-Numbing). This suggests that the moderately strong relationship $(r=-.450, p<.001)$ and that the relationship between EWB and Non-Numbing (remaining combined domains) is not significant $(r=-.106)$.

Table 16 indicates that there is a statistically significant negative relationship between low Existential Well-Being and the PCL-M sub-domain Hyper-Arousal than with the other sub-domains combined (Non-Hyper-Arousal). This suggests a weak to 
moderate relationship $(r=-.320, p<.001)$ and that the relationship between EWB and Non-Hyper-Arousal (remaining combined domains) is not significant $(r=-.159)$.

\section{Table 16}

Correlation between EWB, PCL-M sub-domain Hyper-Arousal and Non-Hyper-Arousal

\begin{tabular}{|c|c|c|c|c|}
\hline \multicolumn{5}{|c|}{ Existential Well-Being and Hyper-Arousal/Non-Hyper-Arousal } \\
\hline & & $\begin{array}{l}\text { Low Existential } \\
\text { Well-Being }\end{array}$ & $\begin{array}{l}\text { Hyper- } \\
\text { Arousal }\end{array}$ & $\begin{array}{l}\text { Non-Hyper- } \\
\text { Arousal }\end{array}$ \\
\hline \multirow{3}{*}{$\begin{array}{l}\text { Low Existential } \\
\text { Well-Being }\end{array}$} & $\begin{array}{l}\text { Pearson } \\
\text { Correlation }\end{array}$ & 1 & $-.320^{* *}$ & -.158 \\
\hline & Sig. (2-tailed) & & .002 & .264 \\
\hline & $\mathrm{N}$ & 116 & 88 & 52 \\
\hline \multirow{3}{*}{ Hyper-Arousal } & $\begin{array}{l}\text { Pearson } \\
\text { Correlation }\end{array}$ & $-.320^{* *}$ & 1 & $.444^{* *}$ \\
\hline & Sig. (2-tailed) & .002 & & .001 \\
\hline & $\mathrm{N}$ & 88 & 116 & 57 \\
\hline \multirow{3}{*}{$\begin{array}{l}\text { Non-Hyper- } \\
\text { Arousal }\end{array}$} & $\begin{array}{l}\text { Pearson } \\
\text { Correlation }\end{array}$ & -.158 & $.444^{* *}$ & 1 \\
\hline & Sig. (2-tailed) & .264 & .001 & \\
\hline & $\mathrm{N}$ & 52 & 57 & 59 \\
\hline
\end{tabular}

\section{Summary of Results}

The purpose of this chapter was to present the findings gleaned from the descriptive and correlational analyses performed to answer the research questions and test the stated hypotheses. Specifically, the goal of this study was to explore the relationships between the constructs of Existential Well-Being, Post-Traumatic Stress Disorder, and Moral Injury as well as their sub-domains. These findings will be discussed in the following chapter. 


\section{CHAPTER V \\ DISCUSSION}

As is often the case in social work research, this study began with an observation from clinical practice recognizing a pattern of concerning behavior and reports from the population of military personnel returning from war. Along with the reports of symptoms consistent with the diagnosis of Post-Traumatic Stress Disorder (PTSD), including reexperiencing, avoiding, numbing and hyper-arousal related to having experienced a traumatic event, there was also something else that didn't quite seem to fit the prevailing diagnostic classification. In addition to, and sometimes independent of, the PTSD symptoms, many Servicemembers also reported struggling with a disturbing and overwhelming sense that they had been deeply and profoundly changed at the core of their being. Turning to the literature, we find that this phenomenon is not new; it has been voiced by returning warriors for centuries. Yet, despite the prevalence of these reports, little empirical attention has been paid to this issue in research or clinical literature, apart from a collective assumption that it was related to trauma and encompassed in the PTSD diagnostic structure.

Early in the preliminary exploration leading to this study, during a clinical interview, a soldier explained, "War is 99\% mind-numbing boredom interrupted only occasionally by moments of sheer chaos," (J.Q. personal correspondence). Traditionally, research has focused predominately on the extraordinary experiences of the traumatic 
events of war, or the moments of "sheer chaos." But, what of the other $99 \%$ of the time a Servicemember is deployed to a war-zone? Is it possible that prolonged exposure to this extraordinary extreme stress could be as injurious as the traumatic events? Could this be a factor in reports of deeply profound personal change reported by these Servicemembers? Could the stress of coping with the on-going duress of deployment, including ethical dilemmas that challenged their beliefs or values, be the catalyst for the pervasive existential crisis seen following deployment? While the diagnosis of PTSD has proven to be a useful and comprehensive model for identifying and measuring the effects of traumatic events, its ability to identify and address the subtler nuances of change to the core self was questioned.

This study, inspired by the observations and discussions described above, was also fueled by a sincere concern about our returning Servicemembers. The rates of military suicides, and other significant risk factors for Veterans, their families and our communities, continue to rise in spite of decades of research and the implementation of various evidence-based treatment programs. The historical review contained herein illustrated that a common thread across the eras remains unbroken; war has the capacity to injure, change, and/or transform an individual in profound ways, despite the ebb and flow of research, terminology, and criteria over time. Engaging in a comprehensive review of empirical literature on war-related psychological disorders revealed multiple relevant, although often overlooked, theoretical models from which to better understand this phenomenon.

In recent years, the term Moral Injury has emerged as a promising construct to identify and describe this phenomenon of deep personal change, from both an etiological 
and phenomenological perspective. Regarding the etiological perspective, Dr. Brett Litz has developed a working definition from which to launch discussion about this proposed collection of symptoms, and to offer a theory about how this phenomenon might be caused by experiencing events that transgress deeply held moral values and beliefs. With this model, Litz focuses on the specific experiences of committing, or failing to prevent, war atrocities. The Moral Injury Experiences Scale (MIES, 2013) developed by Nash, et. al. measures experiences which are thought to precipitate Moral Injury. The symptoms or indicators of an individual actually having Moral Injury, are much less understood or well defined. The available literature cites an array of indicators (now being referred to as the Moral Injury Syndrome (Frankfurt \& Frasier, 2016), but these have yet to be validated, nor has an instrument been created to assess the presence or degree of Moral Injury in an individual. This certainly poses a problem for research and is a recommendation that has been posed by previous researchers (Litz, 2006; Frankfurt, 2016). Given that this common complaint of feeling changed at the moral core is emerging as prevalent and potentially as damaging as PTSD, and evidence suggesting that this array of symptoms could point to a separate, yet highly correlated condition (Ford, 1999), this study set out examine the relationships between the constructs of PTSD, Moral Injury and Existential Well-Being.

\section{Discussion of Population and Descriptive Analysis}

As presented in Chapter IV, the population of the $\mathrm{N}-173$ respondents in this study were predominately Caucasian (78\%), male (88.4\%), upper enlisted (88.3\%), National Guard/Reserved (58.3\%), age (mean age 35.2), married/partnered (65.9\%), have children $(65.9 \%)$, and have been deployed at least once (82.1\%). However, even in this small 
sample, the range of demographics across variables was broad and indicative of the population at large as described in Chapter IV, Table 7. Although this description is noted, the demographic make-up is not relevant to the current research posed, but may offer opportunities to further explore this data set in the future.

\section{Discussion of Results of Analysis related to each Research Question}

\section{How are the constructs, PTSD \& MI, and their sub-domains related within and across the domains?}

Based on an examination of the items associated with each of the constructs in question (PTSD, MI, and EWB), as well as results of the content analysis presented in Chapter II, it was expected that Moral Injury, a construct extrapolated from the Disorders of Extreme Stress Not Otherwise Specified diagnostic classification structure, would be strongly correlated with PTSD but would more effectively in assess reported changes in self-perception and/or personal sense of meaning or purpose than the PTSD items.

To test this hypothesis, the total scores for the recoded scale variables for the PCL-M and Moral Injury, as well as the scores for each of their sub-domain scales were analyzed to determine the strength of the correlations between the parent variables (PTSD and Moral Injury), as well as the associations between each of their sub-domain variables. The initial hypothesis was confirmed as this analysis revealed a strong positive relationship $(r=.832, p<.001)$ between the two parent constructs, answering the first question by illustrating degree to which the constructs of PTSD, and Moral Injury are related in the population surveyed. The results indicate that respondents who endorse PTSD symptoms also endorse symptoms related to Moral Injury; and that this is a linear relationship, meaning that the more PTSD symptoms endorsed, the more Moral Injury indicators will also be endorsed. The finding these two parent constructs to be strongly 
correlated was not surprising as it was consistent with the content analysis and previous research. For example, citing the study conducted by Ford (1999) which indicated that PTSD and DESNOS (the theoretical basis for the proposed construct of Moral Injury used for this study) are highly correlated and co-occurring in $31 \%$ of the study's sample. Yet they also found that, rather than measuring the same construct as might be assumed, these two constructs were found to occur independently from one another in $30 \%$ of the cases.

Since these constructs are comprised of a variety of sub-domains, this study dove deeper into the make-up of the constructs to explore this relationship further, at the subdomain level. Each of the two parent constructs (PCL-M and MI) were comprised of four sub-domains. These include Re-Experiencing, Avoidance, Numbing, and Hyper-Arousal that make up the PCL-M Scale and Alterations in Regulation of Affect/Impulses, Alterations in Relations with Others, Alterations in Self-Perception, and Alterations in Meaning/Purpose, which make up the proposed Moral Injury Scale. However, in preliminary analysis, the MI sub-domain, Alterations in Relations with Others, did not possess enough power to be computed (having one corresponding item) and so was omitted from the model; this left three sub-domains associated with Moral Injury syndrome.

Among these variables, several statistically significant relationships were found. The strongest positive relationship between these 7 variables was between the Numbing $(P C L-M)$, and Alterations of Self-Perception/Identity (MI) which was $r=.601, p<.001$. This finding is consistent with the content analysis assumptions as shown in the PTSD, DESNOS \& MI comparison chart in Appendix A. The Numbing sub-domain (PCL-M) 
consists of five items that assess for the following symptoms: 1) Trouble remembering important parts of a stressful military experience, 2) Loss of interest in activities that you used to enjoy, 3) Feeling distant or cut off from others, 4) Feeling emotionally numb or being unable to have loving feelings for those close to you, and 5) Feeling as if your future somehow will be cut short. The Alterations in Self-Perception items include: 1) Feeling as if no one can understand, 2) Diminished feeling of personal effectiveness, 3) Minimizing, 4) Feeling responsible for things that happened, and 5) Feelings of shame and doubt. At a glance, these items appear to be related themes internalizing a disconnection from one's feelings and from others, potentially precipitated by guilt or shame. While these items are similar, they also have a slightly different tone or focus that could be explored at the item level through subsequent analysis and could explain how the constructs differ. This will be discussed further in the implications for further research section.

The sub-domain Numbing (PCL-M) also has a moderate relationship with Alterations in Meaning and Purpose (MI) with a Pearson correlations of $r=.589, p<$ .001. The questions associated with Alterations in Meaning and Purpose (MI) include: 1) Feeling that I am not the same person that I used to be, 2) Feelings of being permanently damaged, 3) Increased awareness of my own mortality, 4) Feeling that my values and beliefs have changed, and 5) Feelings of despair and hopelessness. Consistent with the item comparison table created during the content analysis (Appendix A), it appears that this is conceptually more closely related to the PTSD sub-domain, Numbing than the other PTSD domains combined. 
In addition, Alterations in Affect/Impulse (MI) was also shown to correlate with the PTSD domain, Numbing $(r=.307)$ and with Hyper-Arousal $(r=.311)$, but these were not as strong of a relationship as was expected. The Moral Injury sub-domain, Alterations in Relationships with Others, only contained one item and therefore did not have enough statistical power to calculate a correlation. It is possible that it may find a better fit with one of the other variable such as Alteration in Affect/Impulse. Further research could determine this fit through factor analysis.

The weakest, yet still significant, relationship was between Avoidance (PCL-M) and Alterations of Meaning \& Purpose (MI) with a correlation of $\mathrm{r}=.276, \mathrm{p}<.05$. The sub-domain, Avoidance (PCL-M) contains only two survey items in the scale which are: 1) thinking about or talking about a stressful event, and 2) avoiding activities or situations which remind you of the stressful event. As described above, the questions related to the Moral Injury domain deal with significant changes in the self and do not assess specifically for avoidant behavior. However, one might wonder if someone who was dealing with such deep, profound changes in the self, leading to despair and hopelessness might endorse being avoidant of those feelings stemming more from their responses to the stressful event than the event itself.

Several variable pairs were found not to have a significant relationship. The PCLM sub-domains Re-Experiencing and Avoidance were shown to lack statistical significance with the MI sub-domain, Alterations in Affect/Impulse $(r=.207$ and .111 respectively) indicating that there are areas in which the two constructs diverge thematically. 


\section{Figure 5}

Illustration of the relationships between PTSD and Moral Injury Sub-domains

\section{CORRELATIONS BETWEEN PTSD (DSM-IV) \& MORAL INJURY SUB-DOMAINS}

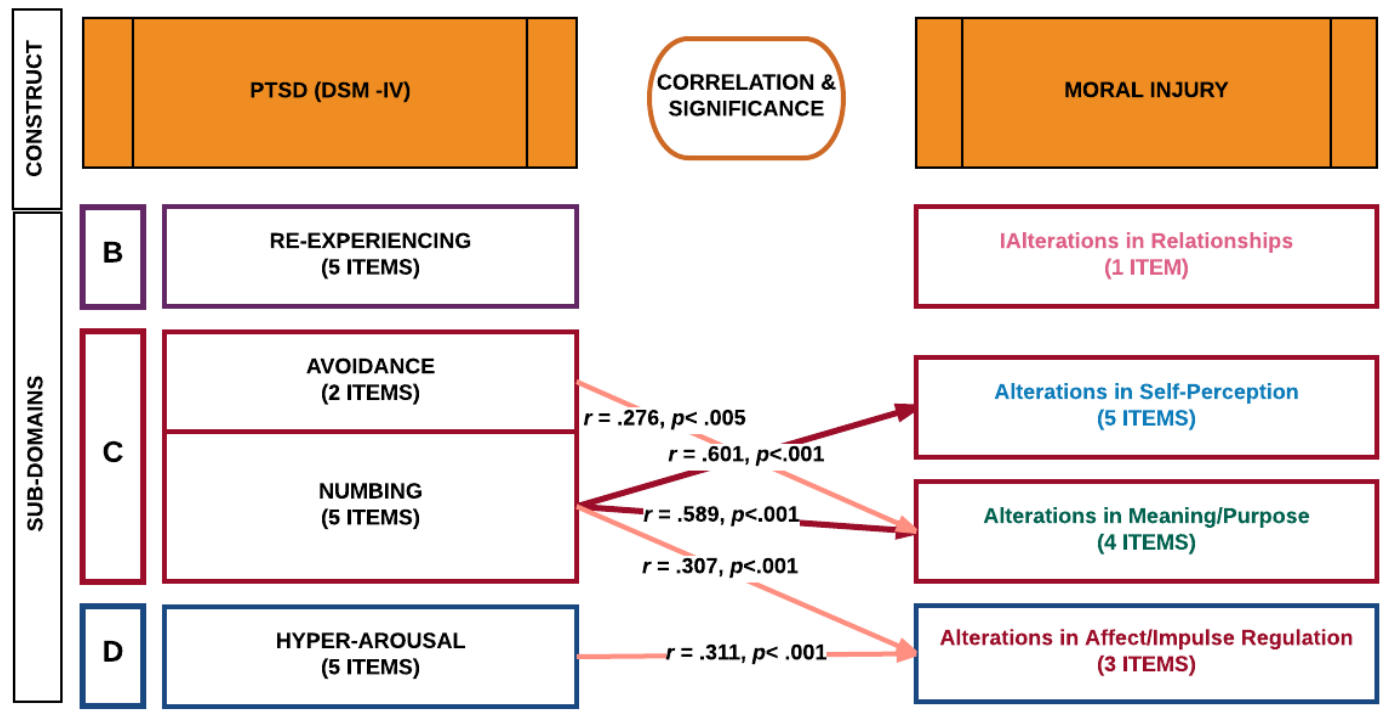

This analysis effectively answers the initial research question by illustrating the complexity of relationships that exist between the constructs, not only at the parent construct level but even more so at the sub-domain level. There are clear, strong, positive correlations between specific domains, as well as differences that support the need for further inquiry to better understand the differences.

\section{How well do the constructs, PTSD and Moral Injury, assess issues with Existential Well-Being?}

At first glance at the sub-domains of Moral Injury, it would appear to assess key components of Existential Well-Being, such as changes in self/identity and loss of meaning or life purpose. One would expect to find that Moral Injury would have a strong negative correlation with the concept of Existential Well-Being, and that this relationship would be stronger than the correlation between PTSD and EWB which was expected to be small or negligible. 
The results were partially consistent with the hypothesis above. Existential WellBeing does show a significant negative correlation with Moral Injury $(r=-.384, p<$ .001). Yet, contrary to the hypothesis, it also shows a nearly as strong negative relationship with PTSD as well $(r=-.349, p<.001)$. As previously reported, the relationship between PTSD and Moral Injury is so strong $(r=.832, p<.001)$ that differentiating these with the third related construct, EWB, is inconclusive with regard to the interpretation of the comparison of correlations with both PTSD and Moral Injury

However, relevant to this study is the indication that higher reports of Existential Well-Being (indicating a healthy self-concept, connection to meaning and purpose, and place in the world) correlate with lower reports of PTSD or Moral Injury. Conversely stated, when Existential Well-Being is low, the PTSD and Moral Injury scores are high. These findings support the posed hypothesis that expected these constructs to be related.

\section{To which Moral Injury sub-domain is low to moderate Existential Well- Being more closely related?}

Delving a little deeper into the relationship between EWB and Moral Injury, one wonders if a specific domain associated with the proposed Moral Injury Scale correlates more strongly with the concept of Existential Well-Being than the others. One would expect to find the relationship to be strongest between low Existential Well-Being high scores on the Alterations in Meaning and Purpose sub-scale than with the remaining items. Also, one would expect to find that EWB would correlate moderately with the items related to Alterations in Self Perception.

Consistent with this hypothesis, the results of the analysis indicated that Existential Well-Being was negatively correlated with both Alterations in Meaning/Purpose and Alterations in Self-Perception at a nearly identical strength $(\mathrm{r}=$ - 
.231 and $r=-.268$ respectively). There was no significant correlation with the domain, Alterations of Affect/Impulse. The two primary domains found to be related to Existential Well-Being were then analyzed to determine if either was more strongly related to EWB than the remaining variables in the scale. It was found that both Moral Injury constructs are significantly correlated with EWB and that the combination of remaining variable is not.

\section{To which PTSD sub-domain is low to moderate Existential Well-Being more closely related?}

The next step was to determine if a specific domain associated with the PTSD correlates more strongly with the concept of Existential Well-Being. The results of the analysis indicated that Existential Well-Being was negatively correlated with both Numbing $(r=-.450)$ and Hyper-arousal $(r=-.320)$ and that both correlations were significate at $\mathrm{p}<.001$. However, there was no significant correlation between EWB and PCL-M Avoidance ( $r=-.069)$ or Re-experiencing $(r=-.090)$. These findings illustrate that PTSD sub-domain Numbing and Hyper-Arousal are significantly related to the concept of low Existential Well-Being.

These two variables were then analyzed to determine the strength of their association to EWB if analyzed independently from the remaining variables in the PTSD scale. This revealed that the (negative) relationship between low Existential Well-Being and the PCL-M sub-domain Numbing was stronger $(r=-.450, p<.001)$ than the relationship with the other remaining sub-domains combined (Non-Numbing) which was not significant $(r=-.106)$.

Regarding the variable, Hyper-Arousal, analysis indicates that there is a statistically significant negative relationship $(r=-.320, p<.001)$ between this variable 
and Existential Well-Being and that the relationship between EWB and the other subdomains combined (Non-Hyper-Arousal) is not significant $(r=-.159)$.

\section{Limitations of this study}

This study was largely exploratory and had to overcome significant challenges to both internal and external validity due to the availability of a suitable data set and number of respondents. Since the concept of Moral Injury is only recently emerging, and has yet to be formally tested and validated, working with the theoretical construct defined by proposed indicators limits the extent of the analysis which could be accomplished. In addition, the lack of accepted operational definitions and small number of respondents also limits the interpretation of results and generalizability. Since there is no empirical basis for this construct, it was extrapolated from the literature review and found to be closely related and contained within he previously postulated construct, Disorders of Extreme Stress Not Otherwise Specified.

There is a significant lack of empirical foundation for bridging the concepts of Existential Well-Being and Moral Injury and a "causal" relationship could not be assessed. In addition, the concepts of existentialism and spirituality are difficult to operationally define and obtaining mainstream validated instruments is difficult. Further study is needed to explore the relationships of these concepts further. Endorsement of Existential Concern based on an interpretation of the suggested cut-off scores for the Existential Well-Being Scale posed an issue with validating Existential issues in relation to the research questions posed.

During the course of the investigation, the DSM-5 (2013) was published, significantly modifying the diagnostic structure of the concept of PTSD and appearing to incorporate more of the indicators associated with the domains of Alterations of 
Meaning/Purpose and Alternations of Self-Perception. However, the assessment instruments such as the PCL-M have not been updated to reflect these changes therefore, data based on this new assessment structure are not readily available. It remains to be seen how these changes may affect the relationship of PTSD diagnostic classification to the concepts posed in this study such as Existential Well-Being.

\section{Implications for Research, Practice, and Policy}

\section{Research.}

As described in Chapter I, the incidence and prevalence psycho-social risk factors for our returning Servicemembers and Veterans is staggering and has the potential for having a tremendous negative impact on our society for decades to come. The historical review of war trauma and the development of the diagnosis, Posttraumatic Stress Disorder, the response of the field to recommend treatment based on prevailing theory, and the continued suffering of our Veterans, are strong indicators that we have yet to fully understand the impact of the war experience on those who have served. It is imperative that we continue to conduct research that broadens to scope of our understanding of this phenomenon and that we do not allow the existing PTSD criteria to continue to limit our exploration of the bio-psycho-social-spiritual changes that occur as a result of war experiences. Additional research is needed to bring together holistic approaches and to validate additional research tools specific to this population. Screening tools need to be developed to help identify those who are suffering from the symptoms associated with Moral Injury syndrome and develop more effective intervention and treatment modalities to specifically address these issues. DSM-5 has attempted to rectify and broaden the 
scope of diagnosis. It remains to be seen if this will prove to be a more comprehensive and inclusive diagnostic structure to provide a basis for further analysis.

\section{Practice.}

By reintegrating the spiritual domain into the realm of the whole being and truly offering a holistic model of care, we open many new doors to therapeutic interventions that were once just out of our reach. These new, as well as time-honored modalities, can serve to guide our brave warriors to construct new meaning in their suffering, and a new purpose in their lives. By addressing these questions, giving this phenomenon a name and a language of its own, and giving our clients and providers the opportunity to talk about the pervasive changes that occur deep within the individual, we can see the transformative potential available to them leading to significant healing and personal development or Post Traumatic Growth (PT-G).

\section{Policy.}

Research needs to inform policy. Practice guidelines must be put in place that allow clinicians to more competently screen for, and address, issues related to Moral Injury Syndrome. It is imperative that DoD and VA policies reflect and support the trends toward more holistic approaches. Moving away from the practice of pathologizing the normal reaction to abnormal events, the field will be able to validate the concerns of returning Servicemembers struggling with both traumatic and existential or spiritual crises, and help them to prepare for and embrace these as normal while still screening for high risk factors and being ready to intervene early. Families are also affected by this phenomenon. Policies need to reflect this understanding and provide outreach, support and education to significant others, along with marital and family counseling. Education, 
prevention and intervention programs must be created and supported by all levels of the command structure. We must stop assuming that only those individuals who are visibly struggling are affected by their experience. Some individuals may appear to be doing well, but are silently suffering in the depths of their Moral Core with deep and profound existential questions about their experience, identity and purpose. Programs need to reflect this new understanding as mental health providers, support staff, cadre and clergy all begining to work together to address this fundamental phenomenon of warriorhood.

\section{Conclusion}

This study has provided a foundation on which future inquiries can be developed. While it may have generated more questions than were answered, it represents a beginning of a formal attempt to operationally define the concept of the Moral Injury Syndrome by establishing its relationships to other known, associated concepts such as Disorders of Extreme Stress Not Otherwise Specified and Existential Well-Being. Clearly, these concepts are so intrinsically entwined in this population that further research is needed to explore the symptomology at a factorial level.

This study also uncovered several themes. First, the debate continues in the field regarding the nature of post-deployment distress, suggesting that we continue to be eluded by the complexity of this condition. Second, in spite of the conflicting theories regarding the etiology of the distress, there seems to be some agreement that the whole experience of engaging in war leads to some level of personal change in nearly all individuals, and is highly debilitating changes in some (Hoge, 2004). And, third, to a varying degree, there seems to be a universal set of symptoms that span many existing categories of diagnosis exhibited during post-deployment reintegration. The complexity 
and comorbidity of these symptoms tend to confound diagnosis, and therefore, potentially prohibit effective treatment.

At this time, the relationship between PTSD, Moral Injury and Existential WellBeing is clearly identified, but warrants further study. More research is needed to better understand the complex reintegration needs of the returning Servicemembers and Veterans in our communities. While this study was not able to provide conclusive evidence of the diagnostic structure for Moral Injury as a stand-alone construct, it succeeded in providing evidence that will support further research into the subject of integrating the spiritual and/or existential needs. 


\section{REFERENCES}

American Psychological Association. (1952). Diagnostic and statistical manual of mental disorders. ( $1^{\text {st }}$ ed.) Washington, DC: Author.

American Psychological Association. (1968). Diagnostic and statistical manual of mental disorders. ( $2^{\text {nd }}$ ed.) Washington, DC: Author.

American Psychological Association. (1980). Diagnostic and statistical manual of mental disorders. ( $3^{\text {rd }}$ ed.) Washington, DC: Author.

American Psychological Association. (1987). Diagnostic and statistical manual of mental disorders. ( $3^{\text {rd }}$ ed. revised) Washington, DC: Author.

American Psychological Association. (1994). Diagnostic and statistical manual of mental disorders. (4 ${ }^{\text {th }}$ ed.) Washington, DC: Author.

American Psychological Association. (2000). Diagnostic and statistical manual of mental disorders - text revision. $\left(4^{\text {th }}\right.$ ed. TR) Washington, DC: Author.

American Psychological Association. (Publication pending). Diagnostic and statistical manual of mental disorders. ( $5^{\text {th }}$ ed.) Washington, DC: Author.

Archibald, H.C., \& Tuddenham, R.D. (1965). Persistent stress reaction after combat: A 20-year follow-up. Arch Gen Psychiatry.12(5):475-481.

doi:10.1001/archpsyc.1965.01720350043006

Armed Forces Health Surveillance Center. (2008). Update: Deployment health assessments, U.S. Armed Forces, January-December, 2007. Medical Surveillance Monthly Report.15(1). Author.

Brett, E.A. (1993). Classification of posttraumatic stress disorder in DSM-IV: Anxiety disorder, dissociative disorder, or stress disorder. In J.R.T. Davidson \& E.B. Foa (Eds.), Posttraumatic Stress Disorder: DSM-IV and beyond.(pp.191-204).

Washington, DC: American Psychiatric Press, Inc.

Bruce, L.E. (2008, November). Mental health brief: Combat stress and PTSD. Paper presented at the Kentucky National Guard symposium, Fort Knox, KY. 
Calhoun, L.G. \& Tedeschi, R.G. (1996). The posttraumatic growth inventory: Measuring the positive legacy of trauma. Journal of Traumatic Stress. 9, 455-471. doi\# 10.1007/BF02103658.

Copeland, L (2013, October 30). Staff perspective: On moral injury. Center for deployment psychology. (Web log post). Retrieved from http://deploymentpsych.org/blog/staff-perspective-moral-injury.

Cruden, R. (1973). The war that never ended: The American Civil War. Englewood Cliffs, NJ: Prentice Hall.

Currier, J.M., Holland, J.M., Drescher, K. \& Foy, D. (2015). Initial psychometric evaluation of the moral injury questionnaire - military version. Clinical Psychological Psychotherapy. Jan-Feb; 22(1): 54-63/ doi: 10.1002/cpp.1855.

Davidson, J. R. \& Foa, E.B. (1993). Posttraumatic stress disorder: DSM-IV and beyond. Washington, DC: American Psychiatric Press, Inc.

Dean, E. T. (1997). Shook over hell: Post-traumatic stress, Vietnam, and the Civil War. Cambridge MA: Harvard University Press.

Department of Defense. (2010). DoD personnel and procurement statistics. Personnel and procurement reports and data files. Retrieved 27 January 2011 from http://siadapp.dmdc.osd.mil/personnel/MMIDHOME.HTM.

Department of Veterans Affairs. (2004). VA/DoD clinical practice guidelines for the management of post-traumatic stress. Washington, DC. Author.

Department of Veterans Affairs. (2008). VHA Directive 2008-084: National Clinical Reminder Program. Retrieved on January 2, 2011 from, http://www1.va.gov/vhapublications/ViewPublication.asp?pub_ID=1815.

Department of Veterans Affairs. (2009). VA, DoD host national mental health summit: Shinseki, Gates address unprecedented forum. Washington, DC. Author. Retrieved from http://www1.va.gov/opa/pressrel/pressrelease.cfm?id=1805 on $1 / 5 / 2011$.

Department of Veterans Affairs. (2010). Suicide Prevention webpage. Retrieved January 21, 2011 from, http://www.mentalhealth.va.gov/suicide_prevention/.

Department of Veterans Affairs/Department of Defense Joint Executive Council. (2009). Joint Strategic Plan Annual Report. Washington, DC. Author. 
Drescher, K.D., Foy, D.W., Kelly, C.M., Schultz, A., Kerri, E. \& Litz, B. (2011). An exploration of the viability and usefulness of the construct of moral injury in war veterans. Traumatology. 17(1). 8-13. DOI: 10.1177/1534765610395615.

Erikson, E. (1963). Childhood and Society. New York: Norton Publisher.

Erikson, E. H. (1980). Identity and the life cycle. New York: W.W. Norton Publishing, Inc.

Figley, (1978) Stress disorder among Vietnam Veterans. NY: Brunner/Mazel Publishers.

Forbes, D., Creamer, M. \& Biddle, D. (2001). The validity of the PTSD checklist as a measure of symptomatic change in combat-related PTSD. Behavior research and Therapy, 39(8), 977-986. doi:10.1016/S0005-7967(00)00084-X.

Ford, J. D. (1999). Disorders of extreme stress following warzone military trauma: Associated features of post-traumatic stress disorders (PTSD) or comorbid but distinct syndromes. Journal of Consulting and Clinical Psychology, 67(1), 3-12.

Frankfurt, S., \& Frazier, P. (2016). A review of research on moral injury in combat veterans. Military Psychology. 29(5)318-330.

Frankl, V. (1969). The will to meaning: Foundations and applications of logotherapy. New York: Meridian - Penguin Publishers.

Frankl, V.E. (1988). The will to meaning: foundations and applications of logotherapy. New York: Penguin Group.

Frankl, V.E. (2006). Man's search for meaning. Boston: Beacon Press.

Friedman, M. (2000). Guidelines for the treatment of PTSD. Department of Veterans Affairs. Washington, DC, National Center for PTSD.

Graber, A. (2004). Viktor Frankl's logotherapy: Method of choice in ecumenical pastoral psychology. Lima, OH: Wyndham Hall Press.

Heimler, E. (1967). Mental Illness and Social Work. Victoria, Australia: Penguin Books.

Heimler, E. (1975). Survival in society. NY: John Wiley and Sons.

Herman, J. L. (1997). Trauma and Recovery: The aftermath of violence - from domestic abuse to political terror. New York: Basic Books.

Hoge, C.W., Castro, C.A., Messer, S.C., McGurk, D., Cotting, D.I \& Koffman, R.L. (2004). Combat duty in Iraq and Afghanistan, mental health problems, and barriers to care. New England Journal of Medicine, 351, 13-22. 
Homer. The Odyssey, translated by S.H. Butcher and A. Lang. Vol. XXII. The Harvard Classics. New York: P.F. Collier \& Son, 1909-14; Bartleby.com, 2001. www.bartleby.com/22/.

Horowitz, M.J. (1997). Stress response syndromes, third edition, Northvale NJ: Aronson.

Horowitz, M.J. (1999). Essential papers on posttraumatic stress disorder. New York: University press.

Janoff-Bulman, R. (1992). Shattered assumptions: Toward a new psychology of trauma. New York: The Free Press.

Kardiner, A. (1941). The traumatic neuroses of war. Washington, DC: American Psychological Association.

Kardiner, A. \& Spiegel, H. (1947). War, stress and neurotic illness. (2 $2^{\text {nd }}$ ed. of The traumatic neuroses of war.) New York: Paul B. Hoeber publishing.

Keane, T. (1993). Symptomatology of Vietnam Veterans with posttraumatic stress disorder. In J.R.T. Davidson \& E.B. Foa (Eds.), Posttraumatic Stress Disorder: DSM-IV and Beyond.(pp.99-112). Washington, DC: American Psychiatric Press, Inc.

Krill, D. F. (1978). Existential Social Work: Treatment approaches in the human services. Free Press. New York.

Lantz, J. G., (1990). Existential social work with Vietnam Veterans. Journal of Independent Social Work, 5(1),12.

Lantz, J. (2004). Research and evaluation issues in existential psychotherapy. Journal of Contemporary Psychotherapy, 34(4), 10.

Leland, A. \& Oboroceanu, M.J. (2010). American War and Military Operations Casualties: Lists and Statistics. Congressional Research Services. Retrieved June 1, 2010 from http://www.fas.org/sgp/crs/natsec/RL32492.pdf.

Levinson, N. (2012). Moral injury and modern war. The American conservative. June 28, 2012.

Lifton, R.J. (2005). Home from the war: Learning from Vietnam Veterans. New York: Other Press.

Linder, M. (2004). Creating post-traumatic stress disorder: A case study of the history, sociology, and politics of psychiatric classification. In Caplan, P. \& Cosgove, L. (eds.), Bias in psychiatric diagnosis. New York. Jason Aronson. 
Litz, B., Stein, N., Delaney, E., Lebowitz, L., Nash, W.P., et. al. (2009). Moral injury and moral repair in war Veterans: A preliminary model and intervention strategy. Clinical Psychology Review. 29. 696-706.

McCann, I.L. \& Perlman, L.A. (1990). Psychological trauma and the adult survivor: Theory, therapy, and transformation. New York: Brunner/Mazel Publishers.

Meagher, I. (2007). Moving a Nation to Care: Post Traumatic Stress Disorder and America's returning Troops. Brooklyn, NY: Ig Publishing.

Menninger, W. C. (1948). Psychiatry in a troubled world. New York: The Macmillan Company.

Minnick, F. (2009). Camera boy. Ashland, OR: The Hellgate Press.

Minnick, F. (2010, August). The war within. VFW Magazine.

Myers, C.S. (1940). Shell shock in France 1914-1918. Oxford, England: University Press. Macmillan.

Nash, W.P., \& Litz, B. (2013). Moral injury: A mechanism for war-related psychological trauma in military family members. Clinical Child and Family Psychological Review. 16. 365-375. DOI: 10.11007/s10567-013-0146-y.

Nash, W.P., Marino Carper, T.L., Mills, M.A., Au, T., Foldsmith, A. \& Litz, B. (2013). Psychometric evaluation of the moral injury events scale. Military Medicine. 178.6, 646-652.

National Center for PTSD (1989). Mission statement. Retrieved January 5, 2011 from, http://www.ptsd.va.gov/about/mission/mission-and-overview.asp.

National Center for Veterans Analysis and Statistics, Office of Policy and Planning. Department of Veterans Affairs. (2009). Analysis of unique Veterans utilization of VA benefits \& services. Washington, DC: Author. Retrieved on November 5, 2010 from, www1.va.gov/VETDATA/docs/SpecialReports/uniqueVeteransMay.pdf

Paloutizian, R.F., Ellison, C.W. (1982). Loneliness, spiritual well-being and the quality of life, in Loneliness: A sourcebook of current theory, research and therapy. New York: Wiley-Interscience.

Pargament, K. J., Smith, B.W., Koenig, H.G. \& Perez, L. (1998). Patterns of positive and negative religious coping with major life stressors. Journal for the Scientific Study of Religion, 37(4), 710-724. 
Pelcovitz, D. , van der Kolk, B.A., Roth, S.H., Mendel, F.S., Kaplan, S. \& Resick, P.A. (1997). Development of a criteria set and a structured interview for disorders of extreme stress (SIDES). Journal of Traumatic Stress, 10, 3-16.

Perniger, T.V., (1998). What's wrong with Bonferroni adjustments. British Medical Journal, 316(7139)1236-1238.

Price, J. L., \& Stevens, S. P. (2010). Partners of Veterans with PTSD: Research findings. National Center for PTSD PILOTS Database. Retrieved December 5, 2010 from, http://www.ncptsd.va.gov/professional /pages/partners_of_vets_resrach_findings.

RAND Center for Military Health Policy Research. (2008). The invisible wounds of war: Psychological and cognitive injuries, their consequences, and services to assist recovery. Tenielian, T. \& Jaycox, L.(Eds.). Washington, DC. Retrieved June 7 , 2008 from www.RAND.org.

Scoboria, A., Ford, J., Lin, H., \& Frisman, L. (2008). Exploratory and confirmatory factor analysis of the structured interview for disorders of extreme stress. Assessment Online First. Doi: 10.1177/1073191108319005.

Shane, L.(2009). Mullen slams mental health treatment failures. Stars \& Stripes. September 16, 2009. Retrieved December 5, 2010 from, www.military.com/news/article/muleens_alsms_dod_va_mental_health.

Shaw, A.J., \& Linley, P.A. (2005). Religion, spirituality, and posttraumatic growth: A systemic review. Mental Health, Religion \& Culture, 8(1),1-11.

Shay, J. (2014). Moral injury. Psychoanalytic psychology. 31(2),182-191.

Shay, J. (2002). Odysseus in America: Combat trauma and the trials of homecoming. New York. Scribner.

Shay, J. (1994). Achilles in Vietnam: Combat trauma and the Undoing of character. New York, Scribner.

Shephard, B. (2001). A war of nerves. Cambridge Mass, Harvard University Press.

Silverstein, R. (1994). Chronic identity diffusion in traumatized combat Veterans. Social Behavior and Personality, 22(1), 69-80.

Stanford dictionary of philosophy (2015) First published Mon Aug 23, 2004; substantive revision Mon Mar 9, 2015 http://plato.stanford.edu/entries/existentialism.

Sutker, P.B., Winstead, D.K., \& Gallina, Z.H. (1991). Cognitive deficits and psychopathology among former prisoners of war and combat veterans of the 
Korean conflict. American Journal of Psychiatry. 148(1), 67-72. Doi\# 10.1176/ajp.148.1.67.

Tedeschi, R.G., Park, C.L., \& Calhoun, L.G. (eds.) (1998). Posttraumatic growth: Positive changes in the aftermath of crisis. Mahwah, New Jersey: Lawrence Erlbaum Associates.

Tick, E. (2005). War and the soul. Wheaton, IL: Quest Books.

Tillich, P. (1952). The courage to be. New Haven, CT: Yale University Press.

United States Army Center for Health Promotion and Preventative Medicine. (2009). Spiritual Attitudes Inventory: User guide. Directorate of Health Promotion and wellness. Aberdeen Proving Ground, MD. Author.

van der Kolk, B.A., Pelcovitz, D., Roth, S.H., Mandel, F.X., McFarlane, A.C. \& Herman, J.L. (1996). Dissociation, somatization, and affect dysregulation: The complexity of adaptation to trauma. American Journal of Psychiatry, 153, 83-93.

van der Kolk, B. A., McFarlane, Alexander, C., and Weisaeth, Lars, Ed. (1996). Traumatic stress: The effects of overwhelming experiences on mind, body, and society. NY: The Guildford Press.

van der Kolk, B.A., (2005). Disorders of extreme stress: The empirical foundation of a complex adaptation to trauma. Journal of Traumatic Stress, 18(5), 389-399.

Walker, M. (2010). Military: Suicide rate confounding Marine Corps. The North County Times. Retrieved November 21, 2010 from, http://www.nctimes.com/news/local/military/article_3dc03ec3-6a37-5.

Wallston, K.A. (2005). The validity of the multidimensional health locus of control scales. Journal of Health Psychology, 10, 623-631.

Weathers, F., Litz, B., Herman, D., Huska, J., \& Keane, T. (1993, October). The PTSD Checklist (PCL): reliability, validity, and diagnostic utility. Paper presented at the Annual Convention of the International Society for Traumatic Stress Studies, San Antonio, TX.

Weems, C. F., Costa, N.M, Dehon, C. \& Berman, S. L. (2004). Paul Tillich's theory of existential anxiety: A preliminary conceptual and empirical examination. Anxiety, Stress, and Coping, 17(4), 383-399.

Wilson, J.P. (2004). Broken spirits: The treatment of traumatized asylum seeker, refugees, war and torture victims. New York: Brunner-Routledge. 
APPENDICES 
Appendix A - PTSD, DESNOS \& MI ITEM COMPARISON CHART

\begin{tabular}{|c|c|c|c|c|c|c|c|c|}
\hline \multicolumn{9}{|c|}{$\begin{array}{l}\text { PTSD/DESNOS/MORAL INJURY INDICATOR COMPARISON CHART } \\
\end{array}$} \\
\hline $\begin{array}{c}\text { DSM IV } \\
\text { Categor } \\
\text { y }\end{array}$ & \begin{tabular}{|c|} 
DSM IV \\
Critero \\
n
\end{tabular} & \begin{tabular}{|c|} 
PTSD (PCL-M 17-ITEM \\
*) \\
(based on DSM-IV Diagnostic Criteria \\
11/1/94)
\end{tabular} & \begin{tabular}{|c|} 
DSM-5 \\
Categor \\
$y$
\end{tabular} & \begin{tabular}{|c|} 
DSM IV \\
Critero \\
$n$
\end{tabular} & $\begin{array}{c}\text { PTSD (PCL-5 20-ITEM } * *) \\
\text { (based on DSM-V Diagnostic Criteria - } \\
\text { 08/14/13) }\end{array}$ & $\begin{array}{l}\text { DESNOS } \\
\text { CRITERIO N }\end{array}$ & DESNOS ITEM & $\begin{array}{l}\text { VIURAT } \\
\text { INJURY } \\
\text { PROPOSED }\end{array}$ \\
\hline \multirow{5}{*}{ 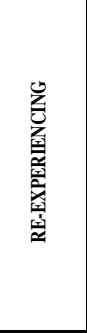 } & B-1 & $\begin{array}{l}\text { Repeated, disturbing memories, thoughts, or } \\
\text { images of a stressful military experience. }\end{array}$ & \multirow{5}{*}{ 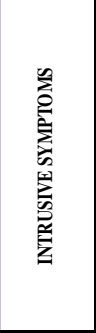 } & B-1 & $\begin{array}{l}\text { Repeated, disturbing and unwanted } \\
\text { memories of the stressful experience. }\end{array}$ & & & \\
\hline & B-2 & $\begin{array}{l}\text { Repeated, disturbing dreams of a stressful } \\
\text { military experience }\end{array}$ & & B-2 & $\begin{array}{c}\text { Repeated, disturbing dreams of a stressful } \\
\text { experience }\end{array}$ & & & \\
\hline & B-3 & $\begin{array}{l}\text { Suddenly acting or feeling as if a stressful } \\
\text { military experience were happening again } \\
\text { (as if you were reliving it) }\end{array}$ & & B-3 & $\begin{array}{c}\text { Suddenly feeling or acting as if a stressful } \\
\text { experience were happening again (as if you } \\
\text { were actually back there reliving it) }\end{array}$ & & & \\
\hline & B-4 & $\begin{array}{l}\text { Feeling very upset when something } \\
\text { reminded you of a stressful military } \\
\text { exnerience }\end{array}$ & & B-4 & $\begin{array}{l}\text { Feeling very upset when something } \\
\text { reminded you of a stressful experience }\end{array}$ & & & \\
\hline & B-5 & $\begin{array}{l}\text { Having physical reactions when something } \\
\text { reminded you of a stressful military } \\
\text { experience }\end{array}$ & & B-5 & $\begin{array}{l}\text { Having strong physical reactions when } \\
\text { something reminded you of a stressful } \\
\text { military experience (for example, heart } \\
\text { pounding, trouble breathing)? }\end{array}$ & & & \\
\hline \multirow{15}{*}{ 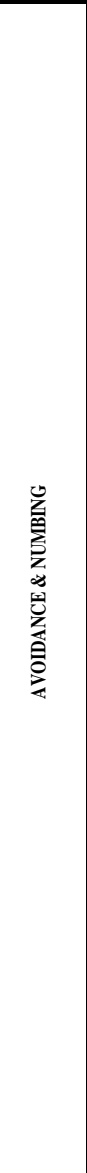 } & C-1 & $\begin{array}{c}\text { Avoiding thinking about or talking about a } \\
\text { stressful military experience or avoiding } \\
\text { having feelings related to it }\end{array}$ & \multirow{2}{*}{ 突 } & C-1 & $\begin{array}{l}\text { Avoiding memories, thoughts, or feelings } \\
\text { related to the stressful experience. }\end{array}$ & & & \\
\hline & $\mathrm{C}-2$ & $\begin{array}{l}\text { Avoiding activities or situation because } \\
\text { they reminded you of a stressful military } \\
\text { experience }\end{array}$ & & $\mathrm{C}-2$ & $\begin{array}{c}\text { Avoiding external reminders of the stressful } \\
\text { experience (for example, people, place, } \\
\text { conversations, activities, objects or } \\
\text { situations)? }\end{array}$ & & & \\
\hline & $\mathrm{C}-3$ & $\begin{array}{l}\text { Trouble remembering important parts of a } \\
\text { stressful military experience }\end{array}$ & \multirow{13}{*}{ 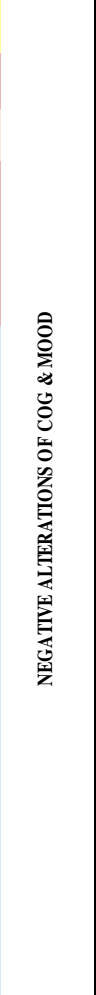 } & D1 & $\begin{array}{c}\text { Trouble remembering important parts of a } \\
\text { stressful experience }\end{array}$ & & & \\
\hline & C-4 & $\begin{array}{l}\text { Loss of interest in activities that you used } \\
\text { to enjoy }\end{array}$ & & D5 & $\begin{array}{l}\text { Loss of interest in activities that you used } \\
\text { to enjoy }\end{array}$ & & & \\
\hline & C-5 & Feeling distant or cut off from other people & & D6 & Feeling distant or cut off from other people & $\begin{array}{c}\text { Alterations in Self } \\
\text { Perception (III) } \\
\end{array}$ & $\begin{array}{l}\text { Feeling as if no one can } \\
\text { underst and } \\
\end{array}$ & $\begin{array}{c}\text { Withdraw \& } \\
\text { Hiding }\end{array}$ \\
\hline & \multirow{2}{*}{ C-6 } & \multirow{2}{*}{$\begin{array}{l}\text { Feeling emotionally numb or being unable } \\
\text { to have loving feelings for those close to } \\
\text { you }\end{array}$} & & D7 & $\begin{array}{l}\text { Trouble experiencing positive feelings (for } \\
\text { example, being unable to feel happiness or }\end{array}$ & $\begin{array}{c}\text { Alteration in } \\
\text { Regulation of } \\
\text { Affect/Impulse (I) }\end{array}$ & $\begin{array}{l}\text { Experiencing problems } \\
\text { with sexual/intimate } \\
\text { relationships }\end{array}$ & \\
\hline & & & & I & $\begin{array}{c}\text { have loving feelings for people close to } \\
\text { you. }\end{array}$ & \begin{tabular}{|c|} 
Alterations in \\
Relations with \\
Others (IV) \\
\end{tabular} & $\begin{array}{c}\text { Experiencing more trouble } \\
\text { trusting others than before } \\
\text { the military experience }\end{array}$ & $\begin{array}{l}\text { Loss of ability } \\
\text { to trust others }\end{array}$ \\
\hline & \multirow{8}{*}{$\mathrm{C}-7$} & \multirow{8}{*}{$\begin{array}{l}\text { Feeling as if your fut ure somehow will be } \\
\text { cut short }\end{array}$} & & \multirow{6}{*}{ D2 } & \multirow{6}{*}{$\begin{array}{l}\text { Having strong negative beliefs about } \\
\text { yourself, other people, or the world (for } \\
\text { example, having throughs such as: I am bad, } \\
\text { no one can be trusted, the world is } \\
\text { completely dangerous)? }\end{array}$} & $\begin{array}{l}\text { Alterations in } \\
\text { Systems of } \\
\text { Meaning (VI) } \\
\text { Alterations in } \\
\text { Systems of } \\
\text { Meaning (VI) } \\
\end{array}$ & \begin{tabular}{|c|}
$\begin{array}{c}\text { Feel that I am not the } \\
\text { same person that I used to } \\
\text { be before the military } \\
\text { experience }\end{array}$ \\
$\begin{array}{c}\text { Feelings of being } \\
\text { permanently damaged by } \\
\text { the military experience }\end{array}$ \\
\end{tabular} & $\begin{array}{c}\text { Loss of } \\
\text { personal } \\
\text { identity/meani } \\
\text { ng }\end{array}$ \\
\hline & & & & & & $\begin{array}{l}\text { Alterations in } \\
\text { Systems of } \\
\text { Meaning (VI) }\end{array}$ & $\begin{array}{c}\text { Increased awareness of my } \\
\text { own mortality thoughts of } \\
\text { death or dying }\end{array}$ & Anomie \\
\hline & & & & & & $\begin{array}{l}\text { Alterations in } \\
\text { Systems of } \\
\text { Meaning (VI) }\end{array}$ & $\begin{array}{c}\text { I feel that my values and } \\
\text { beliefs have changes since } \\
\text { my experience }\end{array}$ & $\begin{array}{l}\text { Enduring } \\
\text { changes in } \\
\text { Belief }\end{array}$ \\
\hline & & & & & & $\begin{array}{c}\text { Alterations in } \\
\text { Systems of } \\
\text { Meaning (VI) } \\
\end{array}$ & $\begin{array}{l}\text { Feelings of despair and } \\
\text { hopelessness }\end{array}$ & Demoralization \\
\hline & & & & & & $\begin{array}{l}\text { Alterations in Self } \\
\text { Perception (III) }\end{array}$ & $\begin{array}{l}\text { Diminished feeling of } \\
\text { personal effectiveness }\end{array}$ & $\begin{array}{c}\text { Self- } \\
\text { Condemnation }\end{array}$ \\
\hline & & & & & & $\begin{array}{c}\text { Alterations in Self } \\
\text { Perception (III) }\end{array}$ & $\begin{array}{c}\text { Everyone has problems } \\
\text { adjust ing, it's no big deal } \\
\text { (minimizing) }\end{array}$ & $\begin{array}{l}\text { Confusion \& } \\
\text { Bewilderment }\end{array}$ \\
\hline & & & & D3 & $\begin{array}{c}\begin{array}{c}\text { Blaming yourself or someone else for the } \\
\text { stressful experience or what happened after } \\
\text { it? }\end{array} \\
\end{array}$ & $\begin{array}{c}\text { Alterations in Self- } \\
\text { Perception (III) }\end{array}$ & $\begin{array}{c}\text { Feeling responsible for } \\
\text { things that happened and } \\
\text { choices I made } \\
\end{array}$ & $\begin{array}{l}\text { Guilt \& } \\
\text { Remorse }\end{array}$ \\
\hline & & & & D4 & $\begin{array}{l}\text { Having strong negative feelings such as } \\
\text { fear, horror, anger, guilt or shame. }\end{array}$ & $\begin{array}{c}\text { Alterations in Self } \\
\text { Perception (III) }\end{array}$ & $\begin{array}{l}\text { Feelings of shame and } \\
\text { doubt }\end{array}$ & Shame \\
\hline \multirow{7}{*}{ 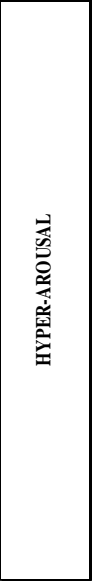 } & D-1 & Trouble falling or staying asleep & \multirow{7}{*}{ 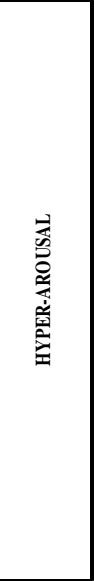 } & E6 & Trouble falling or staying asleep & Somatization (V) & $\begin{array}{l}\text { Somat ic Issues: stomach } \\
\text { upset, chronic pain, } \\
\text { unexplained health issues } \\
\end{array}$ & \\
\hline & $\mathrm{D}-2$ & Feeling irritable or having angry outbursts & & E1 & $\begin{array}{c}\text { Irritable behavior, angry outbursts, or acting } \\
\text { aggressively. }\end{array}$ & $\begin{array}{c}\text { Alteration in } \\
\text { Regulation of } \\
\text { Affect/Impulse (I) }\end{array}$ & $\begin{array}{l}\text { Experience unpredict able } \\
\text { and overwhelming } \\
\text { emotions }\end{array}$ & $\begin{array}{l}\text { Anger, } \\
\text { emotional } \\
\text { lability or } \\
\text { restricted } \\
\text { affect }\end{array}$ \\
\hline & D-3 & Having difficulty concentrating & & E5 & Having difficulty concentrating & $\begin{array}{c}\text { Alteration in } \\
\text { Attention or } \\
\text { Consciousness (II) }\end{array}$ & \begin{tabular}{|c|} 
I have trouble \\
remembering basics day to \\
day events or lose periods \\
of time through the day
\end{tabular} & \\
\hline & D-4 & Being "super alert" or watchful or on guard. & & E3 & Being "super alert" or watchful or on guard. & & & \\
\hline & D-5 & Feeling jumpy or easily startled & & $\mathrm{E} 4$ & Feeling jumpy or easily startled & & & \\
\hline & & & & \multirow[b]{2}{*}{ E2 } & \multirow{2}{*}{$\begin{array}{l}\text { Taking too many risks or doing things that } \\
\text { could cause you harm? }\end{array}$} & $\begin{array}{c}\text { Alteration in } \\
\text { Regulation of } \\
\text { Affect/Impulse (I) } \\
\end{array}$ & 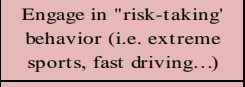 & $\begin{array}{c}\text { Self- } \\
\text { Handicappin } \\
\mathrm{g} \\
\end{array}$ \\
\hline & & & & & & $\begin{array}{c}\text { Alteration in } \\
\text { Regulation of } \\
\text { Affect/Impulse (I) }\end{array}$ & $\begin{array}{c}\text { Engage in self-destructive } \\
\text { behavior (i.e. binge } \\
\text { drinking, poor health } \\
\text { choices) }\end{array}$ & $\begin{array}{c}\text { Self- } \\
\text { Harm/Self- } \\
\text { Punishing }\end{array}$ \\
\hline
\end{tabular}


Appendix B - SPIRITUAL ATTITUDES INVENTORY (2009)

TG 323

MARCH 2009

Please answer the following questions by selecting the one answer that best describes how frequently you engage in the activities ${ }^{1} .$.

\begin{tabular}{|ll|}
\hline 1 & How often do you attend church or other religious or spiritual \\
\hline 06 & meetings? \\
05 & Once a week \\
04 & A few times a month \\
03 & A few times a year \\
02 & Once a year or less \\
01 & Never \\
\hline
\end{tabular}

2 How often do you spend time in private religious or spiritual activities such as prayer, meditation, or the study of religious texts (e.g., Bible, Koran, Torah, etc)?

06 More than once a day

O 5 Daily

O 4 Two or more times a week

O 3 Once a week

O 2 A few times a month

01 Rarely or never

For the following, use the scales provided to select the single answer that best characterizes how true each of the statements is for you...

\begin{tabular}{|l|l|}
\hline 3 & In my life, I \\
& $\begin{array}{l}\text { experience the } \\
\text { presence of the } \\
\text { Divine (i.e., God). }\end{array}$ \\
05 & Definitely True \\
04 & Tends to be True \\
03 & Unsure \\
02 & Tends NOT to be True \\
01 & Definitely NOT True \\
\hline
\end{tabular}

\begin{tabular}{|c|c|}
\hline 4 & $\begin{array}{l}\text { My religious beliefs are } \\
\text { what really lie behind my } \\
\text { whole approach to life. }\end{array}$ \\
\hline 05 & Definitely True \\
\hline 04 & Tends to be True \\
\hline 03 & Unsure \\
\hline 02 & Tends NOT to be True \\
\hline 01 & Definitely NOT True \\
\hline
\end{tabular}

\begin{tabular}{|ll|}
\hline 5 & I try hard to carry my \\
& religion over into all other \\
& dealings in life. \\
05 & Definitely True \\
04 & Tends to be True \\
03 & Unsure \\
02 & Tends NOT to be True \\
01 & Definitely NOT True \\
\hline
\end{tabular}

Using the scales provided, indicate how much you agree or disagree with each of the following statements ${ }^{2}$...

\begin{tabular}{|c|c|}
\hline 6 & Idan't knowich I \\
\hline & $\begin{array}{l}\text { am, where I came } \\
\text { from, or where I'm } \\
\text { going. }\end{array}$ \\
\hline 01 & Strongly Agree \\
\hline 02 & Moderately Agree \\
\hline 03 & Agree \\
\hline 04 & Disagree \\
\hline 05 & Moderately Disagree \\
\hline 06 & Strongly Disagree \\
\hline
\end{tabular}

\begin{tabular}{|ll|}
\hline 1 & I feel that life is a positive \\
06 & Strongly Agree \\
05 & Moderately Agree \\
04 & Agree \\
03 & Disagree \\
02 & Moderately Disagree \\
01 & Strongly Disagree \\
\hline
\end{tabular}

\begin{tabular}{|cl|}
\hline 8 & I feel unsettled about my \\
\hline & future. \\
01 & Strongly Agree \\
02 & Moderately Agree \\
03 & Agree \\
04 & Disagree \\
05 & Moderately Disagree \\
06 & Strongly Disagree \\
\hline
\end{tabular}

\begin{tabular}{|ll|}
\hline 9 & I feel very fulfilled and \\
& satisfied with life. \\
06 & Strongly Agree \\
05 & Moderately Agree \\
04 & Agree \\
03 & Disagree \\
02 & Moderately Disagree \\
01 & Strongly Disagree \\
\hline
\end{tabular}

\footnotetext{
1 Items 1.5 are from the DUREL; Koenig, H. G, Meador, K, \& Parkerson, G. 1997. Religion index for psychiatic research: A 5-item measure for use in health outcome studies. American Joumal of Psychiatry, 154, 885-886.

${ }^{2}$ ttems 6-15 are from the Spiritual Well-being Scale (only the existential well-being subscale is induded); Paloutzian R. F., Ellison C. W. 1982. Loneliness, spiritual well-being, and the quality of lite. In L. A. Peplau \& D. Perman (Eds), Loneliness: a sourcebook of current theory, research, and therapy (pp. 224-237). New York: Wiley-Interscience.
} 


\begin{tabular}{|c|l|}
\hline 10 & $\begin{array}{l}\text { I feel a sense of well- } \\
\text { being about the } \\
\text { direction my life is } \\
\text { headed in. }\end{array}$ \\
06 & Strongly Agree \\
05 & Moderately Agree \\
04 & Agree \\
03 & Disagree \\
02 & Moderately Disagree \\
01 & Strongly Disagree \\
\hline
\end{tabular}

\begin{tabular}{|ll|}
\hline 11 & $\begin{array}{l}\text { Idon't enjoy much about } \\
\text { life. }\end{array}$ \\
\hline 01 & Strongly Agree \\
02 & Moderately Agree \\
03 & Agree \\
04 & Disagree \\
05 & Moderately Disagree \\
06 & Strongly Disagree \\
\hline
\end{tabular}

\begin{tabular}{|c|l|}
\hline 12 & I feel good about my \\
future. \\
\hline 6 & Strongly Agree \\
05 & Moderately Agree \\
04 & Agree \\
03 & Disagree \\
02 & Moderately Disagree \\
01 & Strongly Disagree \\
\hline
\end{tabular}
13 I feel that life is full of conflict and unhappiness.

01 Strongly Agree

O 2 Moderately Agree

O 3 Agree

04 Disagree

O 5 Moderately Disagree

06 Strongly Disagree

\begin{tabular}{|c|l|}
\hline 14 & $\begin{array}{l}\text { Life doesn't have } \\
\text { much meaning. }\end{array}$ \\
\hline 01 & Strongly Agree \\
02 & Moderately Agree \\
03 & Agree \\
04 & Disagree \\
05 & Moderately Disagree \\
06 & Strongly Disagree \\
\hline
\end{tabular}

\section{5} I believe there is some real purpose for my life.

06 Strongly Agree

O 5 Moderately Agree

04 Agree

O 3 Disagree

02 Moderately Disagree

01 Strongly Disagree

Please use the scales provided to indicate how often, you have had thoughts or feelings like those described in the following statements ${ }^{3}$..

\begin{tabular}{|cl|}
\hline 16 & I have wondered whether \\
& God has abandoned me. \\
04 & Not at All \\
03 & Occasionally \\
02 & Frequently \\
01 & A Great Deal \\
\hline
\end{tabular}

20 I have wondered if my church has abandoned me.

O Not at All

O 3 Occasionally

O 2 Frequently

01 A Great Deal

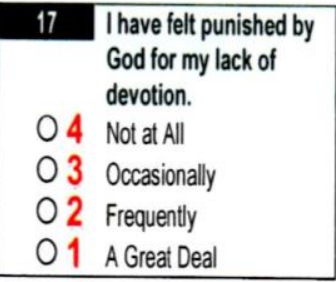

21 I have decided the Devil is responsible for bad things that happen to me.

04 Not at All

O 3 Occasionally

02 Frequently

01 A Great Deal

\begin{tabular}{|l|l|}
\hline 18 & I have wondered what I \\
did for God to punish \\
me. \\
O4 & Not at All \\
03 & Occasionally \\
02 & Frequently \\
01 & A Great Deal \\
\hline
\end{tabular}

\begin{tabular}{|c|c|}
\hline 19 & $\begin{array}{l}\text { I have questioned God's } \\
\text { love for me. }\end{array}$ \\
\hline 04 & Not at All \\
\hline 03 & Occasionally \\
\hline 02 & Frequently \\
\hline 01 & A Great Deal \\
\hline
\end{tabular}

22 I have questioned the power of God.

04 Not at All

O 3 Occasionally

02 Frequently

01 A Great Deal

${ }^{3}$ Items $16-22$ are from the Negative RCOPE; Pargament, K. I., Smith, B. W., Koenig, H. W., \& Perez, L. 1998. Patterns of positive and negative religious coping with major life stressors. Journal for the Scientific Study of Religion, 37, 710-724. 
For each of the following statements, use the scales provided to indicate the extent to which you agree or disagree 4 ...

\begin{tabular}{|l|l|}
\hline 23 & $\begin{array}{l}\text { If I get sick, it is my own } \\
\text { behavior that determines } \\
\text { how soon I get well again. }\end{array}$ \\
01 & Strongly Disagree \\
02 & Moderately Disagree \\
03 & Disagree \\
04 & Agree \\
05 & Moderately Agree \\
06 & Strongly Agree \\
\hline
\end{tabular}

27 If I take care of myself, I can avoid illness.

01 Strongly Disagree

O 2 Moderately Disagree

O 3 Disagree

04 Agree

O 5 Moderately Agree

O 6 Strongly Agree
24 I am in control of my health.

01 Strongly Disagree

O 2 Moderately Disagree

O 3 Disagree

O 4 Agree

O 5 Moderately Agree

O 6 Strongly Agree
25

When I get sick I am to

blame.

01 Strongly Disagree

O 2 Moderately Disagree

03 Disagree

O 4 Agree

O 5 Moderately Agree

O 6 Strongly Agree
26

The main thing that

affects my health is what I myself do.

01 Strongly Disagree

O 2 Moderately Disagree

O 3 Disagree

04 Agree

O 5 Moderately Agree

O 6 Strongly Agree
28 If I take the right actions I can stay healthy.

01 Strongly Disagree

O 2 Moderately Disagree

O 3 Disagree

O 4 Agree

O 5 Moderately Agree

O 6 Strongly Agree

4 Items 23.28 are from the IHLC scale of Form A of the Multidimensional Health Locus of Control Scale; Wallston, K. A., Wallston, B. S., \& DeVellis, R. 1978 Development of the multidimensional health locus of control (MHLC) scales. Heatth Education Monographs, 6, 160-170. 
Appendix C - SPIRITUAL ATTITUDES INVENTORY - REVISED (2010)

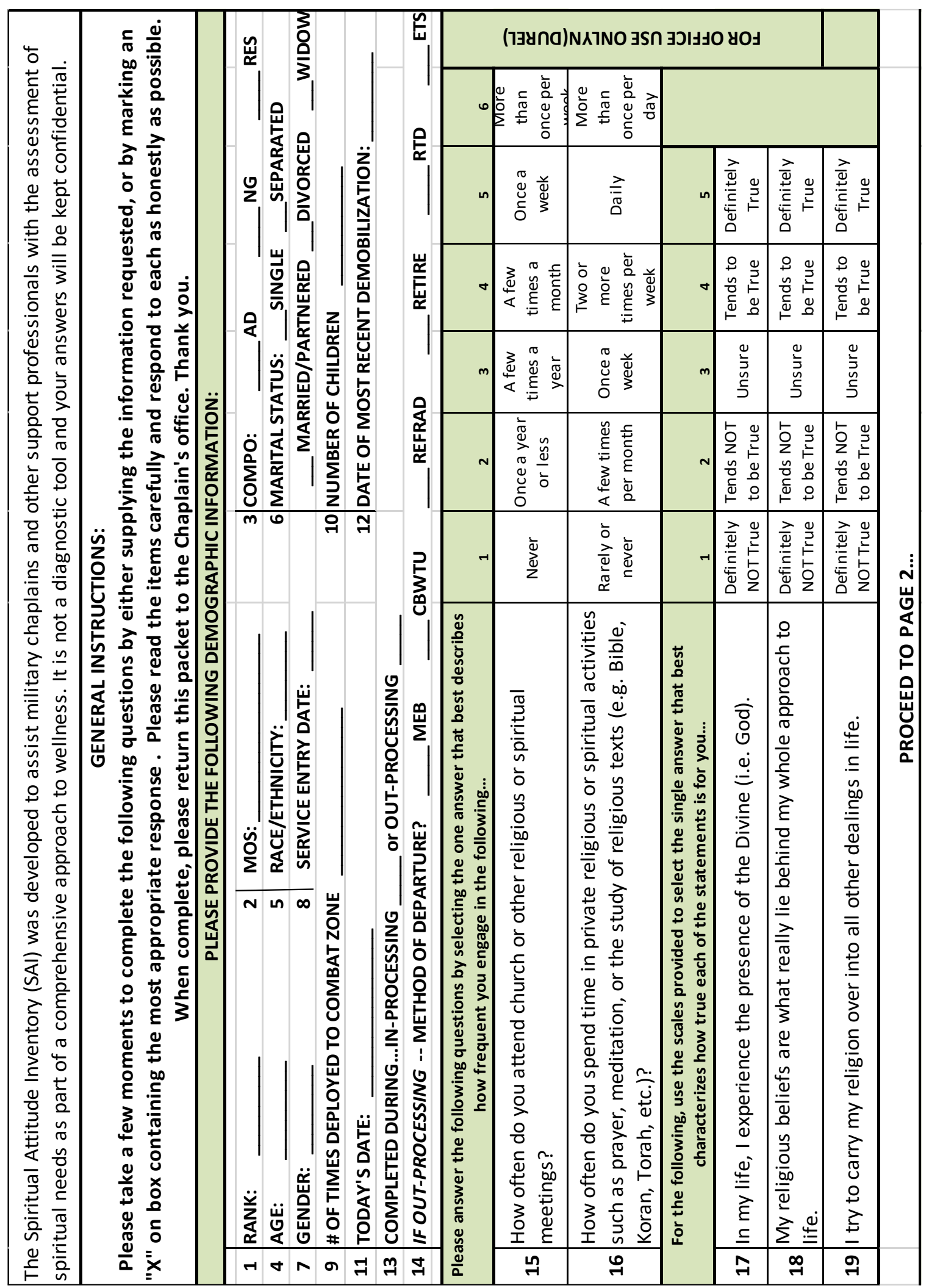




\begin{tabular}{|c|c|c|c|c|c|c|c|c|c|c|c|c|c|c|c|c|c|c|c|}
\hline \multicolumn{10}{|c|}{ 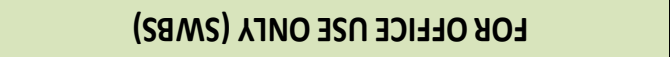 } & & \multicolumn{8}{|c|}{ (ヨdOJy ) ᄉ } & \multirow{8}{*}{ 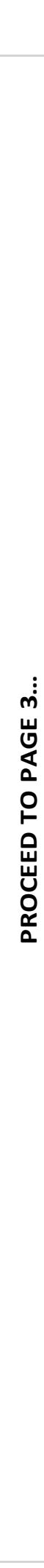 } \\
\hline & 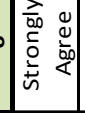 & 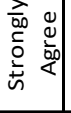 & 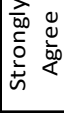 & 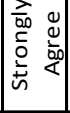 & 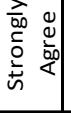 & 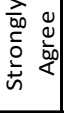 & 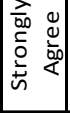 & 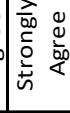 & 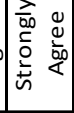 & 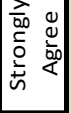 & & & & & & & & & \\
\hline & 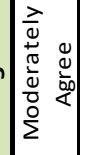 & 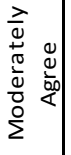 & 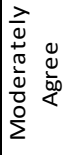 & 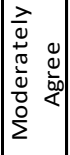 & 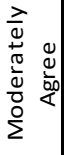 & 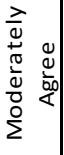 & 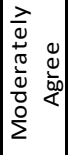 & 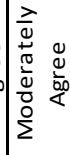 & 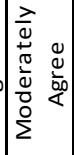 & 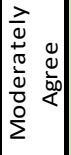 & & & & & & & & & \\
\hline ナ & 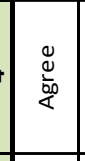 & 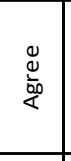 & $\begin{array}{l}\frac{0}{0} \\
\text { o. } \\
\frac{100}{4}\end{array}$ & 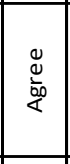 & 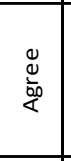 & 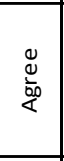 & 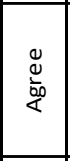 & 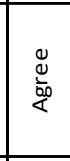 & 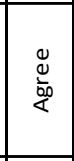 & 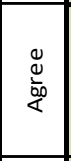 & $\nabla$ & 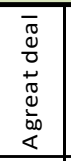 & $\begin{array}{l}\bar{\pi} \\
0 \\
0 \\
+0 \\
0 \\
0 \\
0 \\
\\
\end{array}$ & $\begin{array}{l}\bar{\pi} \\
0 \\
0 \\
0 \\
0 \\
0 \\
0 \\
0 \\
\end{array}$ & 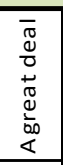 & $\begin{array}{l}\bar{\pi} \\
0 \\
0 \\
+0 \\
0 \\
0 \\
\vdots 0 \\
<\end{array}$ & 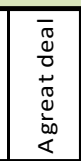 & 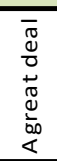 & \\
\hline m & 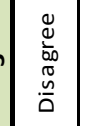 & 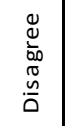 & $\begin{array}{l}0 \\
0 \\
\frac{\omega}{\omega 0} \\
0 \\
.00 \\
0\end{array}$ & 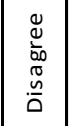 & 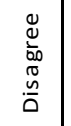 & 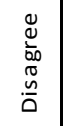 & 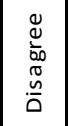 & 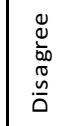 & $\begin{array}{l}0 \\
0 \\
\frac{0}{00} \\
0 \\
.00 \\
0\end{array}$ & 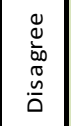 & $m$ & 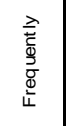 & 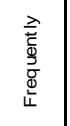 & 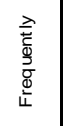 & 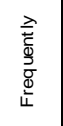 & 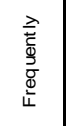 & 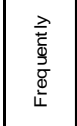 & 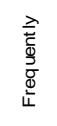 & \\
\hline & 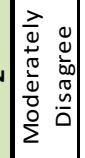 & 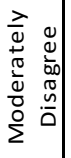 & & 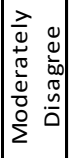 & 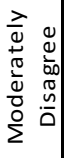 & & 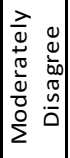 & 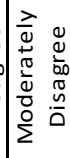 & 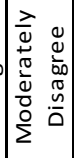 & 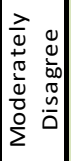 & $N$ & 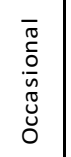 & 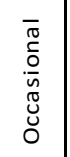 & $\begin{array}{l}\bar{\pi} \\
\overline{0} \\
\frac{0}{n} \\
\tilde{J} \\
\check{U}\end{array}$ & $\begin{array}{l}\bar{N} \\
\overline{0} \\
\bar{n} \\
\tilde{U} \\
\circlearrowright \\
0\end{array}$ & $\begin{array}{l}\overline{0} \\
\overline{0} \\
\frac{0}{n} \\
\tilde{U} \\
\tilde{u}\end{array}$ & $\begin{array}{l}\overline{0} \\
\tilde{o} \\
\bar{y} \\
\widetilde{J} \\
\breve{~}\end{array}$ & $\begin{array}{l}\bar{\pi} \\
\overline{0} \\
\bar{n} \\
\tilde{U} \\
\tilde{u} \\
0\end{array}$ & \\
\hline & 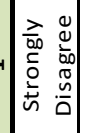 & 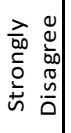 & & 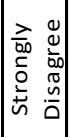 & 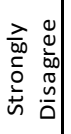 & 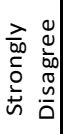 & 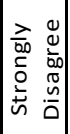 & 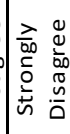 & 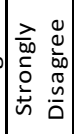 & 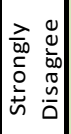 & 4 & $\begin{array}{l}\overline{\bar{\sigma}} \\
0 \\
0 \\
0 \\
0\end{array}$ & $\begin{array}{l}\overline{\bar{\sigma}} \\
0 \\
0 \\
0 \\
2\end{array}$ & $\begin{array}{l}\overline{\bar{\sigma}} \\
0 \\
0 \\
0 \\
\frac{0}{z}\end{array}$ & $\begin{array}{l}\overline{\bar{\sigma}} \\
+0 \\
0 \\
0 \\
2\end{array}$ & $\begin{array}{l}\overline{\bar{\sigma}} \\
\stackrel{0}{\pi} \\
0 \\
0 \\
z\end{array}$ & $\begin{array}{l}\overline{\bar{\pi}} \\
+0 \\
\pi \\
0 \\
0\end{array}$ & $\begin{array}{l}\overline{\bar{\sigma}} \\
+0 \\
\pi \\
0 \\
z\end{array}$ & \\
\hline \multirow[t]{2}{*}{ 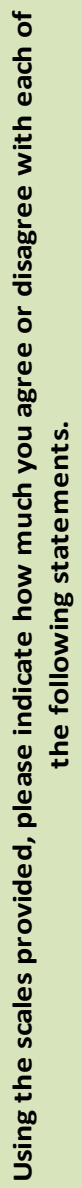 } & 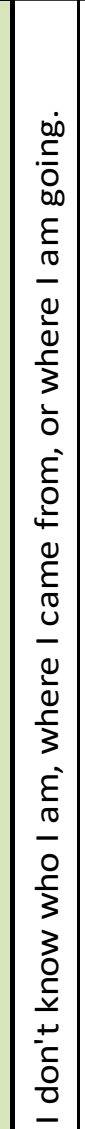 & 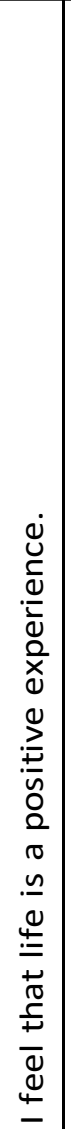 & 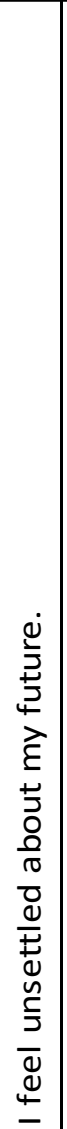 & 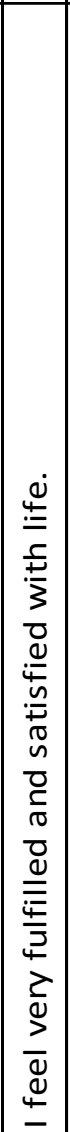 & 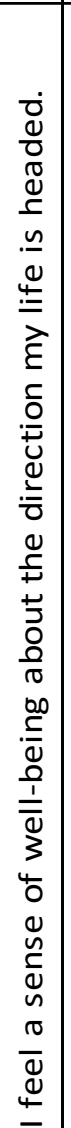 & 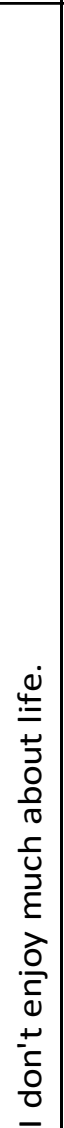 & 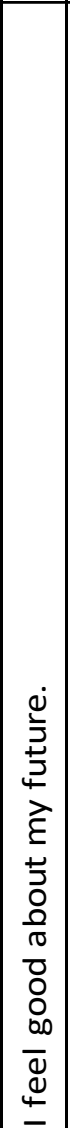 & 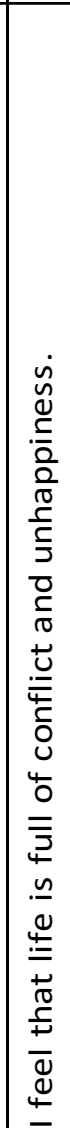 & 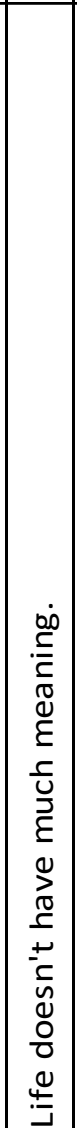 & 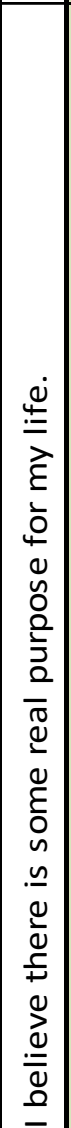 & \multirow[t]{2}{*}{ 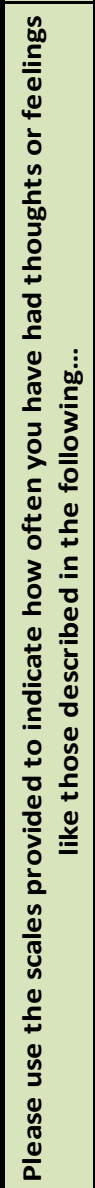 } & 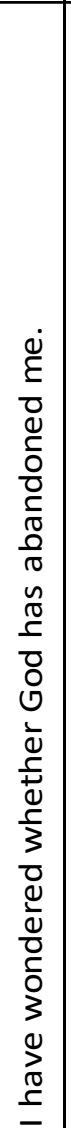 & 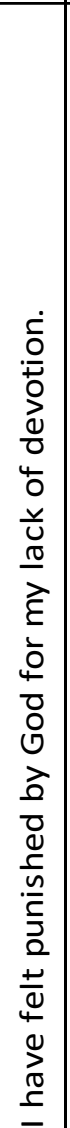 & 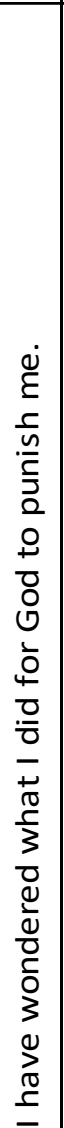 & 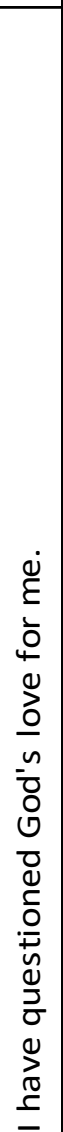 & $\begin{array}{l} \\
\\
\\
\\
j\end{array}$ & 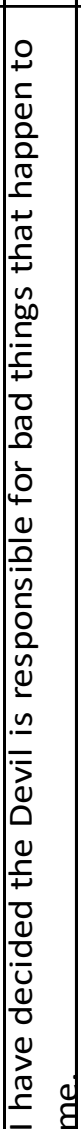 & 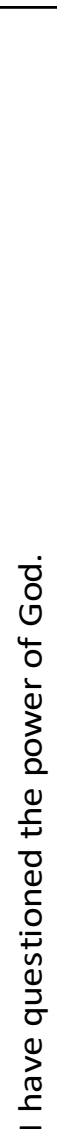 & \\
\hline & 인 & $\vec{N}$ & $N$ & $\tilde{N}$ & 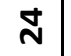 & $\stackrel{\Perp}{N}$ & $\stackrel{\mathscr{N}}{2}$ & $\hat{N}$ & $\stackrel{\infty}{\sim}$ & ก & & 尺े & $\vec{m}$ & N & $m$ & $\dot{m}$ & $\stackrel{n}{m}$ & $\ddot{m}$ & \\
\hline
\end{tabular}




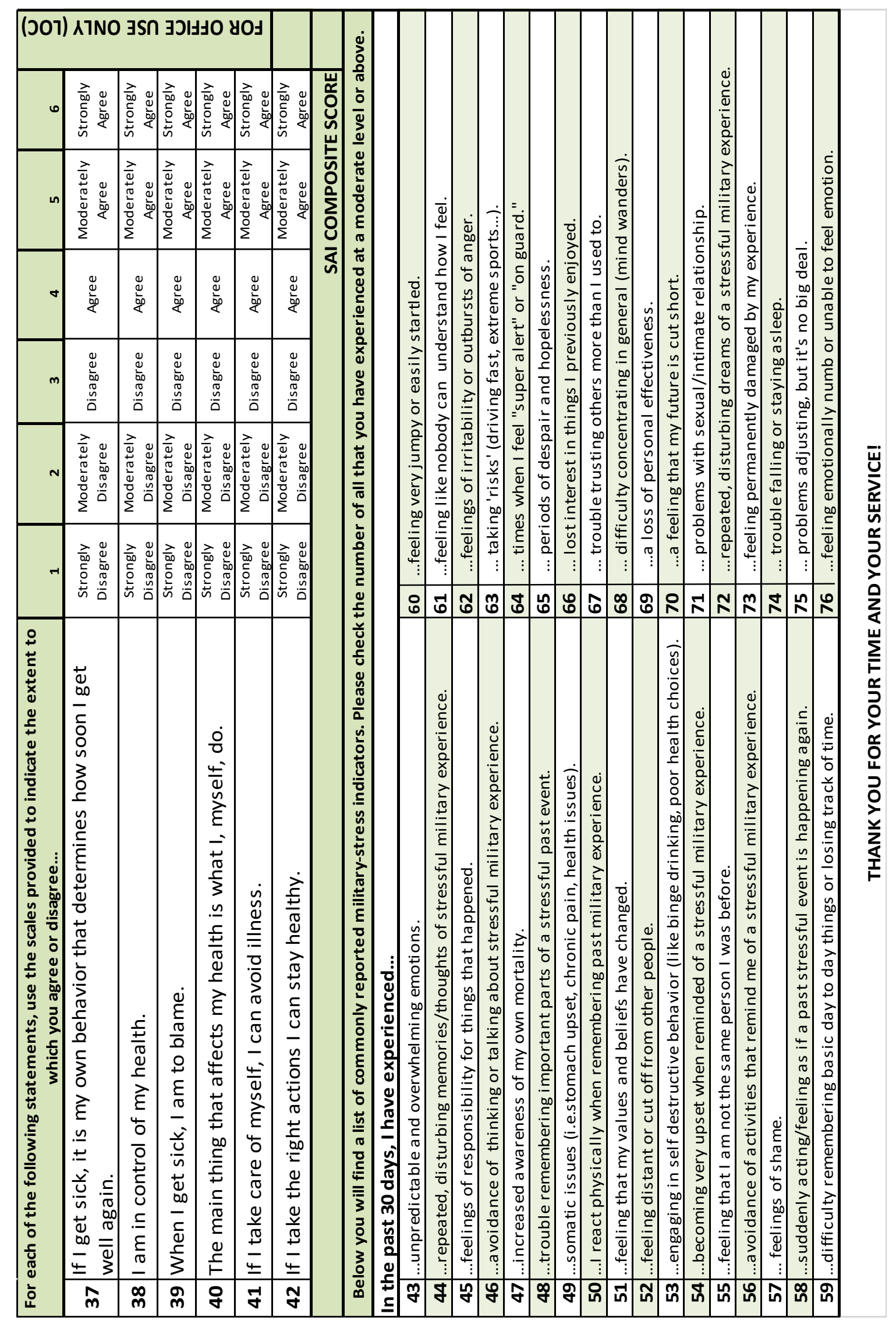




\section{CURRICULUM VITAE}

\section{LeAnn. E. Bruce, Ph.D., LCSW}

\section{Career Objective}

I view my career in social work as both a means to serve others as well as a journey of selffulfillment. I believe that the diversity of my clinical and administrative experiences has enriched my practice and prepared me to succeed in new challenges in support of the VA's mission. I believe I have the ability to make greater contributions to the care and well-being of our country's heroes and their families, while also promoting the practice of ethical and professional social work.

\section{Licenses and Certifications}

Licensed Clinical Social Worker

Conferred July 2002

Board Certified Diplomate in Social Work

Academy of Certified Social Workers (ACSW-NASW)

Certified Military Social Worker - Clinical (MVF-CSW -NASW)

Certified Traumatologist

Master Addiction Counselor

NAADAC \#507209

Conferred Nov 2009

Conferred 2011

October 2013

Conferred since 2010

\section{Education History}

University of Louisville Kent School of Social Work

Doctoral Program - $\mathrm{PhD} / \mathrm{ABD}$

Dec. 2016

Dissertation Interest: Identification of Existential Dissociation in Combat Veterans

Current GPA 3.9

University of Louisville Kent School of Social Work

Dec. 1999

Master of Science in Social Work

Direct Practice Mental Health \& Administration

Mental Health Direct Practice

Western Kentucky University

May 1996

Bachelor of Arts

Major: Psychology

Minor: English Graduated with Honors

\section{Employment History}

Department of Veterans Affairs - GS-13

Robley Rex (Louisville) VAMC

GEC Social Work Supervisor

November, 2014 - present

As Social Work Supervisor for the Geriatric, Extended Care and Rehabilitation Services of the Robley

Rex VA Medical Center, it is my privilege to direct and support the social work component of the interdisciplinary medical team across the array of programs and services offered through the Geriatric \& Extended Care Service. As social work supervisor, I am directly responsible for the coordination and oversight of the Community Residential Care, Contract Adult Day Healthcare, and Medical Foster Home programs as well as collaboratively work to oversee the social work role in our Home-Based Primary Care, Hospice, and Palliative Care programs. My duties include developing and delivering staff and hospital training/in-service, as well as reaching into the community to offer training and collaboration. Cultivating good working relationships with key community partners such as Adult Protective Services, Adult Guardianship and Area Agencies on Aging has been instrumental in the success of the programs under my charge. In addition, I serve as the VISN 9 regional coordinator of 
the Shared Decision Making for Long Term Services and Supports initiative which provides training, materials and support to the medical teams to promote the early discussion with patients and their families on Long Term Care options and encouraging the patient to take their rightful leading role in the discussion and decision process. Through this initiative, launched in all 6 VISN 9 Medical Centers and CBOCs, it is my task to champion this discussion through the provision of staff training, support, and technical assistance. I serve as the VISN point of contact for the national program and assist with program development and national expansion efforts. I serve on multiple local, regional and national committees including leading the local Advanced Directive Workgroup, Adult Guardianship workgroup, and am the chair of the VISN 9 Cover-to-Cover Community partnerships workgroup and the Residential Care Committee as well as serving as co-chair of the national Care Management and Social Work leadership council's Quality, Safety and Management Committee.

\section{Department of Veterans Affairs - GS-12 Social Work Liaison for Healthcare to Fort Knox

Ft. Knox, KY October 12, 2008 - Nov., 2014

As an employee of the Department of Veterans' Affairs Office of Social Work Care Management, the VA Liaison for Healthcare is embedded within the military treatment facility and works across both DoD and VA systems to provide seamless care coordination between service-delivery systems for wounded, ill or injured Soldiers. The success of the program relies on the ability of the VA Liaison to work across both VA and DoD administration to negotiate and develop policy, processes and relationships locally and nationally as well as working individually with transitioning "Veterans-inTransition" and their families. Individualized care coordination requires the ability to provide a comprehensive needs assessment, foster communication and transition services between the military treatment team and the receiving VA treatment team throughout the transition process. As the first VA Liaison assigned to the Fort Knox Warrior Transition Battalion, it was my task to work across both systems to establish processes to allow the facilitation of a smooth transition for the Soldiers. Other administrative duties required providing extensive outreach and education across both DoD and VA nationally, as well as serving as an ambassador from the VA to the Military Treatment Facility. In addition, I led multiple local and national workgroups that have helped to shape and direct the program and support other VA Liaisons and the Liaison/OEF/OIF/OND programs. I have had the opportunity to work directly with the VACO Social Work Service \& Care Management office to participate in national strategic management and program planning efforts and serve as the Chair of the Liaison Program Guide committee - defining and describing policy and procedures. I have been on the faculty of the VA Liaison annual training events for the past three years and frequently serve as a mentor and trainer of other Liaisons across the country. In addition, I am serving as the VA Liaison regional cluster group facilitator. I am also working with the DoD Command Chain of the Warrior Transition Battalion as a VA subject matter expert to help re-vamp the overall transition and referral support process at Fort Knox.

\section{Department of Defense - GS -11 \\ Manager \\ Ft. Knox, Kentucky}

\section{Lead Social Work Care}

As the Lead Social Work Care Manager to the Warrior Transition Battalion, I served as the point of contact between the command team and the social work case managers to support the inclusion of social work case management into the DoD "triad" treatment model. The SW Case Managers assessed and addressed the complex bio-psycho-social-spiritual needs of the returning wounded warriors while processes were developed to ensure that the newly formed Social Work Department was included as an integral facet of the Comprehensive Transition Process. This required conducting full psychosocial assessments including thorough structured assessment of PTSD/combat related issues, and Traumatic Brain Injury, Substance Abuse and other behavioral health issues and well as to provide individual care management, referrals, follow up and individual, family and group counseling as well as to conduct ongoing risk assessment for suicide prevention and family issues. Cultivating a strong working relationship with the Military Police and community partners, incidences of reports of abuse, neglect or domestic violence was investigated and a plan developed with the family, command and - at time the court or community. 
As clinical program director/therapist for a psychiatric in-patient treatment unit for children ages 4-12, I was responsible for the development and implementation of therapeutic programming, milieu therapy, staff development and straining and on-going monitoring of the activities and multi-disciplinary staff on the unit. Policy and procedures were written in conjunction with the nursing director and in compliance with the Joint Commission, and other standards of licensure and regulation.

Department of Defense - GS 11

Army Substance Abuse Program

Ireland Army Community Hospital
Clinical Provider

Dec. 18 - Aug. 14, 2007

Ft. Knox, KY

As therapist for the Army Substance Abuse program, I directly provided substance abuse assessment and treatment, needs and risk assessment, development of groups and programming, and made referrals to community services serving an eight-state area. This required working with the Soldiers' command structure, DoD and community services within DoD Army Substance Abuse Program policies and regulations.

Choctaw Archiving Enterprises (Federal Contractor)

Army Family Advocacy Program

Ireland Army Community Hospital
Clinical Provider Feb. 06 - Dec. 06

Ft. Knox, KY

Responsible for providing comprehensive assessment and treatment of individuals and families who were referred to the program due to self-identified domestic stressors or alleged domestic violence/child abuse. Direct patient care was provided with individual, marital, family and group counseling. Each case was investigated in collaboration with the Military Police and thorough report was presented to the Case Review Board.

Lincoln Trail Behavioral Health System

Willows Program, Acute Psych Services
Therapist/Program Development Jan 05 - Feb.06

Provided development and implementation of programmatic and therapeutic curriculum for acute adolescent unit and the Willows unit for sexually reactive female adolescents, provision of direct therapeutic services to children, adolescents and adults, provided individual, family and group counseling, consulted with treatment team and conferred with psychiatrist on cases, made referrals and aftercare recommendations.

Communicare, Inc.

Therapist

Community Mental Health Center

Feb. 99 - Jan. 05

Provided direct patient services to all age groups and levels of care utilizing individual, family, marital, and group treatment, substance abuse counseling, provided Mental Inquest Warrant evaluations, assessment for crisis admission, suicide assessment for children and adults, referrals to community resources, PASRR assessments for individuals seeking admission to nursing homes, offsite services at nursing home, personal care home and jail.

\section{Presentations and Publications:}

- Presentation to the National Society for Social Work Leadership in Healthcare (Costa Mesa, CA) "VA Basic Training” and facilitated the "My VA JOURNEY" Intensive Leadership Symposium, October 2016

- Presentation to the NASW Conference (Washington, DC) "The VA Social Work Student Practicum Project" July 2016

- Developed the VA Basic Training modules for community providers

- Testified before the Congressional Commission on Care (Washington, DC) - "The role of social work in VA interdisciplinary care. January, 2016

- Geriatric Social Work staff training modules: Led and collaborated on the development of staff training modules for our local medical center and community. 
- TBI \& the community presentation/training: Collaborated with WKU faculty on research and training module on Military TBI for presentation to community first responders (police, fire, EMS).

- VA Liaison Program - Reaching out to CBWTU. VA Liaison Annual Virtual Training, Oct.30, 2013

- System's Redesign Project: Interdisciplinary Transition Model: National Webinar Sept. 2013

- Weaving the Threads of Mind, Body \& Spirit into lasting healing and growth for our Returning Military NASW-KY Chapter Annual Conference - September 2013 (Louisville, KY)

- Easing the Transition from Military to Civilian. Kent School of Social Work Conf 3/2013

- Evidence-Based Practice and Ethics in Social Work. Synergy October 2012

- Evidence-Based Practice \& Research Tool Kit: VA Social Work Leadership Council SharePoint site

- Focus on Treatment Conference: Military Social Work: Reintegration (Sommerset, KY July, 2012)

- Military Stress \& PTSD: Effects on the Family. Fort Knox Child Development Center training $(3 / 12)$

- Finding Balance: Operation Headed Home (Statewide TBI Conference). Fort Knox, KY. Oct. 2011 Also served on the faculty and planning committee for the conference.

- Ethical Considerations of Evidence Based Practice in Social Work. (2008). Social Work and Society. April 2010. http://www.socwork.net/2009/2/articles/farleyetal

- Military 101: Basic Training for Mental Health Professionals. Operation Headed Home (Statewide TBI Conference). Richmond Kentucky. May 2010 Also served on the faculty and planning committee for the conference.

- Beyond PTSD: Trauma Induced Existential Disintegration. AMSUS International Conference, ST. Louis, MO. November, 2009.

- Helping to Heal Heroes: Seamless Transition from DoD to VA. Evolving Paradigms Conference. Las Vegas, NV. September 2009.

- Military 101: Basic Training for Mental Health Providers. University of Kentucky Office on Continuing Education. Elizabethtown, Ky. April 17, 2009.

- Reintegration: Making Marriage Work. Embassy Suites, Louisville, Ky. November, 2008.

- The Wounded Warrior Returns: The Community Responds. Elizabethtown Kentucky. August, 2008. April, 2008.

- Natural Pain Management, Warrior Transition Unit Battalion, Ft. Knox Kentucky, March 2008.

- Using Rational Emotive Behavioral Therapy with Incarcerated Adults in Substance Abuse Treatment Program. Breckinridge County Detention Center Substance Abuse Program. Hardinsburg, Kentucky October 14, 2007.

\section{Accomplishments and Affiliations:}

- Association of VA Social Workers Past President \& Education Committee Chair

- Co-Chair of the VA Social Work and Care Management Leadership Committee for Quality, Safety and Practice.

- Ask about military Service Kentuckiana (ASK) Campaign: Collaborated with VA \& Community coalition to develop campaign to promote awareness about military \& Veteran's in the community. Developed the logo, materials, and training modules.

- University of Louisville Kent School of Social Work - Military Social Work Program - Guest Lecturer

- Western Kentucky University School of Social Work - Military Social Work Faculty

- Multiple awards from Department of Defense and Veteran's Administration for program performance and professional contributions.

References will be provided upon request. 